Métodos heurísticos para o problema de dimensionamento de lotes multiestágio com limitação de capacidade 

SERVIÇO DE PÓS-GRADUAÇÃO DO ICMC-USP

Data de Depósito: 12/05/2011

Assinatura:

\title{
Métodos heurísticos para o problema de dimensionamento de lotes multiestágio com limitação de capacidade
}

\author{
Marcos Mansano Furlan
}

Orientadora: Profa. Dra. Maristela Oliveira dos Santos

Dissertação apresentada ao Instituto de Ciências Matemáticas e de Computação - ICMC-USP, como parte dos requisitos para obtenção do título de Mestre em Ciências - Ciências de Computação e Matemática Computacional. VERSÃO REVISADA.

USP - São Carlos

Maio/2011 
Ficha catalográfica elaborada pela Biblioteca Prof. Achille Bassi e Seção Técnica de Informática, ICMC/USP, com os dados fornecidos pelo(a) autor(a)

\begin{tabular}{|c|c|}
\hline \multirow[t]{3}{*}{ F985m } & $\begin{array}{l}\text { Furlan, Marcos Mansano } \\
\quad \text { Métodos heurísticos para o problema de } \\
\text { dimensionamento de lotes multiestágio com limitação } \\
\text { de capacidade / Marcos Mansano Furlan; orientadora } \\
\text { Maristela Oliveira dos Santos -- São Carlos, } 2011 . \\
\quad 113 \mathrm{p} \text {. }\end{array}$ \\
\hline & $\begin{array}{l}\text { Dissertação (Mestrado - Programa de Pós-Graduação en } \\
\text { Ciências de Computação e Matemática Computacional) -- } \\
\text { Instituto de Ciências Matemáticas e de Computação, } \\
\text { Universidade de São Paulo, } 2011 .\end{array}$ \\
\hline & $\begin{array}{l}\text { 1. dimensionamento de lotes. } 2 \text {. heurísticas. } 3 . \\
\text { métodos híbridos. } 4 \text {. problema inteiro misto. I. dos } \\
\text { Santos, Maristela Oliveira, orient. II. Título. }\end{array}$ \\
\hline
\end{tabular}


Aos meus pais

Moacir e Sueli. 



\section{AGRADECIMENTOS}

Primeiramente gostaria de agradecer aos meus pais Moacir e Sueli pela dedicação, amor, e por todos os conselhos e exemplos que fizeram com que eu me tornasse uma pessoa melhor.

À minha orientadora Maristela Oliveira dos Santos pela orientação, dedicação, paciência, amizade e pela confiança depositada durante o decorrer deste trabalho.

Aos amigos de laboratório sempre presentes e a disposição para o que fosse necessário, nos momentos de trabalho e de lazer.

Ao Victor, Márcio e Tamara, por terem me recebido tão bem em São Carlos e por todos os conselhos e momentos felizes de happy hours e pós happy hours (posto).

Aos meus amigos de Piratininga e arredores, pela amizade e por estarem presentes em minha vida. Um agradecimento especial aos meus grandes amigos de graduação Guilherme, Ígor e Wesley pelos conselhos e apoio nos momentos de incertezas.

Aos membros das bancas de qualificação e de defesa por todas as sugestões e conselhos feitos para melhorar este trabalho.

A todos os funcionários do ICMC que, direta ou indiretamente, contribuíram com este trabalho. Principalmente às funcionárias da secretaria da Pós-graduação por toda o auxílio oferecido para que este trabalho pudesse ser concluído.

Ao $\mathrm{CNPq}$ pelo apoio financeiro durante a execução deste trabalho. 



\section{RESUMO}

O problema de dimensionamento de lotes determina um plano de produção que apoia às tomadas de decisões, a médio prazo, em meios industriais. Este plano de produção indica as quantidades de cada item que devem ser produzidas em cada período do horizonte de planejamento, de acordo com um objetivo dado e satisfazendo a demanda dos clientes. Diversos métodos de solução foram propostas na literatura, considerando a dificuldade de solução de algumas classes de problemas e a necessidade de métodos que gerem soluções de alta qualidade em um tempo computacional adequado. Neste trabalho, abordamos heurísticas baseadas na formulação matemática (LP-and-fix, relax-and-fix e fix-and-optimize), uma metaheurística (algoritmo de abelhas) e dois métodos híbridos, utilizados na solução de dois problemas distintos de dimensionamento de lotes multiestágio com limitação de capacidade. Consideramos também, a utilização de três formulações da literatura, para verificar a influência de cada uma sobre as abordagens de solução verificadas. Os resultados computacionais demonstraram que os métodos baseados na formulação matemática do problema se mostraram eficientes, mas limitados normalmente a ótimos locais, enquanto os métodos híbridos puderam superar estes ótimos locais, utilizando conceitos da metaheurística algoritmo de abelhas para isto. Além disso, pudemos verificar a influência de uma formulação "forte" sobre as soluções geradas pelas abordagens de solução, demonstrando que métodos baseados em relaxação linear conseguem obter maiores vantagens deste tipo de formulação, mas outras abordagens podem ou não obter estas vantagens, dependendo do problema abordado.

Palavras chave: dimensionamento de lotes, heurísticas, métodos híbridos, problema inteiro misto 



\section{ABSTRACT}

The lot-sizing problem determines a production plan, which supports the decision making, in the medium term, at the industrial environment. This production plan indicates the amounts of each item to be produced in each period of the planning horizon, according to a given objective and satisfying customer's demand. Diverse solution methods have been proposed in the literature, considering the difficulty of solving some problem classes and the need of methods to generate solutions quickly. In this work, we develop matheuristics (LP-and-fix, relax-and-fix and fix-and-optimize), one metaheuristic (bees algorithm) and two hybrid methods, used to solve two different multilevel capacitated lot-sizing problems. We also consider the use of three different formulations of the literature to verify the influence of each one on the solutions approaches. The computational results show that the matheuristics proved to be efficient, but usually limited to local optima, while the hybrid methods could escape from these local optima, using concepts of bees algorithm to do this. Additionally, we test the effect of a tight formulation on the solutions approaches, demonstrating that LP-based heuristics can obtain further advantages from this type of formulation, but other approaches can take these advantages, depending on the problem addressed.

Keywords: lot-sizing, heuristics, hybrid methods, mixed integer problem 



\section{SUMÁRIO}

1 Introdução

p. 1

2 Revisão da Literatura $\quad$ p. 7

2.1 Problema de dimensionamento de lotes monoestágio . . . . . . . p. 7

2.2 Problema de dimensionamento de lotes multiestágio . . . . . . . . p. 10

3 Problemas Abordados p. 19

3.1 Problema de dimensionamento de lotes multiestágio com limitação de

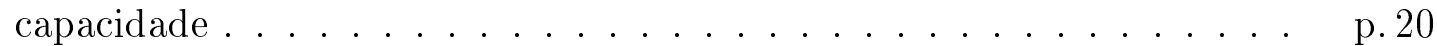

3.1 .1 Formulação Agregada . . . . . . . . . . . . . . . p. 21

3.1.2 Formulação por Localização de Facilidades segundo Sahling et al.

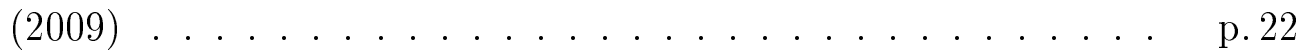

3.1.3 Formulação por Localização de Facilidades segundo Stadtler (2003) p. 23

3.2 Problema de dimensionamento de lotes multiestágio com limitação de capacidade e preservação da preparação . . . . . . . . . . . . . . p. 24

3.2 .1 Formulação Agregada . . . . . . . . . . . . . . . p. 26

3.2.2 Formulação por Localização de Facilidades segundo Sahling et al.

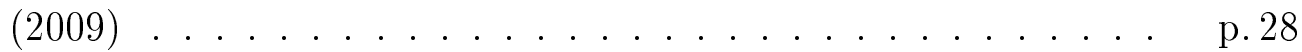

3.2.3 Formulação por Localização de Facilidades segundo Stadtler (2003) p. 28 
4.1 Heurísticas baseadas na formulação matemática $\ldots \ldots$. . . . . . p. 34

4.1.1 Heurística LP-and-fix . . . . . . . . . . . . p. 34

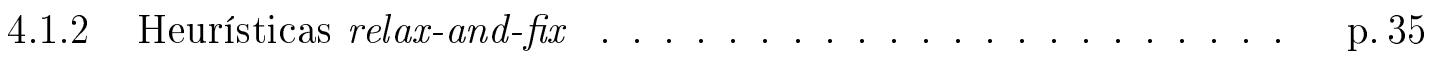

4.1.3 Heurísticas do tipo fix-and-optimize . . . . . . . . p. p. 40

4.2 Metaheurística algoritmo de abelhas . . . . . . . . p 47

4.3 Métodos híbridos . . . . . . . . . . . . . p. 53

4.3.1 Primeira heurística híbrida: fix-and-optimize com algoritmo de

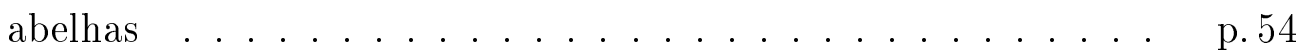

4.3.2 Segunda heurística híbrida: algoritmo de abelhas com fix-andoptimize ............................ p. 56

5 Testes Computacionais p. 61

5.1 Instâncias de Teste . . . . . . . . . . . . . p. 61

5.1.1 Instâncias de Tempelmeier e Derstroff (1996) e Stadtler e Sürie

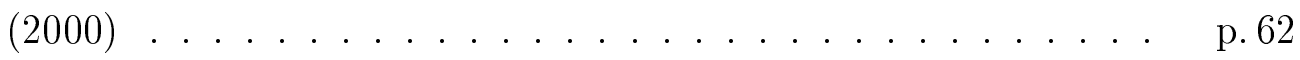

5.1.2 Instâncias de teste de Tempelmeier e Buschkühl (2009) . . . . p p. 65

5.2 Resultados Computacionais . . . . . . . . . . p. 68

5.2.1 Problema de dimensionamento de lotes multiestágio com limitação de capacidade . . . . . . . . . . . . . . . p. 71

5.2.1.1 Análise dos resultados com foco na formulação utilizada p. 71

5.2.1.2 Análise dos resultados com foco nas abordagens de solução p. 79

5.2.2 Problema de dimensionamento de lotes multiestágio com limitação de capacidade e preservação da preparação . . . . . . . . p p. 82

5.2.2.1 Análise dos resultados com foco na formulação utilizada p. 83

5.2.2.2 Análise dos resultados com foco nas abordagens de solução p. 92 
A.1 O problema de localização de facilidades . . . . . . . . . . p. 106

A.2 Reformulação por localização de facilidades . . . . . . . . . . p. 107

A.3 Reformulação pelo problema do menor caminho . . . . . . . . . . p. 112 



\section{LISTA DE TABELAS}

1 Características das instâncias de teste de Stadtler e Sürie (2000) . . . . p. 62

2 Tempos de preparações da classe $\mathrm{B}+\ldots \ldots \ldots \ldots$ p. . . . . . . . . . .

3 Tempos entre pedidos das classes $\mathrm{A}+\mathrm{e} \mathrm{B}+\ldots \ldots \ldots$ p. 64

4 Porcentagem de utilização dos recursos das classes $\mathrm{A}+$ e $\mathrm{B}+\ldots \ldots$ p. 65

5 Características das instâncias de teste de Tempelmeier e Buschkühl (2009) p. 65

6 Tempos de preparações por número de itens. . . . . . . . . . p. 67

7 Tempos entre pedidos por número de itens. . . . . . . . . p. 67

8 Porcentagem de utilização por número de recursos. $\ldots \ldots \ldots$ p. . . . 67

9 Desvio percentual médio - Heurísticas baseadas em relaxação linear . . p. 72

10 Desvio padrão percentual - Heurísticas baseadas em relaxação linear p.72

11 Tempo computacional médio - Heurísticas baseadas em relaxação linear p.73

12 Percentual de melhoria - Heurísticas baseadas em relaxação linear . . . p p.73

13 Percentual de factibilidade - Heurísticas baseadas em relaxação linear . p.74

14 Desvio percentual médio - Heurísticas do tipo fix-and-optimize . . . . p. 74

15 Desvio padrão percentual - Heurísticas do tipo fix-and-optimize . . . p p.74

16 Tempo computacional médio - Heurísticas do tipo fix-and-optimize . . . p.75

17 Percentual de melhoria - Heurísticas do tipo fix-and-optimize . . . . p p.75 
18 Percentual de factibilidade - Heurísticas do tipo fix-and-optimize . . . .

19 Desvio percentual médio e desvio padrão percentual - Metaheurística algoritmo de abelhas . . . . . . . . . . . . . p. 76

20 Tempo computacional médio - Metaheurística algoritmo de abelhas . . p. 76

21 Percentual de melhoria e percentual de factibilidade - Metaheurística algoritmo de abelhas . . . . . . . . . . . . . p. 77

22 Desvio percentual médio - Heurísticas híbridas . . . . . . . . p p. 78

23 Desvio padrão percentual - Heurísticas híbridas . . . . . . . . p 78

24 Tempo computacional médio - Heurísticas híbridas . . . . . . . p 78

25 Percentual de melhoria - Heurísticas híbridas . . . . . . . . p. 78

26 Percentual de factibilidade - Heurísticas híbridas . . . . . . . . . p. 79

27 Desvio percentual médio - Heurísticas baseadas em relaxação linear p. 83

28 Desvio padrão percentual - Heurísticas baseadas em relaxação linear . p. 84

29 Tempo computacional médio - Heurísticas baseadas em relaxação linear p. 84

30 Percentual de melhoria - Heurísticas baseadas em relaxação linear . . p. 85

31 Percentual de factibilidade - Heurísticas baseadas em relaxação linear • p. 85

32 Desvio percentual médio - Heurísticas do tipo fix-and-optimize . . . . p. 86

33 Desvio padrão percentual - Heurísticas do tipo fix-and-optimize . . . . p. 87

34 Tempo computacional médio - Heurísticas do tipo fix-and-optimize . . . p. 87

35 Percentual de melhoria - Heurísticas do tipo fix-and-optimize . . . . p. 88

36 Percentual de factibilidade - Heurísticas do tipo fix-and-optimize . . . p. 88

37 Desvio percentual médio e desvio padrão percentual - Metaheurística algoritmo de abelhas ...................... p. 89

38 Tempo computacional médio - Metaheurística algoritmo de abelhas . . p. 89

39 Percentual de melhoria e percentual de factibilidade - Metaheurística algoritmo de abelhas ................... p. 90

40 Desvio percentual médio - Heurísticas híbridas . . . . . . . . p 90 
41 Desvio padrão percentual - Heurísticas híbridas . . . . . . . . . p. 91

42 Tempo computacional médio - Heurísticas híbridas . . . . . . . . p. 91

43 Percentual de melhoria - Heurísticas híbridas . . . . . . . . . p. 92

44 Percentual de factibilidade - Heurísticas híbridas . . . . . . . . . p. 92

45 Definição das variáveis conforme Bilde e Krarup (1977). . . . . . . . . . p. 108 



\section{LISTA DE FIGURAS}

$1 \quad$ Estruturas de produto. . . . . . . . . . . . . p. 3

2 Partição do horizonte de planejamento. . . . . . . . . . p 9

3 Estrutura de produto com divisão por recurso. . . . . . . . . p. 16

4 Sequenciamento da produção . . . . . . . . . . . . p. 16

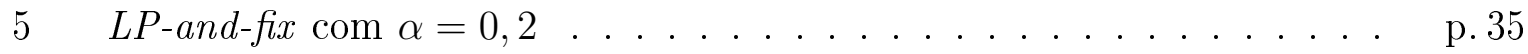

6 Estrutura de produto com divisão por recurso. . . . . . . . . . . p. 38

7 Exemplo de produção, considerando lead-time de um período. $\quad \ldots \ldots$ p. 38

8 Particionamento da primeira heurística relax-and-fix. . . . . . . p. 39

9 Particionamento da segunda heurística relax-and-fix. . . . . . . . p. 39

10 Particionamento da terceira heurística relax-and-fix. . . . . . . p. 40

11 Iterações da heurística fix-and-optimize com particionamento por itens. p. 42

12 Particionamento por itens. . . . . . . . . . . . p. 43

13 Particionamento por períodos. . . . . . . . . . p. 44

14 Classificação de métodos híbridos. . . . . . . . . . . . . p. p 54

15 Partição do item 2 e partição aleatória. . . . . . . . . . . p. 55

16 Criação de uma abelha seguidora. . . . . . . . . . . . p. 56

17 Exemplo de um passo do método de busca local. . . . . . . . . p. 58 
18 Estruturas de produtos da classe $\mathrm{A}+\ldots \ldots \ldots \ldots$ p. 63

19 Estruturas de produtos da classe $1 . \ldots \ldots$ p. 66

20 Gráfico de qualidade de solução com barra de erros igual ao desvio padrão. p. 80

21 Gráfico de qualidade de solução com barra de erros igual ao dobro do desvio padrão. . . . . . . . . . . . . . . . . p. 80

22 Gráfico de qualidade de solução com barra de erros igual ao desvio padrão. p. 81

23 Gráfico de qualidade de solução com barra de erros igual ao dobro do desvio padrão. . . . . . . . . . . . . . . . . p. 81

24 Gráfico de otimalidade média. . . . . . . . . . . . . p. 82

25 Gráfico de qualidade de solução com barra de erros igual ao desvio padrão. p. 93

26 Gráfico de qualidade de solução com barra de erros igual ao dobro do desvio padrão. . . . . . . . . . . . . . . . . p. 93

27 Gráfico de otimalidade média. . . . . . . . . . . . . . p. 94

28 Grafo de rede representando o problema de dimensionamento de lotes com um único item. . . . . . . . . . . . . . . . . . . p. 110 


\section{LISTA DE ABREVIATURAS E SIGLAS}

BFO1 Primeira heurística híbrida

BFO2-P1 Segunda heurística híbrida com particionamento por itens

BFO2-P2 Segunda heurística híbrida com particionamento por períodos

BFO2-P3 Segunda heurística híbrida com particionamento por itens e por períodos

FO-P1 Heurística do tipo fix-and-optimize com particonamento por itens

FO-P2 Heurística do tipo fix-and-optimize com particonamento por períodos

FO-P3 Heurística do tipo fix-and-optimize com particonamento por itens e depois por períodos

FO-P4 Heurística do tipo fix-and-optimize com particonamento por períodos e depois por itens

LPF Heurística do tipo LP-and-fix

RF1 Heurística relax-and-fix com particionamento por períodos

RF2 Heurística relax-and-fix com particionamento por nível da estrutura de produto

RF3 Heurística relax-and-fix com particionamento por itens

SPL Formulação por localização de facilidades 



\section{CAPÍTULO 1}

\section{INTRODUÇÃO}

A globalização ocorrida na economia durante as últimas décadas tem gerado um aumento na competitividade entre empresas pelos mercados consumidores. Além disso, o aumento na demanda de produtos industrializados ocasionou a necessidade do gerenciamento do processo produtivo de forma mais eficiente. Estes fatores geraram a necessidade de um estudo adequado das condições de produção das empresas para auxiliar a tomada de decisão a fim de cumprir seus objetivos. Neste contexto, o planejamento da produção surge como uma ferramenta de auxílio na tomada de decisões.

Em Pochet e Wolsey (2006) o planejamento da produção é visto como o planejamento de aquisições de recursos e matérias primas, bem como as atividades do planejamento da produção que são requeridas para transformar as matérias primas em produtos ${ }^{1}$ finais, de forma a suprir a demanda dos clientes de maneira eficiente.

Segundo Karimi et al. (2003) o planejamento da produção engloba decisões de curto, médio e longo prazo. No planejamento de longo prazo, ou planejamento de nível estratégico, o foco está em antecipar as necessidades envolvidas tais como decisões estratégicas de escolha de produtos, equipamentos e processos, localização de facilidades e planejamento de recursos. O planejamento de médio prazo, ou planejamento de nível tático, envolve decisões sobre as necessidades de materiais, e estabelece as quantidades a serem produzidas ou o tamanho dos lotes em cada período de um horizonte de planejamento, de modo

\footnotetext{
${ }^{1}$ Neste trabalho produto e item serão utilizados de forma análoga.
} 
a otimizar alguns critérios de desempenho, enquanto atende a demanda satisfazendo as restrições existentes. O planejamento de curto prazo, ou planejamento de nível operacional, usualmente envolve decisões do dia-a-dia ou semana-a-semana, como por exemplo, o sequenciamento da produção.

Este trabalho foca o problema de dimensionamento de lotes que se enquadra no nível tático do planejamento da produção. O problema de dimensionamento de lotes consiste em determinar o tamanho dos lotes de cada produto que será produzido ao longo de um horizonte de planejamento com $\mathrm{T}$ períodos, com o intuito de suprir as demandas, sem atrasos. O objetivo do problema é minimizar os custos produtivos, tais como, custos de preparações de máquinas, custos de estoque e, em alguns casos, custos de produção e custos de horas extras.

Os problemas de dimensionamento de lotes podem ser divididos em monoestágio e multiestágio. O problema monoestágio se caracteriza principalmente por ter produtos sendo produzidos em um mesmo meio de produção mas sem relação de produção entre eles, ou seja, a produção de um produto não depende da produção de outro produto. O problema multiestágio se caracteriza principalmente por ter múltiplos produtos sendo produzidos em um mesmo meio de produção, segundo uma estrutura de produto bem definida. Desta forma, alguns produtos têm sua produção dependendo da produção dos produtos sucessores.

Uma estrutura de produto define, para cada item produzido, quais os componentes necessários para produzi-lo e quais são seus itens sucessores. Um exemplo de três tipos diferentes de estruturas de produto está ilustrado na Figura 1. Nesta ilustração, os nós representam os itens e as arestas representam a relação de precedência entre estes itens. O valor associado a cada aresta indica a quantidade de componentes necessários para a produção de uma unidade do item sucessor. Por exemplo, na estrutura de montagem, Figura 1.b, para produzir uma unidade do item 2 precisamos de duas unidades do item 4 e uma unidade do item 5. Neste caso, os itens 4 e 5 são componentes do item 2, ou seja, o item 2 é sucessor dos itens 4 e 5 . Nas estruturas de produto representadas pela Figura 1, os itens do nível superior são itens finais e os demais itens são componentes. Os itens componentes podem ter demanda externa ou serem produzidos apenas para o consumo interno. A estrutura de produto geral (Figura 1.a) apresenta mais de um item final, enquanto a estrutura de montagem (Figura 1.b) e a estrutura sequencial (Figura 1.c) apresentam apenas um item final cada. Podemos classificar a estrutura de montagem como um caso específico da estrutura geral, onde apenas um item final é produzido. Da 
mesma maneira, também podemos verificar que a estrutura de produto sequencial é um caso específico da estrutura de produto de montagem, onde cada produto tem no máximo um componente.

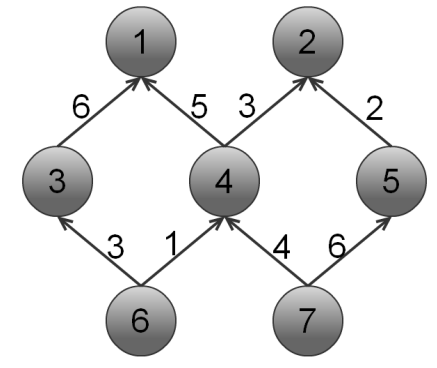

a) Estrutura geral

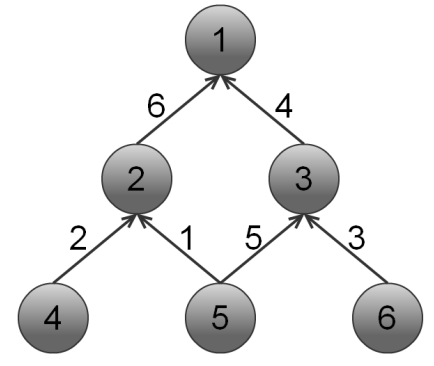

b) Estrutura de montagem

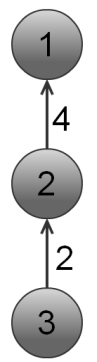

c) Estrutura sequencial

Figura 1: Estruturas de produto.

Segundo Maes et al. (1991) os problemas de dimensionamento de lote multiestágio abordados na literatura são comumente simplificações da realidade. Isso ocorre pois um problema real tem muitas características particulares, como limitação de capacidade, possibilidade de utilização de horas extras e possibilidade de atrasos no atendimento da demanda, entre outros. Devido ao número de características que podem ser consideradas, pode haver uma dificuldade na modelagem e estes modelos poderiam ser tratáveis apenas para exemplos muito pequenos. Ainda segundo Maes et al. (1991), a dificuldade de solução de um problema de dimensionamento de lotes é dependente do número de itens, da estrutura de produto, do número de recursos (nos casos onde existe mais de um recurso), da capacidade limitada dos recursos e do número de períodos do horizonte de planejamento. Além disso, existem algumas características adicionais que podem ser incorporadas a um problema específico, como tempo e custo de preparação para a produção, preservação de preparação entre períodos (setup carry-over), preparação dependente da sequência de produção, atraso na entrega de produtos (backlogging), perda de vendas (backorder) e lead-time positivo. Lead-time é o tempo necessário para que um item esteja pronto para o uso após o início de sua produção, esse tempo é utilizado para evitar que este item tenha sua produção iniciada antes que seus componentes tenham suas produções concluídas, por exemplo, não podemos utilizar um parafuso que não está totalmente produzido para prender o tampo de uma mesa.

O problema de dimensionamento de lotes monoestágio com mais de um item, quando conta com a adição da restrição de capacidade é um problema NP-Difícil, como foi provado em Bitran e Yanasse (1982). Em alguns casos particulares, onde é considerado apenas um item, o problema pode ser resolvido em tempo polinomial. O problema com limitação 
de capacidade torna-se NP-Completo, caso os tempos de preparações sejam não nulos, como foi demonstrado em Maes et al. (1991). Portanto, o simples fato de encontrar uma solução factível para uma instância deste problema, em alguns casos, se torna uma tarefa difícil. Desta forma, obter uma solução para determinados problemas considerando instâncias de médio e grande porte podem tornar-se inviáveis para métodos exatos. Por este motivo, pode-se fazer necessário o desenvolvimento de heurísticas que, mesmo sem oferecer garantias de otimalidade, possam gerar soluções de boa qualidade dentro de um tempo aceitável para instâncias de porte razoável. Uma outra estratégia seria desenvolver abordagens que encontrem soluções quase ótimas (ver Pochet e Wolsey (2006)).

Nesta dissertação de mestrado são abordados problemas de dimensionamento de lotes multiestágio, mais especificamente os problemas apresentados em Tempelmeier e Derstroff (1996) e Sahling et al. (2009). O problema apresentado em Tempelmeier e Derstroff (1996) foi considerado em vários trabalhos na literatura, como em Stadtler (2003) e Akartunali e Miller (2009), e consiste em um problema de dimensionamento de lotes multiestágio com limitação da capacidade, e tempos e custos de preparações não nulos. O problema apresentado em Sahling et al. (2009) consiste em um problema de dimensionamento de lotes multiestágio com limitação de capacidade e preservação da preparação. Neste segundo problema, consideram também os tempos e custos de preparações não nulos, lead-time positivo de um período (independente do item) e estoques iniciais positivos.

Para obtenção de soluções para tais problemas, desenvolvemos métodos heurísticos baseados na formulação matemática do problema, metaheurísticas puras e algoritmos híbridos, bem como discutimos e analisamos algumas abordagens de solução da literatura, propostas para tais problemas. Os métodos heurísticos são abordagens dos tipos relaxand-fix (relaxa e fixa), fix-and-optimize (fixa e otimiza) e LP-and-fix (LP e fixa).

Uma heurística do tipo relax-and-fix consiste em relaxar algumas variáveis de decisão enquanto fixa outras de forma iterativa resolvendo os subproblemas inteiros mistos até que o problema original esteja resolvido. A heurística fix-and-optimize (fixa e otimiza) se baseia no particionamento do conjunto de variáveis inteiras em subconjuntos disjuntos que são fixados e liberados para otimização a cada iteração. A cada passo desta heurística, uma partição fica "livre" para ser otimizada e as demais são fixadas no valor da solução incumbente. Já a heurística $L P$-and-fix é composta de três passos, no primeiro, resolve-se a relaxação linear do problema, fixa-se as variáveis de decisão que resultaram em valores inteiros na solução do problema relaxado e, por último, resolve-se um branch-and-bound considerando o subproblema anteriormente fixado. 
A metaheurística desenvolvida para os problemas abordados se baseia no algoritmo de abelhas (PHAM et al., 2005) e os métodos híbridos consideram as idéias de algoritmos colaborativos propostas por Puchinger e Raidl (2005) e Jourdan et al. (2009), e são compostas pela metaheurística algoritmo de abelhas e pela heurística fix-and-optimize.

Os métodos de solução foram testados considerando os dois problemas abordados. Além disso, reformulamos os problemas de acordo com refomulações clássicas da literatura. Para cada uma das formulações, analisamos as soluções obtidas pelos métodos de solução, discutindo as vantagens de cada abordagem em relação às formulações dos problemas.

Esta dissertação está organizada da seguinte forma: No Capítulo 2 será apresentada uma breve revisão da literatura sobre problemas de dimensionamento de lotes. As formulações matemáticas serão apresentadas no Capítulo 3. No Capítulo 4 são apresentadas as abordagens de solução, seguida dos testes e resultados computacionais no Capítulo 5 e conclusões e perspectivas no Capítulo 6 . 


\section{CAPÍTULO 2}

\section{REVISÃO DA LITERATURA}

A apresentação deste capítulo foi dividida em duas partes. Na primeira, são apresentados alguns trabalhos sobre o problema de dimensionamento de lotes monoestágio. Na segunda, são discutidos alguns trabalhos sobre o problema de dimensionamento de lotes multiestágio, e trabalhos correlacionados aos problemas abordados nesta dissertação.

\subsection{Problema de dimensionamento de lotes monoestá- gio}

O problema de dimensionamento de lotes monoestágio caracteriza-se principalmente por um meio de produção onde são produzidos um ou mais produtos sem relação direta entre si. Isto significa que cada produto não tem outros produtos deste meio de produção como seus componentes e, ao mesmo tempo, não é componente de nenhum outro produto.

O problema de dimensionamento de lotes monoestágio tem sido muito estudado na literatura. Um dos primeiros trabalhos nesta área foi o de Wagner e Whitin (1958) que trata do compromisso entre custos de preparação e de estoque. O problema considera demanda dinâmica e determinística de um único item, sem restrição de capacidade. Neste trabalho, os autores apresentaram um método ótimo baseado em programação dinâmica, o qual é amplamente utilizado nos dias atuais.

Em Trigeiro et al. (1989) foi abordado o problema de dimensionamento do lotes mono- 
estágio com múltiplos itens, limitação de capacidade, tempos e custos de preparações não nulos. Os autores propuseram um método heurístico muito utilizado devido a sua simplicidade e eficiência. A heurística se baseia em relaxação lagrangiana (WOLSEY, 1998), sendo composta de três passos. No primeiro passo é feita uma relaxação sobre as restrições de capacidade utilizando os multiplicadores lagrangianos, desta forma, obtém-se um subproblema para cada item. Cada subproblema é resolvido pelo algoritmo ótimo de Wagner e Whitin (1958). Em geral, os resultados dos subproblemas quando integrados não atendem as restrições de capacidade, então uma heurística de transferência de produção é utilizada para tentar factibilizar a solução. No último passo, os multiplicadores lagrangianos são atualizados pelo método de otimização do subgradiente (WOLSEY, 1998).

Araujo e Arenales (2000) consideram o mesmo problema de Trigeiro et al. (1989) e modificam o método proposto para considerar custos variáveis no tempo. Baseados nas condições de otimalidade (GEOFFRION, 1974), os autores propuseram melhorias para o método de Trigeiro et al. (1989). Nas conclusões do trabalho, os autores consideram que as melhorias foram percentualmente pequenas, e isto pode ter ocorrido devido a eficiência do método de factibilização de Trigeiro et al. (1989).

Em Mercé e Fontan (2003) foi considerado o problema de dimensionamento de lotes monoestágio com múltiplos itens, restrições de capacidade e possibilidade de atraso na entrega de itens (Backlogging). Foram considerados também, a necessidade produção de um lote mínimo, caso ocorresse a produção, e tempos e custos de preparações não nulos. Neste trabalho, foram desenvolvidos variações de heurísticas do tipo relax-and-fix. Como esta ilustrado na Figura 2, a heurística se baseia na separação do horizonte de planejamento em três partes. A primeira parte ou seção inicial, é composta pelos conjuntos de variáveis fixadas de acordo com a estratégia de fixação, esta seção cresce a cada iteração da heurística. A segunda parte ou seção central, é composta pelo conjunto de períodos nos quais as variáveis serão consideradas como no modelo original, ou seja, como variáveis inteiras ou binárias. A última parte ou seção final, é composta pelos conjuntos de períodos simplificados (relaxados) de acordo com a estratégia de simplificação. Os autores utilizaram dois parâmetros para controlar a fixação e a simplificação, a quantidade de períodos fixados a cada iteração (TF) e o tamanho da seção central (TS). Com estes parâmetros, os autores fizeram inúmeros estudos e variações na heurística, para verificar qual a influência de cada um destes parâmetros, além de propor duas variações da heurística com formas de fixação diferentes. Os resultados foram comparados entre as variações e os autores indicam a necessidade de trabalhos futuros para comparar resultados com outras heurísticas propostas na literatura. 


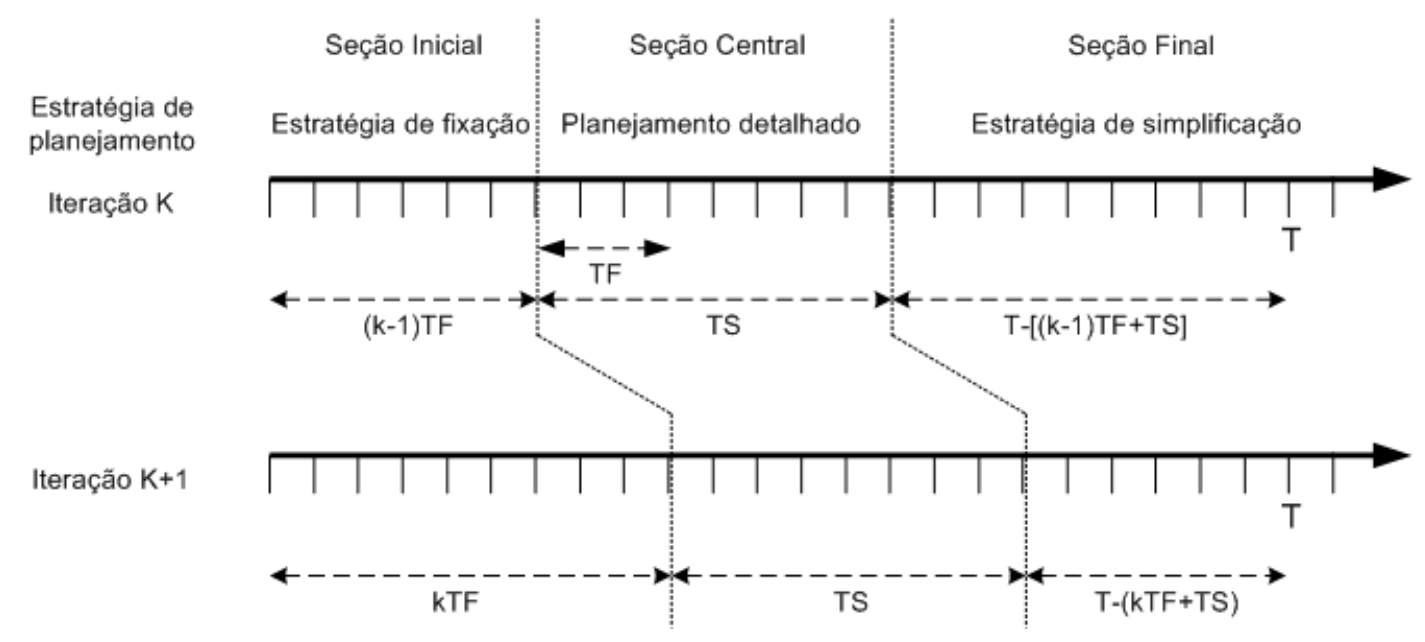

Figura 2: Partição do horizonte de planejamento. Imagem adaptada de Mercé e Fontan (2003).

Jans e Degraeve (2004) abordam o problema de dimensionamento de lote monoestágio com múltiplos itens, restrições de capacidade, tempos e custos de preparações não nulos e estoque inicial não nulo. Os autores fazem uma reformulação do problema pela abordagem do menor caminho (EPPEN; MARTIN, 1987). Os autores aplicam decomposição DantzigWolfe ao modelo reformulado, decompondo o problema por períodos. Neste trabalho também é feita uma discussão sobre os limitantes da literatura com o modelo original e são apresentados novos limitantes para o problema.

O problema de dimensionamento de lotes monoestágio pode ser visto como uma relaxação do problema multiestágio, pois neste caso poderíamos ignorar a estrutura de produto existente e resolver o problema como se a demanda de cada produto fosse independente. Este tipo de relaxação possibilita a utilização dos métodos de solução de problemas monoestágio em heurísticas de decomposição para a solução de problemas multiestágio. O método proposto em Tempelmeier e Derstroff (1996) utiliza uma abordagem deste tipo para a resolução do problema considerado.

Boas revisões para o problema de dimensionamento de lotes monoestágio podem ser encontradas em Karimi et al. (2003) e Brahimi et al. (2006). Jans e Degraeve (2008) fazem uma revisão dos problemas de dimensionamento de lotes monoestágio com foco na modelagem de problemas industriais. 


\subsection{Problema de dimensionamento de lotes multiestá- gio}

O problema de dimensionamento de lotes multiestágio caracteriza-se por um meio de produção onde são produzidos itens com relação direta de produção entre si. Isto significa que cada produto pode ter outros produtos deste meio de produção como seus componentes e pode ser componente de outros produtos deste mesmo meio, de acordo com a estrutura de produto (ver Figura 1).

Um modelo matemático para o problema de dimensionamento de lotes multiestágio com restrição de capacidade foi proposto em Billington et al. (1983), um dos trabalhos pioneiros neste tópico. Neste artigo, os autores apresentam uma formulação matemática para o problema estendendo a formulação do problema de dimensionamento de lotes monoestágio com restrição de capacidade. Deste então, o problema tem sido abordado na literatura, de inúmeras maneiras e com variadas características. Na formulação a seguir, considerem que:

- Atrasos de itens finais não são permitidos;

- Um item só pode ser produzido quando os seus componentes estiverem disponíveis;

- Existem limites da capacidade de recursos (podem ser máquinas, operários, entre outros) que devem ser respeitados;

- Para que um item possa ser produzido, o recurso utilizado para sua produção deve estar preparado para a mesma, e esta preparação demanda um custo e um tempo para ser feita.

- Todo momento que um item for produzido, o recurso utilizado na produção deve estar preparado para produzí-lo, e isto implica em um custo que deve ser contabilizado e um tempo de produção que será utilizado para este preparo;

- O custo de estoque é calculado baseado no estoque no final de cada período.

Para a formulação matemática de Maes et al. (1991), considerem os conjuntos, as variáveis e os parâmetros declarados abaixo.

Conjuntos e índices

$N \quad$ Conjunto de itens $(i \in\{1, \ldots, N\})$;

$M \quad$ Conjunto de recursos $(m \in\{1, \ldots, M\})$;

$T \quad$ Conjunto de períodos $(t \in\{1, \ldots, T\})$; 
$S(i)$ Conjunto de sucessores de $i$;

$K_{m} \quad$ Conjunto de itens produzido pelo recurso $m$;

$B \quad$ Valor muito grande.

\section{Parâmetros}

$S_{i} \quad$ Custo de preparação relacionado ao item $i$;

$h_{i} \quad$ Custo de estoque relacionado ao item $i$;

$r_{i j} \quad$ Unidades do item $i$ necessários para produzir uma unidade do item $j$;

$d_{i t} \quad$ Demanda externa do item $i$ no período $t$;

$\hat{I}_{i} \quad$ Estoque inicial físico do item $i$;

$a_{i} \quad$ Tempo de produção de cada unidade do item $i$;

$t s_{i} \quad$ Tempo de preparação para a produção do item $i$;

$C_{m t}$ Capacidade do recurso $m$ no período $t$.

Variáveis de Decisão

$X_{i t} \quad$ Quantidade produzida do item $i$ no período $t$;

$I_{i t} \quad$ Estoque do item $i$ no final período $t$;

$Y_{i t} \quad$ Variável de preparação/produção do item $i$ no período $t$.

$$
\begin{aligned}
& \left(Y_{i t}=1, \text { se } X_{i t}>0\right. \\
& Y_{i t}=0, \text { caso contrário.) }
\end{aligned}
$$

$$
\begin{gathered}
\text { minimize } \quad Z=\sum_{i=1}^{N} \sum_{t=1}^{T}\left(s_{i} * Y_{i t}+h_{i} * I_{i t}\right) \\
\text { sujeito a: } I_{i, t-1}+X_{i t}-I_{i t}=d_{i t}+\sum_{j \in S(i)} r_{i j} * X_{j t} \quad \forall i, t \\
\sum_{i \in K_{m}}\left(a_{i} * X_{i t}+t s_{i} * Y_{i t}\right) \leq C_{m t} \quad \forall m, t \\
X_{i t} \leq B * Y_{i t} \quad \forall i, t \\
X_{i t}, I_{i t} \geq 0 \quad \forall i, t \\
Y_{i t} \in\{0,1\} \quad \forall i, t
\end{gathered}
$$

A função objetivo (2.1) consiste na soma dos custos de preparação e de estoque. As restrições (2.2) são responsáveis pelo balanceamento do estoque para cada item e período, onde são considerados as quantidades estocadas no período anterior $\left(I_{i, t-1}\right)$ e no final do 
período atual $\left(I_{i t}\right)$, a produção no período $\left(X_{i t}\right)$, a demanda externa $\left(d_{i t}\right)$ e a demanda interna $\left(\sum_{j \in S(i)} r_{i j} * X_{j t}\right)$. Observe aqui, que o modelo acima difere de um modelo para o problema monoestágio devido ao termo $\sum_{j \in S(i)} r_{i j} * X_{j t}$. Este termo, representa a demanda de produção entre os itens, ou seja, um item $i$ deve ser produzido antes da produção de seus sucessores $(S(i))$, de forma a atender suas demandas por componentes. As restrições (2.3) são responsáveis pela limitação da capacidade de cada recurso disponível em cada período. As restrições (2.4) asseguram a necessidade de preparação caso haja produção do item $i$ no período $t$. As variáveis de preparação são do tipo binário (2.6) e as demais são reais e positivas $(2.5)$.

Em Maes et al. (1991) foram propostas algumas heurísticas baseadas em relaxação linear, para a solução do problema (2.1)-(2.6), além de um estudo da complexidade do problema. O modelo matemático utilizado nas heurísticas foi uma reformulação do modelo (2.1)-(2.6) por localização de facilidades (Ver Apêndice A). A primeira heurística consiste em fixar uma variável de preparação a cada iteração, sendo que se o valor da variável for inteiro na solução relaxada, esta variável é fixada e passa para a próxima iteração. Cada iteração da heurística corresponde a resolução do problema relaxado.

A segunda heurística de Maes et al. (1991) é semelhante a primeira, porém se baseia no fato que os valores fracionários das variáveis de preparação normalmente não aparecem sozinhos, eles se encontram em uma sequência de frações e a heurística trabalha utilizando este fato. Ela tenta descobrir uma sequência de valores fracionários nas variáveis de preparação e as condensa em uma única preparação, fixando a primeira variável da sequência em um e as demais em zero. A terceira heurística consiste em uma abordagem do tipo LP-and-fix, denominada pelos autores de um branch-and-bound parcial. A heurística é composta de três passos, no primeiro passo resolve-se a relaxação linear do problema. No segundo passo fixam-se as variáveis de preparação que resultaram em valores inteiros na solução do problema relaxado, e no último passo resolve-se um branch-and-bound considerando o subproblema fixado no segundo passo. Além destas heurísticas, que segundo os autores foram as primeiras deste tipo para o problema, no artigo foi demonstrado que um problema de dimensionamento de lotes com tempos de preparação positivos pertence a classe NP-Completo.

Em Tempelmeier e Helber (1994) foi considerado o problema com vários recursos com capacidade limitada, que podem ser utilizados em vários níveis da estrutura de produto, tempos de preparações não nulos e demanda externa que ocorre somente para os itens 
finais. Os autores consideram apenas a estrutura geral de produção e lead-times positivos. Os autores de propuseram uma heurística baseada em uma versão modificada da heurística de Dixon-Silver (DIXON; SILVER, 1981) para problemas de dimensionamento de lotes monoestágio com restrição de capacidade. A heurística consiste em resolver vários problemas monoestágios pelo método de Dixon-Silver, começando dos itens finais para os intermediários, descendo de nível na estrutura de produto. A cada iteração, a capacidade utilizada é desconsiderada para a produção do próximo item (resolução do subproblema seguinte). Utilizando esta abordagem, o problema foi resolvido em tempo pseudo-polinomial. Segundo os autores, os resultados encontrados pela heurística obtiveram soluções com desvio percentual entre $2 \%$ e $26 \%$. Este desvio foi calculado apenas para as instâncias que foram resolvidas até a otimalidade utilizando o solver CPLEX. ${ }^{1}$ Neste mesmo trabalho, foi utilizada uma reformulação do problema de dimensionamento de lotes pelo problema do menor caminho, como proposto por Eppen e Martin (1987).

Clark e Armentano (1995) considera o problema de dimensionamento de lotes multiestágio com tempos e custos de preparações não nulos para quatro tipos distintos de estruturas de produto. Os autores consideram ainda lead-time não nulo para todos os itens. Para melhorar os limitantes inferiores da relaxação linear do problema, os autores propuseram uma forma iterativa de adição de inequações válidas ao problema com o auxílio de um método de separação desenvolvido neste trabalho. As inequações, identificadas pelos autores, definem faces da envoltória convexa e são utilizadas para eliminar as soluções da relaxação linear do problema, alterando o limitante inferior obtido. Estes limitantes são posteriormente utilizados em um método Branch-and-Bound e os resultados computacionais são apresentados.

Tempelmeier e Derstroff (1996) consideram o problema estudado em Tempelmeier e Helber (1994), adicionando ao problema tempos de preparações não nulos. Os autores propuseram uma heurística baseada em relaxação lagrangiana. A heurística consiste em relaxar as restrições de capacidade e de balanceamento de estoque, decompondo o problema em múltiplos subproblemas sem restrição de capacidade de um único item. A solução do problema decomposto pode obter estoque negativo, para evitar que isto ocorra, os autores adicionaram restrições de controle ao modelo relaxado, onde a produção acumulada deve ser maior ou igual a demanda de escalão acumulada. A demanda de escalão é a soma da demanda externa e a demanda interna, de acordo com a estrutura de produto. Os múltiplos subproblemas são resolvidos pelo algoritmo de Wagner e Whitin (1958). Obtidas as soluções dos subproblemas, os multiplicadores lagrangianos são atualizados.

\footnotetext{
${ }^{1}$ Para mais informações acesse: http://www-01.ibm.com/software/integration/optimization/cplex/
} 
Em Stadtler (2003) foi considerado o problema (2.1)-(2.6), com a adição da possibilidade de utilização de horas extras nas restrições de capacidade. A utilização de horas extras resulta em um alto custo. Para a resolução deste problema, foi proposta uma heurística de decomposição por janela de tempo (períodos). As janelas de tempo consistem em conjuntos de 4 períodos, onde o último deles é resolvido de forma relaxada. A janela seguinte começa no terceiro período da anterior, ou seja, dois períodos são sobrepostos em janelas consecutivas e a decisão tomada na janela anterior é levada em consideração na janela seguinte. O lead-time é negligenciado neste trabalho, pois a heurística não foi desenvolvida para trabalhar com lead-time positivo. Os autores comentam, na conclusão do artigo, que novos estudos são necessários para adequar o método de solução para a inclusão do lead-time positivo. Neste artigo, foi proposta uma reformulação do modelo matemático por localização de facilidade.

Sahling et al. (2009) apresentam uma heurística do tipo fix-and-optimize para o problema de dimensionamento de lotes multiestágio com limitação da capacidade e preservação da preparação. Além disso, existe a possibilidade de utilização de horas extras e o lead-time foi considerado positivo e igual a um para todos os componentes. Neste artigo foram feitas quatro variações de decomposição para a escolha do conjunto de variáveis que são fixadas: decomposição orientada a produto, decomposição orientada a produto seguida de decomposição orientada a recurso, decomposição orientada a produto seguida de decomposição orientada a processo e decomposição orientada a produto, depois orientada a recurso e por último orientada a processo. A formulação utilizada no artigo foi uma reformulação por localização de facilidades baseada em Stadtler (2003).

Em Akartunali e Miller (2009) foi tratado o problema de dimensionamento de lotes multiestágio com limitação de capacidade, e tempos e custos de preparações não nulos. Para a resolução deste problema, foi proposto um framework de solução baseado na heurística relax-and-fix. Seguindo a mesma idéia de janela de tempo utilizada por Stadtler (2003), os autores resolvem o problema utilizando a heurística apenas sobre as partições pertencentes ao subproblema. O subproblema é resolvido somente dentro da janela de tempo, ou seja, é considerada apenas uma quantidade de períodos. A cada subproblema resolvido, as variáveis dos primeiros períodos da janela são fixadas e as demais, períodos de intercalação (overlapping) e períodos relaxados, são levadas em consideração para a solução da janela seguinte. Os autores também utilizam a heurística $L P$-and-fix para gerar soluções factíveis do problema original e assim tentar melhorar os limitantes superiores para as janelas seguintes. 
Em Almeder (2010) foi abordado o problema de dimensionamento de lotes multiestágio com limitação de capacidade, tempos e custos de preparações não nulos e possibilidade de utilização de hora extra. Para a solução deste problema, foi proposto um método híbrido de Colônia de Formigas (Ant Colony Optimization ou ACO) com ferramentas de solução de problemas LP/MIP, mais especificamente a ferramenta CPLEX 10.1. Neste caso, a ACO foi utilizada para determinar os períodos onde cada produto deveria ser produzido. Baseado nesta escolha, as quantidades a serem produzidas, em cada período de cada produto, são determinadas pelo CPLEX. Os autores indicam que este método funcionou bem para instâncias de tamanho pequeno e médio. Para instâncias de grande porte, encontrou soluções de alta qualidade, mas não conseguiu ser melhor que heurísticas especializadas para o problema.

Em Helber e Sahling (2010) foi abordado o problema estudado por Almeder (2010), porém com lead-time não nulo. Neste trabalho é proposta uma heurística do tipo fixand-optimize para o problema. Os autores utilizaram instâncias de testes da literatura, geradas em Tempelmeier e Derstroff (1996) e Stadtler e Sürie (2000), e compararam os resultados com as heurísticas propostas em Tempelmeier e Derstroff (1996) e Stadtler (2003).

Em Almeder et al. (2009) foi abordado o problema de dimensionamento de lotes multiestágio proposto em Billington et al. (1983). Neste trabalho, importantes considerações sobre lead-time são apresentadas. Segundo os autores, existem duas formas de tratamento do lead-time na literatura. Na primeira, ele é negligenciado, permitindo que itens predecessores e sucessores sejam produzidos no mesmo período, isso muitas vezes gera um sequenciamento infactível. Para uma exemplificação, considere a Figura 3 que representa a mesma estrutura da Figura 1 com a divisão dos itens por recurso de produção (A, B, C). A Figura 3.a representa a estrutura de produto e a Figura 3.b representa a sequência de uso dos recursos. No exemplo, temos um ciclo no recurso B, pois o item 2 é produzido no mesmo recurso de um componente, no caso, o item 4. Este tipo de estrutura é nomeada de estrutura de produto cíclica.

Quando o lead-time é considerado nulo, os itens são alocados no dimensionamento de lotes de forma a atender a demanda, respeitando as restrições de capacidade dos seus recursos, mas negligenciando a possibilidade de falta de componentes (estoque negativo) durante o decorrer do período, pois as restrições do modelo matemático garantem estoque não nulo apenas no final de cada período. Na Figura 4, podemos ver uma possível produção dos itens de 1 até 6 , respeitando a estrutura de produto da Figura 3. A Figura 4.a 


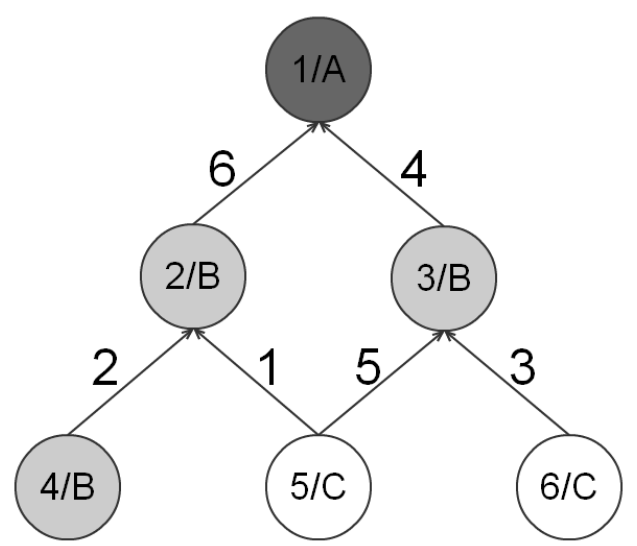

a) Estrutura de produto

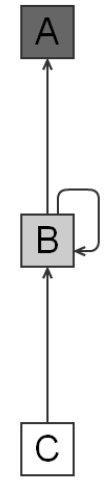

b) Sequência de recursos

Figura 3: Estrutura de produto com divisão por recurso.

apresenta a solução do dimensionamento de lotes antes do sequenciamento da produção, onde temos componentes sendo produzidos simultaneamente com seus sucessores (estão sendo produzidos simultaneamente o componente 5 com o sucessor 2 , o componente 6 com o sucessor 3 e o item 1 está sendo produzido antes do início da produção de seus componentes 2 e 3). Quando o sequenciamento é feito, na Figura 4.b, temos a produção dos itens 1 e 3 sendo enviadas ao período seguinte, por ter excedido a capacidade, ou gerando a necessidade de utilização de hora extra.

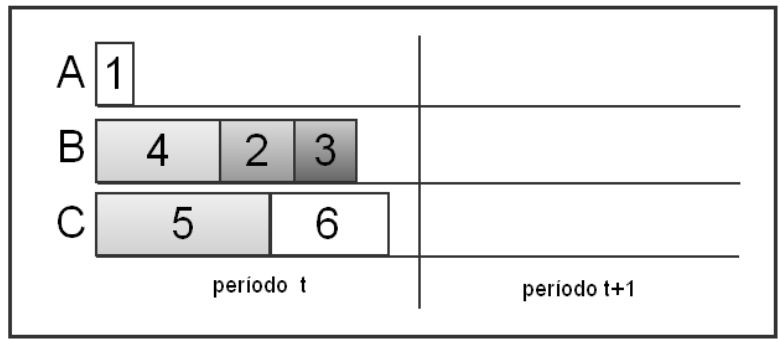

a) Antes do sequenciamento

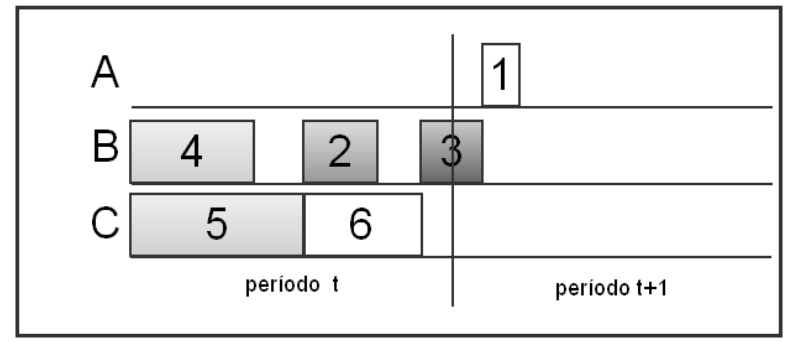

b) Após o sequenciamento

Figura 4: Sequenciamento da produção. Imagem adaptada de Almeder et al. (2009).

Na segunda forma de tratamento do lead-time apontada por Almeder et al. (2009), o lead-time é dado como sendo um número fixo de períodos (usualmente um período), forçando a produção de itens finais a demorar pelo menos um número de períodos igual ao número de níveis da estrutura de produto. Esta abordagem foi utilizada em Tempelmeier e Helber (1994), Sahling et al. (2009) e Helber e Sahling (2010).

Devido as dificuldades geradas pelas duas formas de tratamento do lead-time, Almeder et al. (2009) propõem duas novas formulações para o problema, que consideram o leadtime, mas de forma desvinculada de um número inteiro de períodos. A primeira formulação 
consiste em um modelo de produção em lotes (batching) onde são consideradas as trocas de preparação dentro dos períodos, e itens sucessores não são produzidos até que seus antecessores tenham estoques suficientes para o atendimento de sua demanda. Na segunda formulação, a produção é considerada por taxa de produção, então conforme cada unidade é produzida, ela pode ser utilizada para a produção do item seguinte. Todo o processo é controlado pelas equações de balanço de estoque, para evitar estoque negativo. Apesar destas considerações de Almeder et al. (2009), nesta dissertação considera-se o problema como proposto por Sahling et al. (2009), ou seja, o lead-time de um período para todos os itens componentes.

Uma revisão para o problema de dimensionamento de lotes multiestágio é apresentada em Buschkühl et al. (2010). Nesta revisão, os autores discutem diferentes modelos matemáticos e diferentes abordagens de solução. Esta classificação teve como foco trabalhos que tratam separadamente os problemas de dimensionamento de lotes e de sequenciamento da produção. Duas revisões e classificações para problemas de dimensionamento de lotes monoestágio e multiestágio foram feitas em Bahl et al. (1987) e Kuik et al. (1994). 


\section{CAPÍTULO 3}

\section{PROBLEMAS ABORDADOS}

Neste trabalho consideramos dois problemas de dimensionamento de lotes multiestágio com algumas características distintas entre si. O primeiro problema foi abordado em vários trabalhos na literatura, como Tempelmeier e Derstroff (1996), Stadtler (2003) e Akartunali e Miller (2009), e consiste em um problema de dimensionamento de lotes multiestágio com limitação da capacidade e possibilidade de utilização de hora extra. São considerados também custos e tempos de preparações não nulos. O segundo problema, proposto em Sahling et al. (2009), considera tempos e custos de preparações não nulos, possibilidade de preservação da preparação entre períodos, lead-time positivo de um período independente do item e estoques iniciais também positivos.

Além dos problemas abordados, neste capítulo apresentaremos três formulações matemáticas para cada um dos problemas. Entre estas formulações temos o modelo agregado, o modelo reformulado por localização de facilidades e um modelo misto de agregado com parte de localização de facilidades.

Uma explicação mais detalhada sobre a reformulação por localização de facilidades pode ser encontrada no Apêndice A. 


\subsection{Problema de dimensionamento de lotes multiestá- gio com limitação de capacidade}

O problema de dimensionamento de lotes multiestágio com limitação de capacidade já vem sendo abordado a algum tempo na literatura. As características do problema em questão são as seguintes:

- Demandas externas (itens finais) determinísticas $\left(d_{i t}\right)$ que devem ser totalmente satisfeitas sem atraso, isto é, não é permitido backlogging;

- A produção de cada item utiliza apenas um dos recursos de produção e cada recurso tem um limite de capacidade por período $\left(C_{m t}\right)$ que deve ser respeitado;

- Cada recurso conta com a possibilidade de utilização de horas extras $\left(O_{m t}\right)$ para estender sua capacidade, mas o custo associado a sua utilização é muito elevado;

- Na operação de preparação incide custo e tempo que são considerados na função objetivo e na restrição de capacidade, respectivamente;

- O lead-time é considerado nulo.

O objetivo do problema consiste em determinar um plano de produção de forma a minimizar custos de preparação, de estocagem e de hora extra, enquanto atende as restrições do problema.

As três formulações matemáticas abordadas para este problema são as seguintes:

- Modelo agregado. Este modelo tem como base o modelo clássico ((2.1)-(2.6)) com o acréscimo da possibilidade de utilização de hora extra.

- Modelo parcialmente reformulado por localização de facilidades como proposto em Sahling et al. (2009). Este modelo, segundo os autores, mesmo tendo um número bem maior de variáveis, gera um limitante inferior de melhor qualidade do que o modelo agregado. Esta é uma formulação mista, pois mantém as variáveis de produção do modelo agregado e adiciona as variáveis de localização de facilidade.

- Modelo totalmente reformulado com localização de facilidade. Diferente da formulação utilizada por Sahling et al. (2009), as variáveis de produção do modelo agregado são totalmente substituídas pelas variáveis de localização de facilidades, conforme Stadtler (2003). 


\subsubsection{Formulação Agregada}

Os modelos matemáticos agregados têm por intuito, determinar as quantidades a serem produzidas para todos os itens $\left(X_{i t}\right)$ ao longo do horizonte de planejamento, as quantidades a serem estocadas de todos os itens no final de cada período $t\left(I_{i t}\right)$ e indicar os períodos onde deverão ser feitas as preparações $\left(Y_{i t}\right)$.

Para a apresentação da formulação matemática, considere a notação apresentada a seguir. Considere também a definição de demanda de escalão do item $i$ no período $t\left(D_{i t}\right)$, dada por: $D_{i t}=d_{i t}+\sum_{j \in S(i)} D_{j t}$. A demanda de escalão consiste na soma das demandas independente $\left(d_{i t}\right)$ e dependente $\left(\sum_{j \in S(i)} D_{j t}\right)$. Já $B_{i t}$ é a demanda de escalão acumulada do produto $i$ do período $t$ até o último período do horizonte de planejamento $(T)$, sendo dado por : $B_{i t}=\sum_{\pi=t}^{T} D_{i \pi}$. Desta forma a produção do item $i$ no período $t$ pode ser limitada por este valor, pois a produção precisa ser no máximo igual a demanda total do problema até o final do horizonte de planejamento, para que toda a demanda seja atendida.

Conjuntos e índices

$N \quad$ Conjunto de produtos $(i \in\{1, \ldots, N\})$;

$M \quad$ Conjunto de recursos $(m \in\{1, \ldots, M\})$;

$T \quad$ Conjunto de períodos $(t \in\{1, \ldots, T\})$;

$S(i)$ Conjunto de sucessores de $i$;

$A(i)$ Conjunto de antecessores de $i$;

$K_{m} \quad$ Conjunto de produtos produzindo com o recurso $m$.

\section{Parâmetros}

$S_{i} \quad$ Custo de preparação relacionado ao produto $i$;

$h_{i} \quad$ Custo de estoque relacionado ao produto $i$;

$o c_{m} \quad$ Custo de horas extras relacionada ao recurso $m$;

$r_{i j} \quad$ Unidades do produto $i$ necessários para produzir uma unidade de $j$;

$d_{i t} \quad$ Demanda externa do produto $i$ no período $t$;

$a_{i} \quad$ Tempo de produção de cada unidade do produto $i$;

$t s_{i} \quad$ Tempo de preparação para a produção de $i$;

$C_{m t}$ Capacidade do recurso $m$ no período $t$.

Variáveis do problema

$O_{m t}$ Horas extras do recurso $m$ no período $t$; 
$X_{i t} \quad$ Quantidade produzida do produto $i$ no período $t$;

$I_{i t} \quad$ Estoque do produto $i$ no final do período $t$;

$Y_{i t} \quad$ Variável de preparação/produção do produto $i$ no período $t$;

$\left(Y_{i t}=1\right.$, se $X_{i t}>0$

$Y_{i t}=0$, caso contrário.)

\section{Formulação Agregada}

$$
\begin{gathered}
\text { minimize } Z=\sum_{i=1}^{N} \sum_{t=1}^{T}\left(s_{i} * Y_{i t}+h_{i} * I_{i t}\right)+\sum_{m=1}^{M} \sum_{t=1}^{T} o c_{m} * O_{m t} \\
\text { sujeito a: } \quad I_{i, t-1}+X_{i t}-\sum_{j \in S(i)} r_{i j} * X_{j, t}-I_{i t}=d_{i t} \quad \forall i, t \\
\sum_{i \in K_{m}}\left(a_{i} * X_{i t}+t s_{i} * Y_{i t}\right) \leq C_{m t}+O_{m t} \quad \forall m, t \\
X_{i t} \leq B_{i t} * Y_{i t} \quad \forall i, t \\
X_{i t}, I_{i t} \geq 0 \quad \forall i, t \\
Y_{i t} \in\{0,1\} \quad \forall i, t
\end{gathered}
$$

A função objetivo (3.1) consiste da soma dos custos de preparação, de estoque e de horas extras. As restrições (3.2) são responsáveis pelo balanceamento do estoque. As restrições (3.3) são responsáveis pela limitação da capacidade de recurso disponível, além das horas extras necessária para factibilizar o plano de produção. As restrições (3.4) asseguram a necessidade de preparação caso haja produção no período. As demais restrições (3.5)-(3.6) são restrições de domínio.

\subsubsection{Formulação por Localização de Facilidades segundo Sahling et al. (2009)}

Baseado na reformulação de Stadtler (2003), os autores de Sahling et al. (2009) propõem uma reformulação parcial do problema (3.1)-(3.6), substituindo as variáveis de produção $\left(X_{i t}\right)$ pelas variáveis de localização de facilidades $\left(\delta_{i t \pi}\right)$ apenas no conjunto de restrições (3.4). Desta forma, os autores procuraram melhorar os limitantes do problema, sem que isso gere um aumento no tempo de solução com o aumento do número de variáveis. As variáveis $\delta_{i t \pi}$ significam que parte da demanda do item $i$ no período $\pi$ será produzida no período $t$. 
Na formulação matemática agregada (3.1)-(3.6), foram substituídas as restrições (3.4) pelas restrições (3.8) e (3.9), como segue na formulação abaixo.

\section{Formulação Mista}

$$
\begin{aligned}
& \text { minimize } Z=\sum_{i=1}^{N} \sum_{t=1}^{T}\left(s_{i} * Y_{i t}+h_{i} * I_{i t}\right)+\sum_{m=1}^{M} \sum_{t=1}^{T} o c_{m} * O_{m t} \\
& \text { sujeito a: } \quad(3.2)-(3.3) \\
& X_{i t}=\sum_{\pi=t}^{T} \delta_{i t \pi} \quad \forall i, t \\
& \delta_{i t \pi} \leq B_{i \pi} * Y_{i t} \quad \forall i, t, \pi \geq t, D_{i \pi}>0 \\
& (3.5)-(3.6) \\
& \delta_{i t \pi} \geq 0 \quad \forall i, t, \pi \geq t, D_{i \pi}>0
\end{aligned}
$$

As restrições (3.8) fazem com que a soma de produção das variáveis de localização de facilidades $\left(\sum_{\pi=t}^{T} \delta_{i t \pi}\right)$ que atendem parte da demanda do período $t$ até o final do horizonte de planejamento $(T)$ sejam iguais as variáveis do modelo agregado $X_{i t}$ que definem a produção total no período $t$. As restrições (3.9) obrigam a necessidade de preparação caso haja produção no período $t$, além de limitar a produção da porção que será consumida no período $\pi$ pela demanda de escalão acumulada deste mesmo período. As restrições (3.10) são restrições de não negatividade. O termo $\left(D_{i \pi}>0\right)$ elimina restrições desnecessárias, quando um item $i$ não tem demanda no período $\pi$. Quando $D_{i \pi}=0$ então $\delta_{i t \pi}=0 \forall t \leq \pi$. Neste caso, as restrições (3.9) ficarão iguais a relaxação do domínio das variáveis $Y_{i t}$ correspondentes $\left(Y_{i t} \geq 0\right)$.

\subsubsection{Formulação por Localização de Facilidades segundo Stad- tler (2003)}

Em Stadtler (2003) utilizou-se a reformulação por localização de facilidades, com o intuito de obter uma formulação mais forte. A proposta de Stadtler (2003) consiste em definir as variáveis de localização de facilidades como sendo a fração de cada lote que é consumida nos períodos após a produção do mesmo. Desta forma, a variável correspondente a produção de um item $i$ em um período $t\left(X_{i t}\right)$ é substituída pelo conjunto de variáveis $\sum_{\pi=t}^{T} \delta_{i t \pi}$, onde $\delta_{i t \pi}$ indica a quantidade do produto $i$ produzido no período $t$ para 
ser consumido no período $\pi$.

Desta forma, o modelo reformulado de acordo com Stadtler (2003) é o seguinte: Formulação por Localização de Facilidades

$$
\begin{gathered}
\quad Z=\sum_{i=1}^{N} \sum_{t=1}^{T}\left(s_{i} * Y_{i t}+h_{i} * I_{i t}\right)+\sum_{m=1}^{M} \sum_{t=1}^{T} o c_{m} * O_{m t} \\
\text { minimize } \sum_{\pi=1}^{t} \delta_{i \pi t}=D_{i t} \quad \forall i, t, D_{i t}>0 \\
\text { sujeito a: } I_{i, t-1}+\sum_{\substack{\pi=t \\
D_{i \pi}>0}}^{T} \delta_{i t \pi}-\sum_{j \in S(i)} \sum_{\substack{\pi=t \\
S e}}^{T} r_{i \pi} * 0 \\
\sum_{i \in K_{m}} \sum_{\substack{\pi=t \\
S e}}^{T} a_{i \pi} * \delta_{i t \pi}+\sum_{i \in K_{m}}-I_{i t}=d_{i t} \quad \forall i, t \\
\delta_{i t \pi} \leq B_{i \pi} * Y_{i t} \quad \forall i, t, \pi \geq t, Y_{i t} \leq C_{m t}+O_{m t} \quad \forall m, t \\
\delta_{i t \pi}, I_{i t} \geq 0 \quad \forall i, t, \pi \geq t, D_{i \pi}>0 \\
Y_{i t} \in\{0,1\} \quad \forall i, t
\end{gathered}
$$

A função objetivo (3.11) consiste da soma dos custos de estoque, de preparação e de horas extras. As restrições (3.12) garantem que a demanda de escalão de cada item $i$ em cada período $t$ do horizonte de planejamento esta sendo atendida sem atraso. As restrições (3.13) são responsáveis pelo balanceamento do estoque. As restrições (3.14) são responsáveis pela limitação da capacidade disponível além das horas extras necessária para factibilizar o plano de produção. As restrições (3.15) fazem com que a quantidade do produto $i$ produzido em $t$ para consumo em $\pi$ seja limitado pela demanda de escalão acumulada $\left(B_{i \pi}\right)$ do período $\pi$ e obriga a necessidade de preparação em $t$. As restrições (3.16)-(3.17) são restrições de domínio.

\subsection{Problema de dimensionamento de lotes multiestá- gio com limitação de capacidade e preservação da preparação}

O problema de dimensionamento de lotes multiestágio com limitação de capacidade e preservação da preparação, proposto em Sahling et al. (2009), tem as seguintes caracte- 
rísticas:

- Demandas externas determinísticas $d_{i t}$ (demanda externa do produto $i$ no período t) que deve ser totalmente satisfeita sem atraso. Observe que é permitido demanda externa tanto para itens finais como para componentes;

- Cada produto tem um estoque inicial $\left(\hat{I}_{i}\right)$ que garante a factibilidade do primeiro período;

- A produção de cada item utiliza apenas um dos recursos e cada recurso tem um limite de capacidade por período $\left(C_{m t}\right)$ que deve ser respeitado;

- Cada recurso conta com a possibilidade de horas extras $\left(O_{m t}\right)$ para estender sua capacidade, mas o custo associado a utilização de horas extras é muito elevado;

- Para cada preparação de máquina temos um custo operacional que é computado na função objetivo e um tempo de execução que é computado na restrição de capacidade;

- A preservação da preparação ocorre se um item $i$ for produzido em um período $t-1$ e no seu período sucessor $(t)$, assim podemos manter a máquina preparada para produzir $i$ e não consumir os recursos de preparação no período $t$. Isto é indicado pela váriável $W_{i t}$, sendo que $W_{i t}=1$ indica que houve preservação da preparação do recurso utilizado para produzir $i$, do período $t-1$ para o período $t$;

- Só é permitida a preservação de no máximo uma preparação por recurso e período, ou seja, para um determinado recurso $m$, somente a preparação para um único item produzido com este recurso poderá ser preservada a cada período;

- O lead-time será fixado em um para todos os itens utilizados como componentes.

O objetivo do problema consiste em determinar a produção de forma a minimizar a soma dos custos de preparação, de estocagem e de hora extra.

A seguir serão apresentadas as três formulações matemáticas adaptadas para este problema. Como no problema anterior, apresentaremos a seguir uma formulação agregada, uma reformulação parcial por localização de facilidades e uma reformulação total por localização de facilidades. Para a apresentação das formulações, considere as variáveis abaixo.

Variáveis adicionais do problema

$W_{i t}$ Variável de preservação da preparação para produção de $i$ no período $t$;

$\left(W_{i t}=1\right.$, se houver preservação da preparação

$W_{i t}=0$, caso contrário.) 
$V_{m t} \quad$ Variável auxiliar do recurso $m$ no período $t$;

\subsubsection{Formulação Agregada}

O Modelo Agregado proposto em Sahling et al. (2009) segue o modelo agregado ((3.1)(3.6)), com o acréscimo das restrições e variáveis de preservação da preparação.

O modelo matemático segue abaixo:

\section{Formulação Agregada}

$$
\begin{aligned}
& \text { minimize } \quad Z=\sum_{i=1}^{N} \sum_{t=1}^{T}\left(s_{i} *\left(Y_{i t}-W_{i t}\right)+h_{i} * I_{i t}\right)+\sum_{m=1}^{M} \sum_{t=1}^{T} o c_{m} * O_{m t} \\
& \text { sujeito a: } I_{i, t-1}+X_{i t}-\sum_{j \in S(i)} r_{i j} * X_{j, t+1}-I_{i t}=d_{i t} \quad \forall i, t=2, \ldots, T-1 \\
& I_{i, T-1}+X_{i T}-I_{i T}=d_{i T} \quad \forall i \\
& \hat{I}_{i}-\sum_{j \in S(i)} r_{i j} * X_{j 1}-I_{i 0}=0 \quad \forall i \\
& I_{i 0}+X_{i 1}-\sum_{j \in S(i)} r_{i j} * X_{j 2}-I_{i 1}=d_{i 1} \quad \forall i \\
& \sum_{i \in K_{m}}\left(a_{i} * X_{i t}+t s_{i} *\left(Y_{i t}-W_{i t}\right)\right) \leq C_{m t}+O_{m t} \quad \forall m, t \\
& X_{i t} \leq B_{i t} * Y_{i t} \quad \forall i, t \\
& \sum_{i \in K_{m}} W_{i t} \leq 1 \quad \forall m, t \\
& W_{i t} \leq Y_{i, t-1} \quad \forall i, t=2, \ldots, T \\
& W_{i t} \leq Y_{i t} \quad \forall i, t \\
& W_{i t}+W_{i, t+1} \leq 1+V_{m t} \quad \forall m, i \in K_{m}, t \\
& \left(Y_{i t}-W_{i t}\right)+V_{m t} \leq 1 \quad \forall m, i \in K_{m}, t \\
& W_{i 1}=0 \quad \forall i \\
& W_{i, T+1}=0 \quad \forall i \\
& X_{i t}, I_{i t} \geq 0 \quad \forall i, t \\
& I_{i 0} \geq 0 \quad \forall i \\
& O_{m t}, V_{m t} \geq 0 \quad \forall m, t \\
& Y_{i t}, W_{i t} \in\{0,1\} \quad \forall i, t
\end{aligned}
$$


A função objetivo (3.18) consiste da soma dos custos de estoque, de preparação e de hora extra. O custo de preparação é considerado, para um determinado período, somente se houver preparação no período $\left(Y_{i t}=1\right)$ e não houver preservação da preparação $\left(W_{i t}=0\right)$. As restrições (3.19)-(3.22) são responsáveis pelo balanceamento do estoque, com um lead-time igual a um somente para os produtos utilizados como componentes e não para os produtos finais. As restrições de balanceamento de estoque foram separadas para um melhor entendimento. As restrições (3.20) tratam do balanceamento do último período do horizonte de planejamento, onde não existe demanda dependente devido ao lead-time positivo. As restrições (3.21) fazem o cálculo do estoque inicial resultante (estoque inicial menos os componentes utilizados na produção do primeiro período), estas são necessárias devido também ao lead-time positivo. As restrições (3.19) e (3.22) são similares e foram divididas apenas para facilitar o entendimento da introdução do estoque inicial, no caso da segunda.

As restrições (3.23) são responsáveis pela limitação da capacidade disponível além das horas extras necessárias para factibilizar o plano de produção. As restrições (3.24) obrigam a necessidade de preparação caso haja produção no período, além de limitar a produção pela demanda de escalão acumulada do período atual até o horizonte de planejamento. Em (3.25) é garantido que haverá no máximo uma preservação da preparação por recurso em cada período do horizonte de planejamento. As restrições (3.26) e (3.27) garantem que para haver preservação da preparação no período $t$ para o item $i$, o recurso deve estar preparado para a produção deste item $i$ nos períodos $t-1$ e $t$.

As restrições (3.28) e (3.29) garantem a possibilidade de preservação da preservação por múltiplos períodos. Por exemplo, se preservarmos a preparação para um produto $k$ do período $t-1$ para o período $t$, e se produzirmos somente este produto durante todo o período $t$, no recurso $m$, e preservarmos novamente a preparação para o período $t+1$, de acordo com (3.28) temos que $W_{k t}+W_{k, t+1}=2$ e assim $2 \leq 1+V_{m t}$. Como $V_{m t} \geq 0$, então $V_{m t} \geq 1$. Porém de acordo com (3.29) podemos verificar que $\left(Y_{k t}-W_{k t}\right)=0$ devido a restrição (3.27), resultando em $V_{m t} \leq 1$. Como resultado temos que $V_{m t}=1$. O valor de $V_{m t}=1$ faz com que $Y_{i t}-W_{i t}=0, \quad \forall i \in K_{m}$. Como somente uma preservação por período e recurso é permitida, todos $W_{i t}=0, \quad \forall i \in K_{m}, i \neq k$ e com isto $Y_{i t}=0, \quad \forall i \in$ $K_{m}, i \neq k$. Desta forma garante-se que nenhum outro produto será produzido no período $t$ utilizando o mesmo recurso do produto $k$.

As restrições (3.30) e (3.31) estabelecem as preservações das preparações do primeiro e do período seguinte ao final do horizonte de planejamento. As demais restrições são de 
domínio.

\subsubsection{Formulação por Localização de Facilidades segundo Sahling et al. (2009)}

A formulação proposta em Sahling et al. (2009) é um modelo matemático misto entre o modelo agregado e o modelo de localização de facilidades, como no problema anterior. Nesta formulação matemática, o conjunto de restrições (3.24) é substituído pelos conjuntos (3.37) e (3.38). A restrição (3.37) mantém a proporção entre as variáveis de produção da formulação agregada e da formulação de localização de facilidades, e as variáveis da formulação de localização de facilidades substituem as variáveis de produção da formulação agregado na restrição (3.38).

O modelo reformulado segue abaixo:

\section{Formulação Mista}

$$
\begin{gathered}
\text { minimize } Z=\sum_{i=1}^{N} \sum_{t=1}^{T}\left(s_{i} *\left(Y_{i t}-W_{i t}\right)+h_{i} * I_{i t}\right)+\sum_{m=1}^{M} \sum_{t=1}^{T} o c_{m} * O_{m t} \\
\text { sujeito a: }(3.19)-(3.23) \\
\sum_{\pi=t}^{T} \delta_{i t \pi}=X_{i t} \quad \forall k, t \\
\delta_{i t \pi} \leq B_{i \pi} * Y_{i t} \quad \forall i, t, \pi \geq t, D_{i \pi}>0 \\
(3.25)-(3.35) \\
\delta_{i t \pi} \geq 0 \quad \forall i, t, \pi \geq t, D_{i \pi}>0
\end{gathered}
$$

As restrições (3.38) obrigam a necessidade de preparação caso haja produção no período, além de limitar a produção pela demanda de escalão acumulada do período de demanda $(\pi)$ até o final do horizonte de planejamento. As restrições (3.39) são restrições de não negatividade das variáveis de localização de facilidades.

\subsubsection{Formulação por Localização de Facilidades segundo Stad- tler (2003)}

À formulação de Stadtler (2003) foram adicionadas as variáveis de estoque inicial e as restrições de controle da preservação da preparação, para adequar o modelo ao problema, além do lead-time igual a um para componentes. 
O modelo reformulado segue abaixo: 


\section{Formulação por Localização de Facilidades}

minimize $\quad Z=\sum_{i=1}^{N} \sum_{t=1}^{T}\left(s_{i} *\left(Y_{i t}-W_{i t}\right)+h i * I_{i t}\right)+\sum_{m=1}^{M} \sum_{t=1}^{T} o c_{m} * O_{m t}$

sujeito a:

$$
\begin{aligned}
& (3.25)-(3.31) \\
& \sum_{\pi=1}^{t} \delta_{i \pi t}=D_{i t} \quad \forall i, t, D_{i t}>0
\end{aligned}
$$

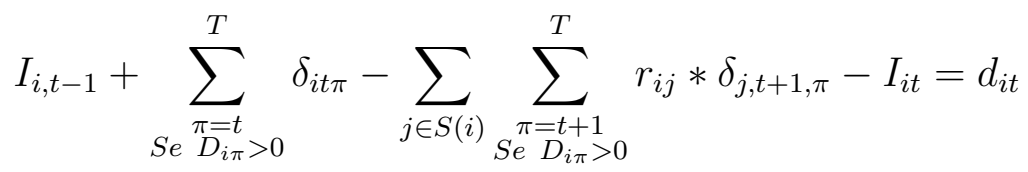

$$
\begin{aligned}
& \forall i, t=2, \ldots, T-1
\end{aligned}
$$

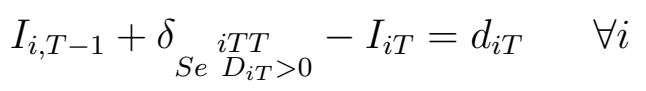

$$
\begin{aligned}
& \hat{I}_{i}-\sum_{j \in S(i)} \sum_{\substack{\pi=1 \\
S e}}^{T} r_{i j} * \delta_{j 1 \pi}-I_{i 0}=0 \quad \forall i
\end{aligned}
$$

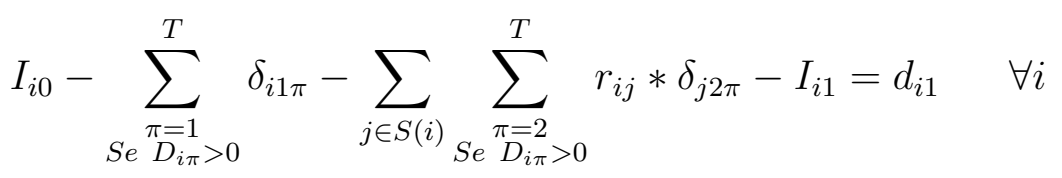

$$
\begin{aligned}
& \sum_{i \in K_{m}} \sum_{\substack{\pi=t \\
S e}}^{T} a_{i} * \delta_{i t \pi}+\sum_{i \in K_{m}} t s_{i} *\left(Y_{i t}-W_{i t}\right) \leq C_{m t}+O_{m t} \quad \forall m, t \\
& \delta_{i t \pi} \leq B_{i \pi} * Y_{i t} \quad \forall i, t, \pi \geq t, D_{i \pi}>0 \\
& I_{i t} \geq 0 \quad \forall i, t \\
& I_{i 0} \geq 0 \quad \forall i \\
& O_{m t}, V_{m t} \geq 0 \quad \forall m, t \\
& \delta_{i t \pi} \geq 0 \quad \forall i, t, \pi \geq t, D_{i \pi}>0 \\
& Y_{i t}, W_{i t} \in\{0,1\} \quad \forall i, t
\end{aligned}
$$

As restrições (3.41) garantem que a soma de tudo o que é produzido de um produto $i$ do período 1 até $t$ para ser consumido no período $t$ é igual a sua demanda de escalão $\left(D_{i t}\right)$. As restrições (3.42)-(3.45) são responsáveis pelo balanceamento do estoque, com um lead-time igual a 1 somente para os produtos utilizados como componentes de sucessores e não para os que suprem demanda externa, ou seja, os produtos finais. A separação das restrições de balanceamento de estoque seguem o mesmo raciocínio apresentado no modelo matemático anterior. 
As restrições (3.46) são responsáveis pela limitação da capacidade disponível além da horas extras necessária para factibilizar o plano de produção. As restrições (3.47) obrigam a necessidade de preparação caso haja produção no período, além de limitar a produção pela demanda de escalão acumulada do período de demanda $(\pi)$ até o final do horizonte de planejamento. As demais restrições são de domínio. 


\section{CAPÍTULO 4}

\section{ABORDAGENS DE SOLUÇÃO}

Para a obtenção de soluções para os problemas considerados, trabalharemos com métodos heurísticos de solução. Entre eles, três tipos de heurísticas baseadas na formulação matemática do problema, que são as heurísticas relax-and-fix, LP-and-fix e fixand-optimize, uma metaheurística pura algoritmo de abelhas, e dois métodos híbridos de algoritmo de abelhas com a heurística fix-and-optimize.

Os métodos foram desenvolvidos considerando as características dos problemas de dimensionamento de lotes abordados nesta dissertação e descritos no Capítulo 3. Os métodos propostos serão utilizados na resolução de dois conjuntos de testes da literatura. O primeiro conjunto de testes, gerado por Tempelmeier e Buschkühl (2009), considera a possibilidade de preservação da preparação, lead-time e estoque inicial positivos, horas extras e, custos e tempos de preparações positivos. O segundo conjunto de testes, gerado por Tempelmeier e Derstroff (1996) e Stadtler e Sürie (2000), considera problemas de dimensionamento de lotes multiestágio com custos e tempos de preparações positivos e hora extra.

Inicialmente apresentaremos as heurísticas desenvolvidas baseadas na formulação matemática, ou seja, as heurísticas LP-and-fix, relax-and-fix e fix-and-optimize. Em seguida, descrevemos a metaheurística algoritmo de abelhas e no final descrevemos os métodos híbridos de algoritmo de abelhas e fix-and-optimize. 


\subsection{Heurísticas baseadas na formulação matemática}

Os métodos relax-and-fix e fix-and-optimize se baseiam na decomposição das variáveis inteiras do problema original em subconjuntos disjuntos, enquanto que as heurísticas do tipo LP-and-fix consistem em resolver a relaxação linear de problemas inteiros mistos e em seguida, aplicar estratégias de fixação das variáveis inteiras. Os métodos baseados em decomposição das variáveis inteiras resolvem o problema original de forma iterativa, considerando um número finito de subproblemas. No caso do problema de dimensionamento de lotes multiestágio com limitação de capacidade, as variáveis utilizadas no particionamento são as variáveis de preparação e preservação da preparação. Na literatura, existem algumas formas de particionamento utilizadas para este problema, entre elas, a partição por períodos, por itens, por recursos, por processos, entre outras (STADTLER, 2003; SAHLING et al., 2009). A seguir, apresentamos com mais detalhes cada uma das heurísticas.

\subsubsection{Heurística LP-and-fix}

Como descrito em Pochet e Wolsey (2006), a heurística LP-and-fix é bem simples. O método consiste em primeiro resolver a relaxação linear do problema e fixar todas as variáveis que tenham resultado inteiro na relaxação. O problema MIP restrito é então resolvido por algum método de solução de problemas MIP, como o branch-and-bound ou branch-and-cut, por exemplo.

Em Maes et al. (1991) foi proposta uma heurística do tipo LP-and-fix para o problema de dimensionamento de lotes multiestágio com limitações de capacidade e os autores denominaram o método de "Parcial branch-and-bound". Neste trabalho, consideramos este método com o acréscimo de um parâmetro $\alpha$, como descrito abaixo.

No método proposto, tanto as variáveis de preparação como as de preservação da preparação podem ser fixadas, dependendo do resultado da relaxação linear do problema. Para a fixação das variáveis consideramos que todas as variáveis tais que $Y_{i t} \geq 1-\alpha$ são fixadas em um $\left(\bar{Y}_{i t}=1\right)$ e todas as variáveis tais que $Y_{i t} \leq \alpha$ são fixadas em zero $\left(\bar{Y}_{i t}=0\right)$ de acordo com um parâmetro $\alpha(0 \leq \alpha \leq 1)$. As mesmas regras valem para as variáveis de preservação da preparação.

Por exemplo, na Figura 5 apresentamos um fluxo deste método de solução considerando seis itens e sete períodos. A partir da solução da relaxação, apresentada na Figura 5.a, verificamos quais variáveis estão dentro do intervalo de fixação definido pelo parâmetro $\alpha(\alpha=0,2)$. Neste caso, fixamos todas as variáveis que tiveram resultados nos 
seguintes intervalos: $0,0 \leq Y_{i t} \leq 0,2$ e $0,8 \leq Y_{i t} \leq 1,0$. Então fixamos as variáveis $Y_{i t} \leq 0,2$ em zero e $0,8 \leq Y_{i t}$ em um, como na Figura 5.b. Este subproblema fixado é então resolvido por um método de solução exata para obter uma solução inteira (Figura 5.c). Neste trabalho, utilizamos a ferramenta CPLEX para a solução da relaxação linear e do subproblema fixado.

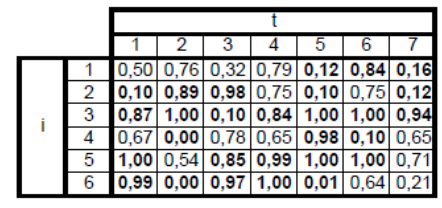

a) Relaxação das variáveis binárias

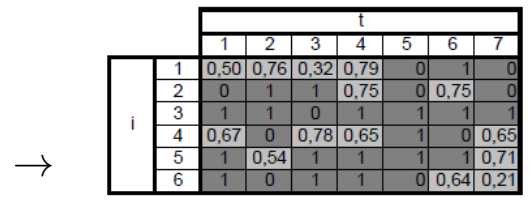

b) Arredondamento e fixação das variáveis

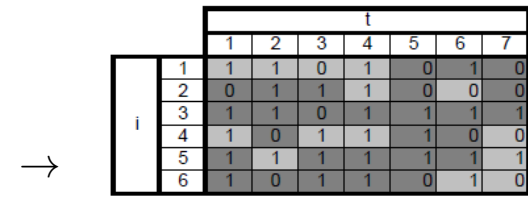

c) Solução do sub-MIP fixado

Figura 5: LP-and-fix com $\alpha=0,2$

Como critérios de parada foram utilizados otimalidade do problema fixado e limite máximo de tempo.

A heurística LP-and-fix proposta difere da heurística proposta por Maes et al. (1991) pois além de considerar as características adicionais como preservação da preparação e lead-time, também consideramos a possibilidade de uma faixa de valores ser arredondada e fixada com a utilização do parâmetro $\alpha$.

\subsubsection{Heurísticas relax-and-fix}

Heurísticas do tipo relax-and-fix (POCHET; WOLSEY, 2006) são amplamente utilizadas para resolução de problemas de planejamento da produção, como pode ser visto, por exemplo, em trabalhos na indústria de bebidas (FERREIRA et al., 2010, 2009), na indústria de ração animal (TOSO et al., 2009), na indústria de fundição (ARAUJO et al., 2008) e na indústria de papel e celulose (SANTOS; ALMADA-LOBO, 2011). Outros exemplos de trabalhos que abordaram a heurística relax-and-fix são Mercé e Fontan (2003), Stadtler (2003) e Akartunali e Miller (2009). Em Mercé e Fontan (2003) foi abordado o problema de dimensionamento de lotes monoestágio multi-item com limitação de capacidade, já nos demais trabalhos foi abordado o problema de dimensionamento de lotes multiestágio com limitação de capacidade (STADTLER, 2003; AKARTUNALI; MILLER, 2009).

Além de se basear na decomposição do conjunto de variáveis inteiras, métodos do tipo relax-and-fix utilizam-se de relaxação linear como parte da abordagem de solução, para tornar a resolução dos subproblemas mais "fáceis". Considere o conjunto de variáveis binárias do problema (Q). Este conjunto é particionado em $\mathrm{R}$ subconjuntos disjuntos, 
tal que cada conjunto pode ser representado por $Q^{r}$ com $r=1, \ldots, R$. Desta forma $Q=Q^{1} \cup \ldots \cup Q^{R}$ e $Q^{1} \cap \ldots \cap Q^{R}=\emptyset$.

Para a resolução do problema, o método procede de forma iterativa. Associado a cada iteração resolvemos um subproblema $M I P^{r}$ (problema inteiro misto com a partição $Q^{r}$ considerada como inteira) com $r=1, \ldots, R$. No primeiro subproblema $\left(M I P^{1}\right)$ apenas o subconjunto $\left(Q^{1}\right)$ é integralizado e as variáveis pertencentes aos demais subconjuntos $\left(Q^{2} \cup \ldots \cup Q^{R}\right)$ são consideradas reais. Após a resolução de $M I P^{1}, Q^{1}$ é fixado no valor da solução do passo anterior, caso a solução seja factível, e o subconjunto $Q^{2}$ é integralizado $\left(M I P^{2}\right)$. Estes passos são executados até que o subconjunto $Q^{R}$ seja integralizado $\left(M I P^{R}\right)$. A solução do $M I P^{R}$ é a solução heurística para o problema original. Caso não obtenha uma solução factível para um subproblema $M I P^{r} \operatorname{com} r=1, \ldots, R$, todo o processo é interrompido, pois não é possível encontrar uma solução para o problema $M I P$ original com esta forma de particionamento.

Em algumas abordagens, todas as variáveis do problema podem ser fixadas; por exemplo, em uma abordagem com particionamento por períodos, a cada iteração, além de fixarmos as variáveis de decisão (preparação, preservação da preparação, entre outras), fixaríamos também as variáveis de produção $\left(X_{i t}=\bar{X}_{i t} \mid \forall i, t \in Q^{1} \cup \ldots \cup Q^{r-1}\right)$. No entanto, optamos por fixar apenas as variáveis de decisão binárias, como descrito em Pochet e Wolsey (2006), por dar maior flexibilidade ao método durante o processo de resolução, além de possibilitar deslocamento da produção durante as iterações.

Em alguns casos, pode ser considerado uma partição de sobreposição (overlapping) como tentativa de obter soluções de melhor qualidade. Vale lembrar que este procedimento aumenta a dificuldade de resolução do problema, já que existe um maior número de variáveis consideradas inteiras, a cada iteração. A sobreposição consiste em uma partição onde as variáveis são integralizadas mas não são fixadas imediatamente. Desta forma, no passo $r$ temos que o conjunto $Q^{1} \cup \ldots \cup Q^{r-1}$ foi fixado, $Q^{r}$ foi integralizado e a sobreposição $S U^{r}$, dada por $S U^{r} \subseteq Q^{r+1} \cup \ldots \cup Q^{R}$, também integralizada. As demais variáveis são reais. Este tipo de abordagem foi utilizado em Stadtler (2003) e Mercé e Fontan (2003).

O Algoritmo 4.1 apresenta os passos básicos dos algoritmos do tipo relax-and-fix que foram implementados para os problemas em estudo. Observe que consideramos o método conforme proposto em Mercé e Fontan (2003) (Ver Figura 2, Capítulo 2), onde o horizonte de planejamento é dividido em três partes: seção inicial, seção central e seção final, e as variáveis são fixadas do início para o fim do horizonte de planejamento. Para tentar 
melhorar o desempenho do método, os autores utilizaram uma partição de sobreposição, onde suas variáveis são consideradas inteiras juntamente com a partição referente ao subproblema atual. A sobreposição, no entanto, não será fixada nesta mesma iteração. Nas abordagens do tipo relax-and-fix propostas nesta dissertação, teremos formas distintas de particionamento e de fixação das apresentadas por Mercé e Fontan (2003).

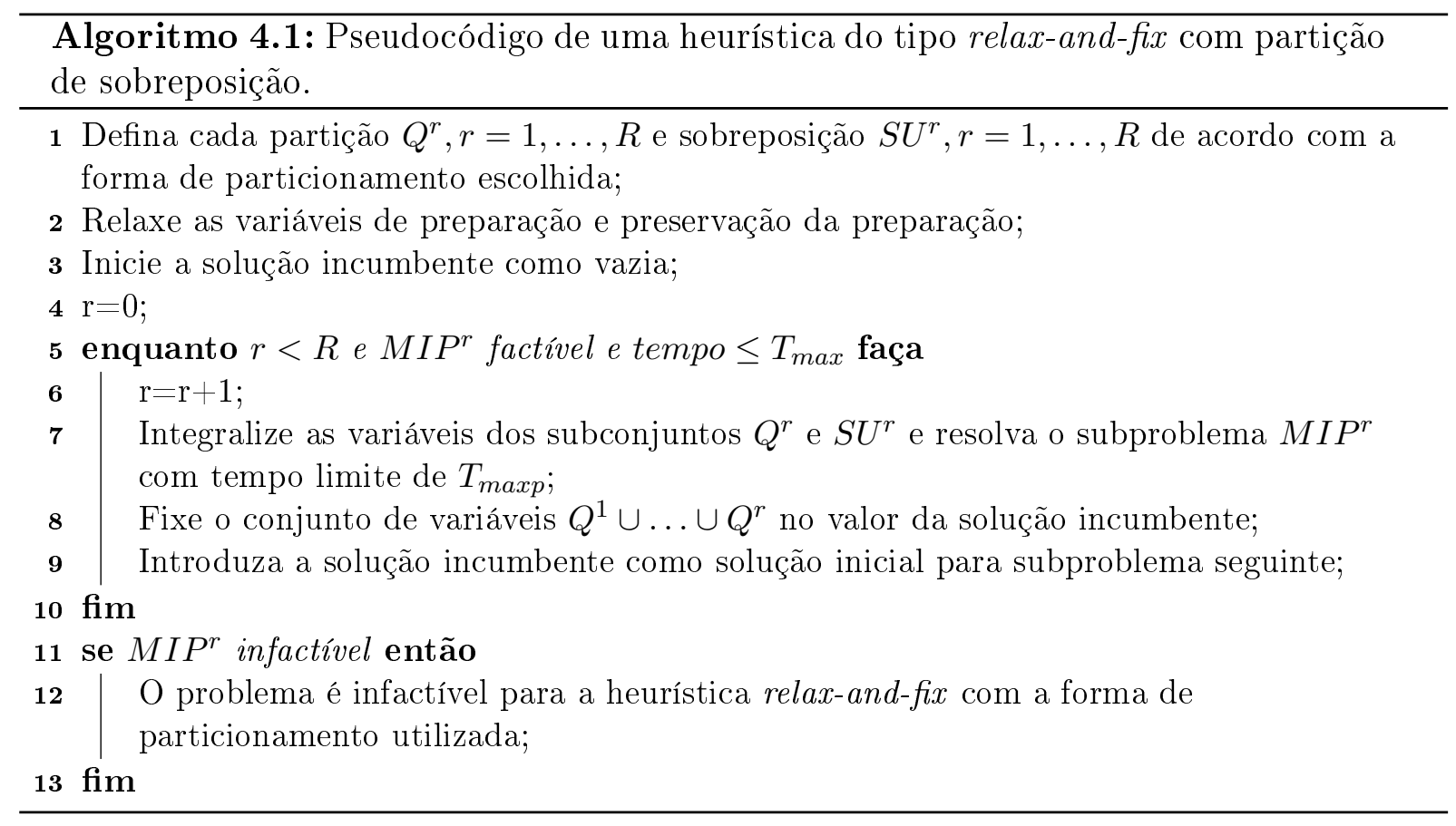

A utilização de particionamento por períodos pode gerar planos infactíveis para o problema de dimensionamento multiestágio devido ao lead-time não nulo. O particionamento por período faz com que em alguns casos sejam gerados subproblemas infactíveis, quando o lead-time é não nulo. Esta dificuldade foi discutida em Stadtler (2003), onde o leadtime foi considerado nulo. Por exemplo, podemos ter a preparação de um determinado componente $i$ igual a zero em um período $t$ já fixado, ou seja, não produziremos o item $i$ no período $t$. Em passos seguintes do método, devido ao adiantamento da produção de um de seus sucessores, surge a necessidade de produzirmos $i$ neste período $t$, no entanto esta variável de preparação já foi fixado pelo método, gerando assim uma impossibilidade de atendimento da demanda dependente.

Neste trabalho, foram desenvolvidos três heurísticas do tipo relax-and-fix com formas distintas de particionamento que levam em consideração o lead-time não nulo. Para a explicação da forma de particionamento das três heurísticas, considere o exemplo da estrutura de produto com divisão por recursos apresentada na Figura 6. Na Figura 7 apresentamos um exemplo de como seria um plano de produção para a estrutura apresentada pela Figura 6 considerando lead-time de um período para todos os componentes. Para 
que possamos produzir o item 1 no período $t+1$, precisamos ter estoque dos seus componentes ou produzir seus componentes no período $t$. Da mesma forma, para a produção dos itens 2 e 3 no período $t$, precisamos ter estoque de seus componentes ou produzir seus componentes no período $t-1$, ou seja, quando o lead-time é considerado não nulo e dado em um número de períodos, não é permitido que um item seja produzido para atender a demanda de seus sucessores no mesmo período.

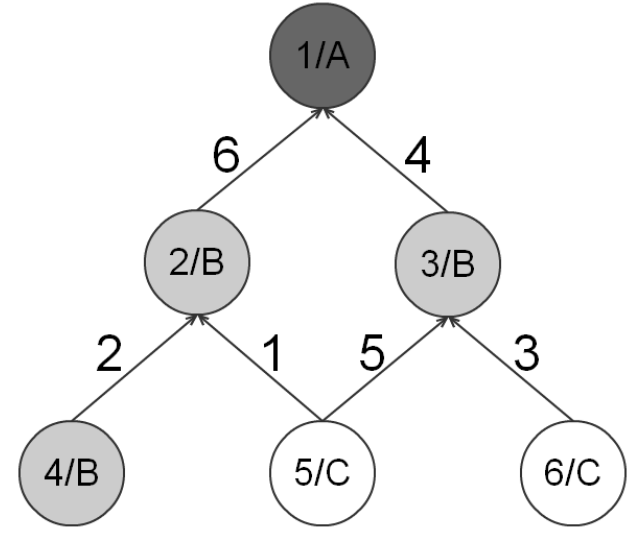

a) Estrutura de produto

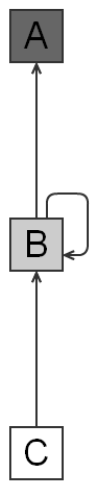

b) Sequência de recursos

Figura 6: Estrutura de produto com divisão por recurso.

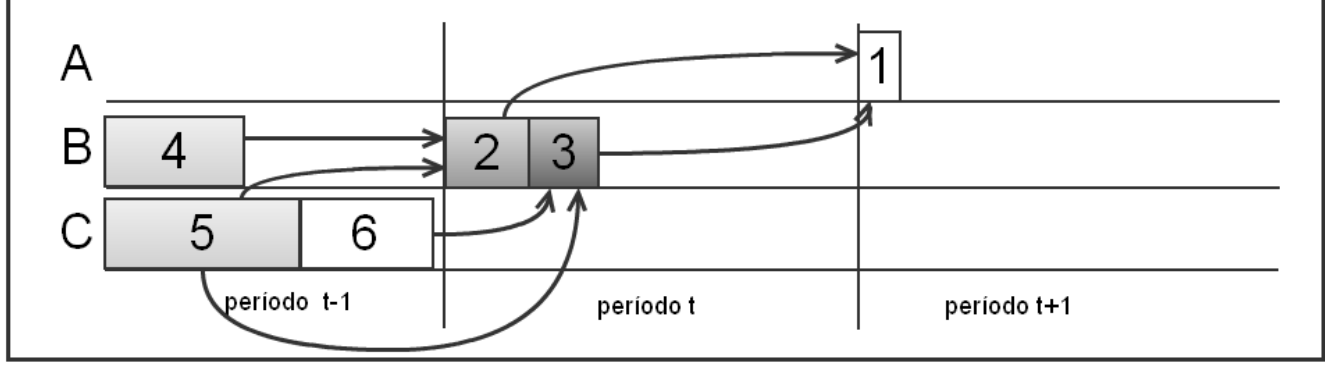

Figura 7: Exemplo de produção, considerando lead-time de um período.

\section{- RF1 - Primeira heurística do tipo relax-and-fix.}

A primeira heurística utiliza uma decomposição por períodos, sendo o subconjunto integralizado e fixado, tomado do último para o primeiro período, pois assim evitamos a necessidade de alterar a preparação em períodos que já tenha sido fixado, já que as decisões fixadas levaram em consideração todo o horizonte que as antecede de forma relaxada. Deste modo, a decisão de fixação pode superestimar a necessidade de produção (gerando preparações que poderiam ser evitadas), mas não corre-se o risco de subestimar esta necessidade (fixando preparações necessárias em zero, devido ao lead-time). Foi utilizado um tamanho de partição de dois períodos, além de 
um tamanho de partição de sobreposição também de dois períodos. A cada iteração dois períodos serão fixados $\left(Q^{r-1}\right)$ e quatro períodos serão considerados de forma inteira $\left(Q^{r} \cup S U^{r}\right)$. O restante das variáveis serão considerados de forma relaxada. Esses valores se basearam no estudo feito por Mercé e Fontan (2003) para o problema de dimensionamento de lotes monoestágio com limitação de capacidade. A Figura 8 apresenta o particionamento do exemplo acima (representado pela Figura 6), segundo esta heurística, em um horizonte de planejamento de 7 períodos. A cada iteração do método, o número de variáveis relaxadas é reduzido na proporção do tamanho da partição, como ilustrado na Figura 2, dado que a cada iteração, apenas uma partição é fixada. A heurística termina quando não houver nenhuma variável inteira relaxada no subproblema resolvido. A cada iteração, a solução do subproblema anterior é utilizado como solução inicial para o próximo subproblema. Nas Figuras 8, 9 e 10, as variáveis marcadas em branco estão relaxadas, as variáveis marcadas em cinza claro são inteiras e estão "livres" para otimização e, as variáveis marcadas em cinza escuro são fixadas no valor da solução incumbente.

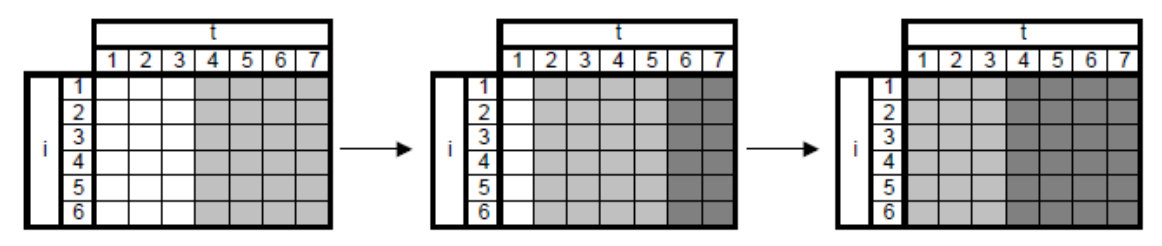

Figura 8: Particionamento da primeira heurística relax-and-fix.

\section{- RF2 - Segunda heurística do tipo relax-and-fix.}

A segunda heurística se baseia na partição por nível da estrutura de produto. Desta forma a cada iteração, um nível é integralizado e então fixado após a solução do subproblema. Isto é feito iniciando do nível de produtos finais para os níveis intermediários. Deste modo um produto não é fixado antes de seus sucessores. Nesta heurística em particular, não foi utilizada a partição de sobreposição, pois o número de variáveis inteiras aumentaria muito em alguns subproblemas. A Figura 9 apresenta o particionamento do exemplo anterior, segundo a heurística RF2.

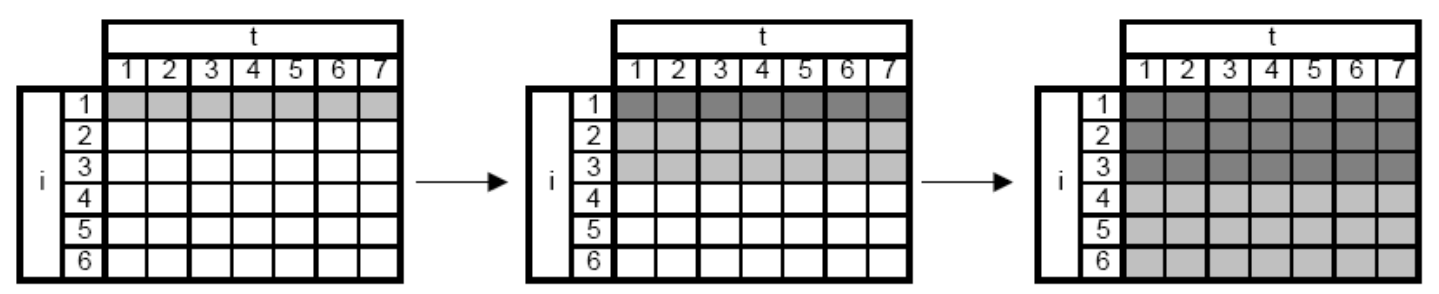

Figura 9: Particionamento da segunda heurística relax-and-fix. 


\section{- RF3 - Terceira heurística do tipo relax-and-fix.}

A terceira heurística se utiliza da partição por itens. Nesta heurística cada partição é composta pelas variáveis de preparação e preservação de dois itens durante todo o horizonte de planejamento. A partição de sobreposição também é composta pelas variáveis de preparação e preservação de dois outros itens. Estas variáveis são integralizadas dos produtos finais para os componentes, para evitar que um produto tenha a produção de seus componentes fixados antes da própria produção. A cada iteração do método, as variáveis de decisão de dois itens serão fixadas e as variáveis de decisão de quatro itens estarão integralizadas (partição atual e partição de sobreposição). O restante das variáveis serão considerados de forma relaxada. A heurística termina quando todos os produtos são integralizados e o subproblema correspondente é resolvido. A Figura 10 apresenta o particionamento segundo a heurística RF3.

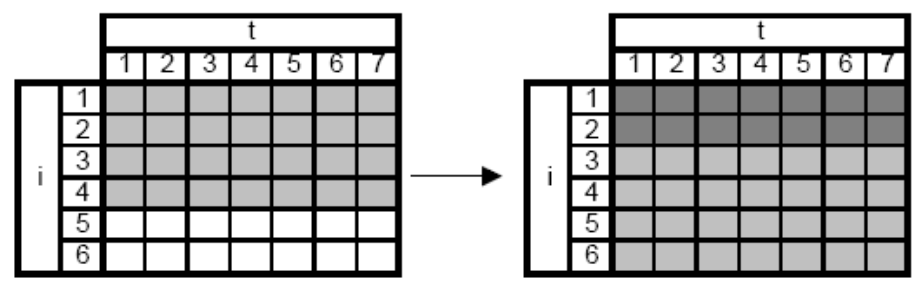

Figura 10: Particionamento da terceira heurística relax-and-fix.

As heurísticas do tipo relax-and-fix desenvolvidas para o problema, além de considerar o lead-time positivo (pela forma do particionamento), também apresentam formas alternativas de particionamento das variáveis de decisão, conforme mostrado anteriormente.

\subsubsection{Heurísticas do tipo fix-and-optimize}

Diferente do método relax-and-fix, na abordagem fix-and-optimize ao invés de utilizar relaxação linear, utiliza-se a fixação dos conjuntos de variáveis em seus valores inteiros para tornar os subproblemas resultantes "mais simples". Desta forma, uma iteração do método consiste de dois passos básicos: no primeiro passo uma das partições de variáveis inteiras é escolhida para ficar livre, ou seja, definimos as variáveis que serão otimizadas; no segundo passo, todas as demais partições são fixadas no valor da solução incumbente. Desta forma, ao resolver o subproblema, apenas um pequeno conjunto de variáveis inteiras será otimizado. Se a solução do subproblema for melhor que a solução incumbente, esta será substituída. Na iteração seguinte, uma outra partição é escolhida para ficar livre para 
a otimização e as variáveis das demais partições são fixadas. Observe que nesta heurística é necessário ter uma solução inicial factível, por isso pode ser vista como uma heurística de melhoria.

A heurística do tipo fix-and-optimize foi inicialmente proposta em Pochet e Wolsey (2006) com o nome de exchange. Os autores propuseram este método de solução, como uma melhoria da heurística relax-and-fix. O nome fix-and-optimize foi inicialmente utilizado nos trabalhos de Sahling et al. (2009) e Helber e Sahling (2010). Além deste trabalho, esta heurística também foi abordada em James e Almada-Lobo (2010) e Santos e Almada-Lobo (2011).

Considerando os conjuntos definidos para as heurísticas relax-and-fix, no primeiro passo da heurística, $Q^{1}$ fica livre para otimização e o subproblema é resolvido com as variáveis dos conjuntos $Q^{2} \cup \ldots \cup Q^{R}$ fixadas nos valores da solução incumbente. No segundo passo, $Q^{2}$ fica livre e o subproblema é resolvido com as variáveis dos conjuntos $Q^{1} \cup Q^{3} \cup \ldots \cup Q^{R}$ fixadas nos valores da solução incumbente. Isto é feito de forma iterativa até que a solução de todos os subproblemas, gerados com a aplicação das R partições, não gerem melhoria na solução incumbente. A cada iteração, se houver um subproblema com solução melhor que a solução incumbente, esta é substituída pela solução do subproblema. Neste trabalho, consideramos a heurística como proposta por Sahling et al. (2009), onde fixam-se apenas as variáveis inteiras, que são as variáveis dificultadoras do problema. Este é um método iterativo, onde formas de particionamento distintos podem ser utilizados em passos consecutivos. O método encerra quando todos os subproblemas gerados pelas partições utilizadas forem resolvidos e não houver melhora na solução incumbente. Formas aleatórias de escolha ou de tamanho das partições podem ser implementadas, com o objetivo de diversificar o processo de busca.

Um ilustração de particionamento e resolução pela heurística fix-and-optimize é apresentada na Figura 11. Nesta figura, considere que as variáveis marcadas em cinza escuro são "livres" para otimização e as variáveis marcadas em cinza claro têm seus valores fixados conforme a solução incumbente. Neste exemplo, utiliza-se o particionamento por itens, ou seja, a cada iteração apenas um item é otimizado e todos os demais são fixados na solução incumbente. Convém observar mais uma vez que necessita-se de uma solução inicial para aplicação da abordagem de solução, pois pode-se ver esta abordagem como um procedimento de melhoria. Uma solução inicial, para o problema considerado, consiste em produzir todos os itens em todos os períodos do horizonte de planejamento uma vez que consideramos horas extras ilimitadas (política lote-por-lote). As partições são deter- 
minadas de forma sequencial quanto aos índices dos itens, por exemplo, para a Figura 11, $Q^{1}$ é formada apenas pelas variáveis do item $1, Q^{2}$ pelas variáveis do item 2 , e assim por diante. Este tipo de abordagem não é obrigatório, podendo variar tanto na forma de obtenção da solução inicial, quanto a sequência de utilização das partições.

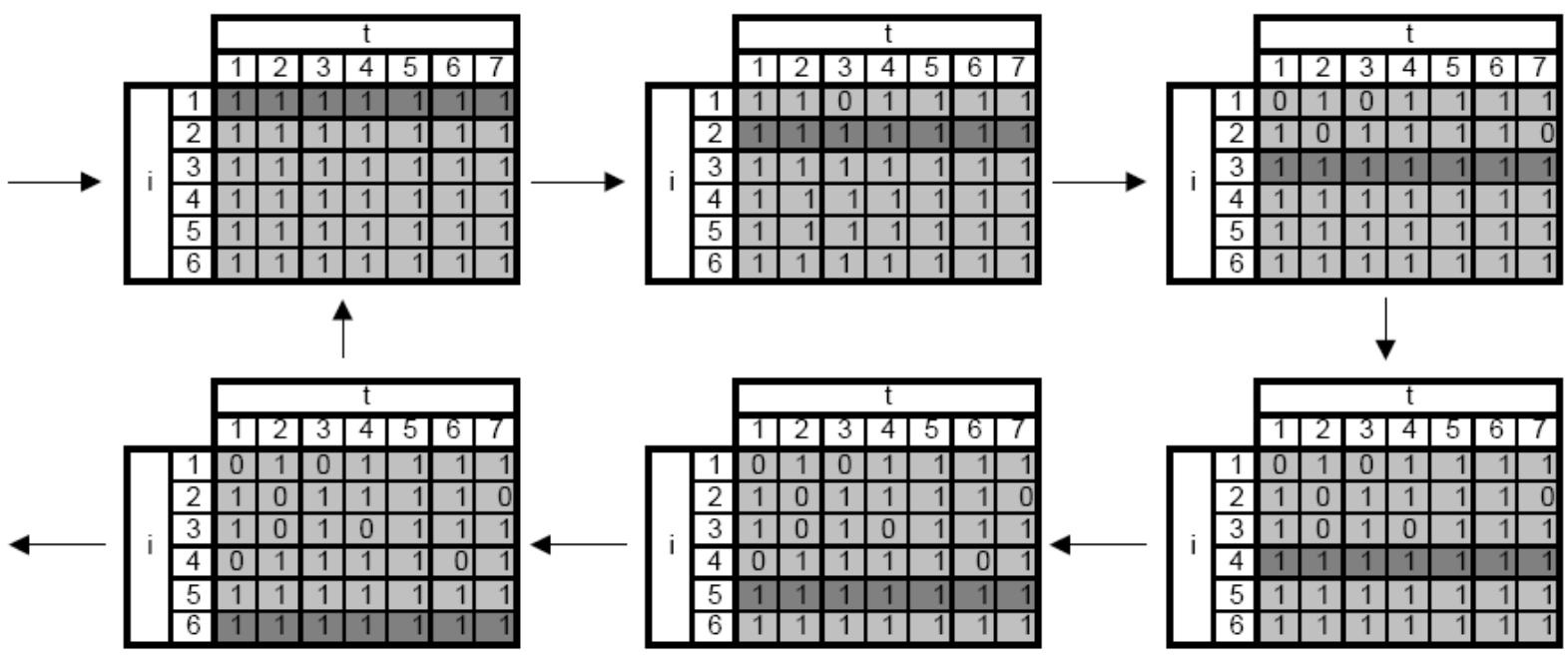

Figura 11: Iterações da heurística fix-and-optimize com particionamento por itens.

Nesta dissertação de mestrado, foram implementadas duas variações de particionamento e quatro variantes de combinações destas partições.

\section{- Primeira forma de particionamento: Particionamento por itens}

A primeira forma de particionamento faz uso de partições por itens. A cada iteração do método, apenas um item fica "livre" para otimização, enquanto todos os demais são fixados no valor da solução incumbente, como implementado em Sahling et al. (2009) e apresentado no exemplo acima. No caso do problema com preservação da preparação, além das variáveis de preparação, algumas variáveis de preservação da preparação também são liberadas para otimização. São liberadas as variáveis de preservação da preparação do próprio item liberado e de todos os itens que utilizam o mesmo recurso.

A Figura 12 apresenta uma ilustração de um passo da heurística com este particionamento, considerando a estrutura de produto apresentada na Figura 6. Como no algoritmo proposto por Sahling et al. (2009), a partir do cálculo de custos relativos, obtidos através da relaxação do problema, fazemos uma ordenação que define a sequência de liberação dos itens. Os itens que têm maior custo relativo são os primeiros a serem liberados. A fórmula de cálculo de custos relativos se baseia na função objetivo, com acréscimo de uma fração de custos de horas extras utilizadas, caso haja a necessidade de utilizá-las. Para cada item $i$, o custo relativo $\left(Z_{i}\right)$ é 
calculado pela equação (4.1), onde $Y_{i t}^{r e l}$ e $W_{i t}^{r e l}$ representam o valor da solução da relaxação linear das variáveis de preparação e de preservação da preparação de máquina para o item $i$ no período $t$, respectivamente. Denotamos o recurso $m$ utilizado na produção do item $i$ por $m(i)$, enquanto $K_{m(i)}$ representa o conjunto de itens que utilizam o mesmo recurso que o item $i$.

$$
\begin{aligned}
Z_{i}= & \sum_{t=1}^{T}\left(s_{i} *\left(Y_{i t}^{r e l}-W_{i t}^{r e l}\right)+h_{i} * I_{i t}\right)+ \\
& +\frac{\sum_{t=1}^{T}\left(a_{i} * X_{i t}+t s_{i} *\left(Y_{i t}^{r e l}-W_{i t}^{r e l}\right)\right) * \sum_{t=1}^{T}\left(o c_{m(i), t} * O_{m(i), t}\right)}{\sum_{j \in K m(i)} \sum_{t=1}^{T}\left(a_{j} * X_{j t}+t s_{j} *\left(Y_{j t}^{r e l}-W_{j t}^{r e l}\right)\right)}
\end{aligned}
$$

Para o problema que não considera a possibilidade de preservação da preparação, podemos reduzir o cálculo de custos relativos, resultando na equação (4.2).

$$
Z_{i}=\sum_{t=1}^{T}\left(s_{i} * Y_{i t}^{r e l}+h_{i} * I_{i t}\right)+\frac{\sum_{t=1}^{T}\left(a_{i} * X_{i t}+t s_{i} * Y_{i t}^{r e l}\right) * \sum_{t=1}^{T}\left(o c_{m(i), t} * O_{m(i), t}\right)}{\sum_{j \in K m(i)} \sum_{t=1}^{T}\left(a_{j} * X_{j t}+t s_{j} * Y_{j t}^{r e l}\right)}
$$

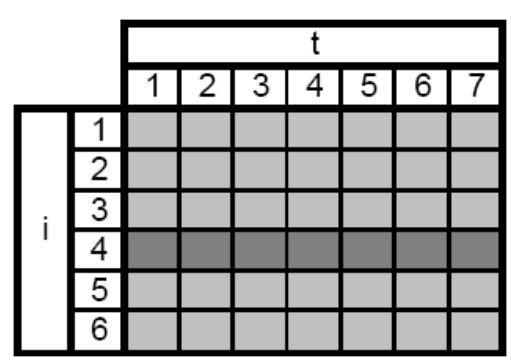

a) Variáveis de preparação

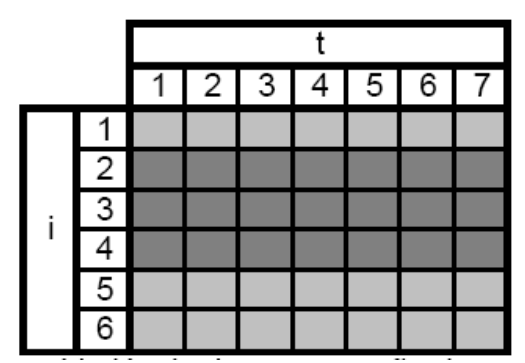

b) Variáveis de preservação da preparação

Figura 12: Particionamento por itens.

\section{- Segunda forma de particionamento: Particionamento por períodos}

A segunda forma de particionamento segue uma abordagem por períodos. Neste particionamento são liberados dois períodos consecutivos a cada partição. No problema que considera preservação da preparação são liberados os mesmos dois períodos das variáveis de preservação da preparação, além de um período posterior. Por exemplo, se liberarmos os períodos $t$ e $t+1$ das variáveis de preparação, liberaremos os 
períodos $t, t+1$ e $t+2$ das variáveis de preservação da preparação. O objetivo de utilizar múltiplos períodos é aumentar a melhoria obtida em cada partição, dado a alta correlação entre períodos consecutivos. No entanto, não podemos aumentar muito o número de períodos, pois a dificuldade de resolução dos subproblemas também aumentaria muito. Como as restrições de controle da preservação da preparação utilizam-se dos valores das variáveis de preparação do período anterior, optamos por liberar o período extra para as variáveis de preservação da preparação. A Figura 13 apresenta uma ilustração de um passo da heurística com este particionamento.

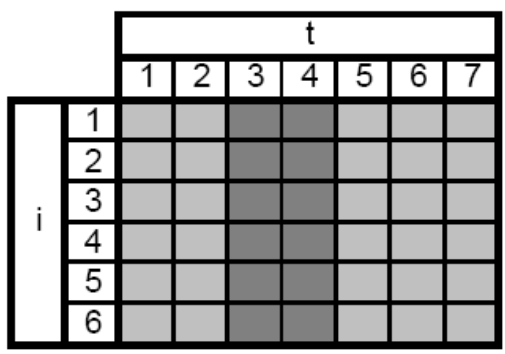

a) Variáveis de preparação

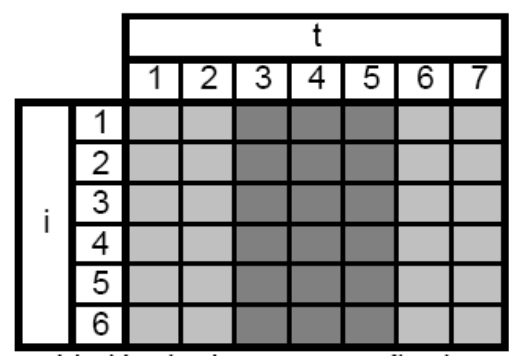

b) Variáveis de preservação da preparação

Figura 13: Particionamento por períodos.

As duas formas de particionamento implementadas foram combinadas, originando quatro heurísticas do tipo fix-and-optimize. A seguir, listamos estas quatro variantes.

- FO-P1 - Particionamento por itens;

- FO-P2 - Particionamento por períodos;

- FO-P3 - Particionamento por itens seguido de particionamento por períodos;

- FO-P4 - Particionamento por períodos seguido de particionamento por itens.

O cálculo dos custos relativos, apresentados pelas equações (4.1) e (4.2) foram utilizados apenas na variante FO-P1, pois é a única que utiliza apenas o particionamento por itens, e por isso tende a aproveitar melhor as características desta abordagem. Nas variantes FO-P3 e FO-P4, as partições por itens foram aplicadas de forma sequencial e crescente quanto ao índice do item.

No trabalho de Sahling et al. (2009) foram apresentadas quatro variações diferentes deste tipo de heurística, diferindo na forma de particionamento. Os autores utilizaramse de três tipos de decomposições para gerar as quatro variações. Foram utilizados os seguintes particionamentos: 


\section{- Particionamento por itens}

\section{- Particionamento por recursos}

A partição por recurso, leva em consideração cada recurso existente e gera os subconjuntos de acordo com os itens que utilizam cada recurso. Como cada item utiliza apenas um recurso em sua produção, os subconjuntos gerados são disjuntos por natureza.

\section{- Particionamento por processo}

A partição por processo gera partições de acordo com a estrutura de produto, considerando um determinado item e seus componentes. Assim, na partição por processo, como a mudança na produção de um item influência na produção de seus componentes, esses podem ser otimizados em conjunto. Neste tipo de decomposição, Sahling et al. (2009) ainda dividem as variáveis de cada subconjunto em duas partes. A primeira parte aborda as variáveis daquele subconjunto do início até a metade do horizonte de planejamento. A segunda parte aborda as variáveis restantes. Isto pode ser feito para reduzir o número de variáveis inteiras livres, e assim, facilitar a solução do subproblema.

As quatro variações apresentadas por Sahling et al. (2009) são as seguintes:

\section{- Apenas particionamento por itens;}

- Particionamento por itens seguida de particionamento por recursos;

- Particionamento por itens seguida de particionamento por processo;

- Primeiro particionamento por itens, seguida de particionamento por recursos e por último particionamento por processos.

O Algoritmo 4.3 descreve o pseudocódigo da heurística do tipo fix-and-optimize como proposto em Sahling et al. (2009), mas com alteração na forma de obtenção da solução inicial. No algoritmo original, a solução inicial era gerada segundo uma política lote-porlote.

\section{Solução inicial}

O método proposto para a obtenção da solução inicial se baseia em uma heurística de arredondamento proposta por Maes et al. (1991). Nesta heurística, os autores resolvem iterativamente a relaxação linear do problema original e, a cada iteração, os autores arredondam uma variável. Isto é feito, até que todas as variáveis sejam arredondadas.

Além da questão do arredondamento, nosso método de obtenção da solução inicial 
também tenta gerar soluções com certa variabilidade. Esta variabilidade é adicionada as soluções através do parâmetro $\alpha$. Desta forma, escolhemos aleatoriamente $k$ variáveis de um conjunto de variáveis no intervalo $\alpha$ de distância da variável de maior valor fracionário, ou seja, o conjunto de variáveis candidatas a fixação é dado por: $C=\left\{Y_{i t} \mid Y_{i t}+\alpha \geq\right.$ $\left.Y_{\text {max }} \forall i, t\right\}$, onde $Y_{\max }$ é dado por $Y_{\max }=\max \left\{Y_{i t} \mid Y_{i t} \notin Z \forall i, t\right\}$.

Para obtenção de soluções iniciais, consideramos formulações matemáticas simplificadas, onde as variáveis de preservação da preparação não são consideradas, ou seja, as soluções geradas não contam com este tipo de preservação. As variáveis de preservação da preparação são novamente considerados durante a resolução do problema original. Utilizamos apenas a formulação agregada na heurística de obtenção da solução inicial, pois o modelo agregado apresentou tempo computacional menor para a resolução da relaxação, além de um número maior de variáveis não-inteiras a priori, o que garante uma possibilidade maior de variabilidade das soluções da heurística. O Algoritmo 4.2 apresenta o pseudocódigo da heurística de obtenção das soluções iniciais.

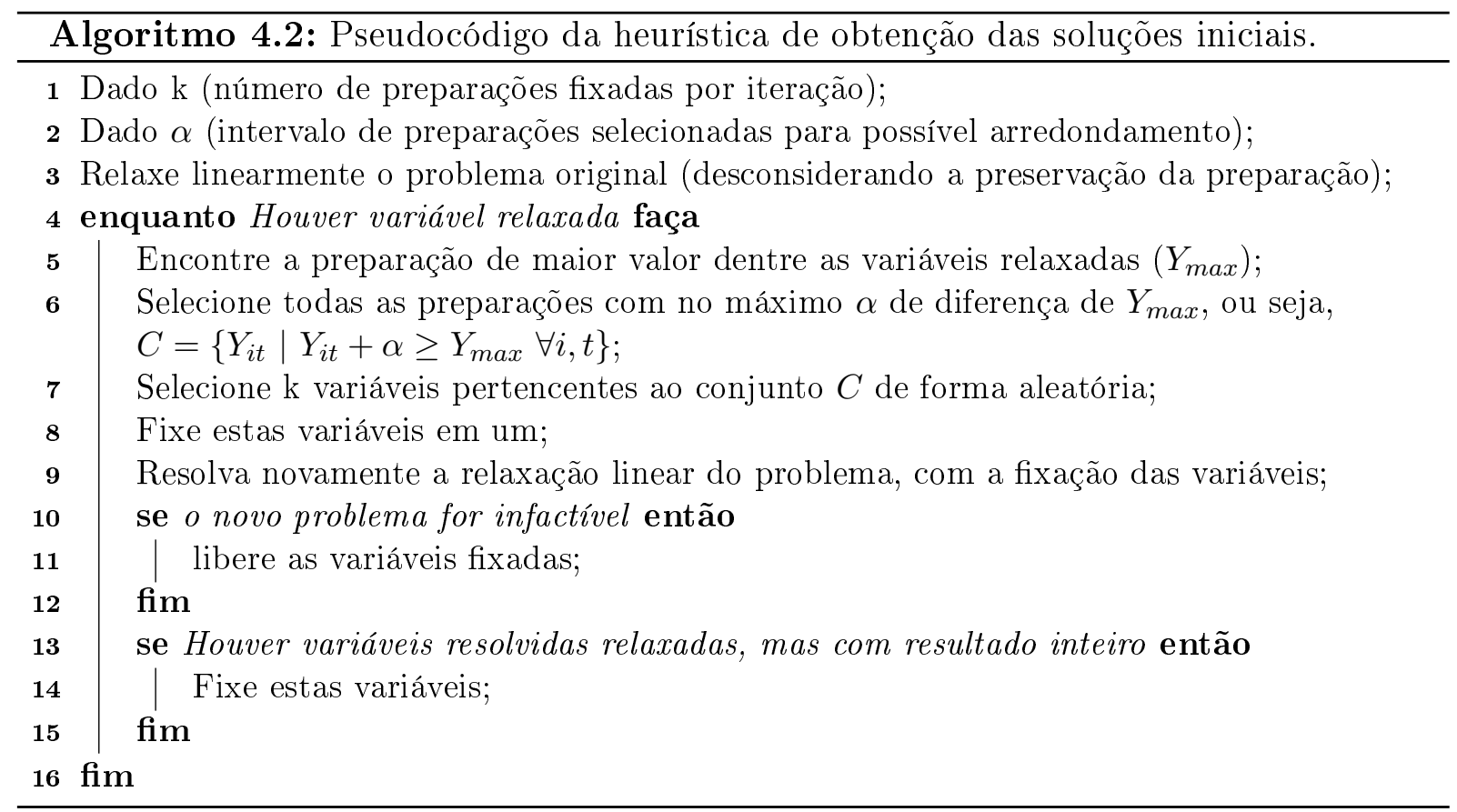

A aleatoriedade foi aplicada para que pudéssemos obter a variabilidade desejada nas heurísticas populacionais, que serão apresentadas a seguir. No entanto, o método proposto será utilizado para obtenção da solução inicial da heurística fix-and-optimize, neste caso, utiliza-se os parâmetros $\alpha=0$ e $k=M$, onde $M$ é um valor muito maior que o número de variáveis inteiras do problema. Com estes valores de parâmetros, a cada passo fixamos apenas a maior variável de preparação fracionária $\left(Y_{\max }\right)$. Caso exista empate, ou seja, mais de uma variável com o valor máximo $\left(C=\left\{Y_{i t} \mid Y_{i t}=Y_{\max } \forall i, t\right\}\right)$, fixaremos o 
conjunto $C$ em um único passo.

A notação utilizada no Algoritmo 4.3, algoritmo da heurística fix-and-optimize, é dado abaixo.

\section{Conjuntos e índices}

$N T_{y, s}^{f i x} \quad$ Partição das variáveis de preparação fixadas no subproblema $s$;

$N T_{w, s}^{f i x} \quad$ Partição das variáveis de preservação da preparação fixadas no subproblema $s$;

$N T_{y, s}^{o p t} \quad$ Partição das variáveis de preparação livres no subproblema $s$;

$N T_{w, s}^{o p t} \quad$ Partição das variáveis de preservação da preparação livres no subproblema $s$;

\section{Variáveis auxiliares}

$l$

Z

$Z^{\text {novo }}$

$Z^{\text {velho }}$

CapFeas

CapFeas ${ }^{\text {novo }}$

$\bar{Y}_{i t}$ e $\bar{W}_{i t}$
Contador de iterações;

Recebe o valor da função objetivo do subproblema atual;

Armazena o valor de uma nova solução incumbente;

Armazena o valor da solução incumbente a cada passo $l$ da heurística;

Indica se a solução incumbente utiliza hora extra;

Indica se a nova solução utiliza hora extra;

Solução incumbente (preparação e preservação da preparação).

No Algoritmo 4.3, nas linhas 4 e 5 é verificado se houve a necessidade de uso de hora extra. Nas linhas 12 a 16 define-se as partições que serão fixadas e as partições que ficarão livres, resolve-se o subproblema e, em seguida, verifica-se a utilização de hora extra. E nas linhas 17 a 21 armazena-se a solução encontrada no subproblema, caso essa seja melhor que a solução incumbente.

Os critérios de parada utilizados foram os propostos no artigo de Sahling et al. (2009), ou seja: número máximo de iterações e não melhoria após a aplicação de todas as partições utilizadas na variante, além de um tempo limite para o método todo. Para cada subproblema, considerou-se também um limite de tempo para a sua resolução. Este limite é proporcional ao número de variáveis livres da partição que será utilizada.

\subsection{Metaheurística algoritmo de abelhas}

Várias metaheurísticas baseadas na inteligência de grupos de animais já foram propostas e muitos trabalhos aplicados utilizam este tipo de abordagem de solução. Para 


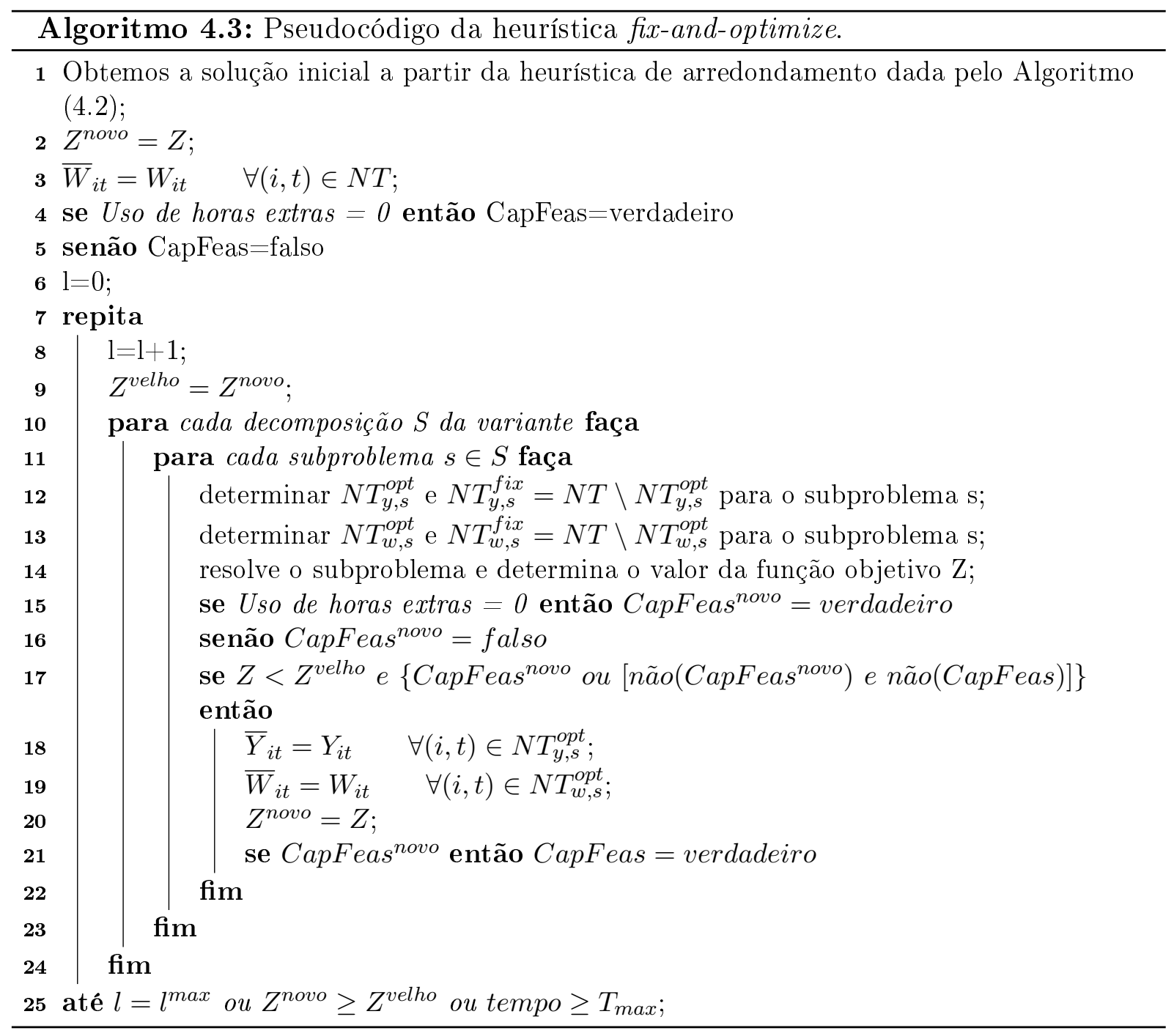

alguns problemas específicos, podem existir vantagens na utilização de determinados métodos bioinspirados. Por exemplo, a metaheurística colônia de formigas (DORIGO et al., 1996) é bastante aplicada a problemas de caminho, como o problema do caixeiro viajante (DORIGO; GAMBARDELLA, 1997; GARCíA-MARTíNEZ et al., 2007; RAIS et al., 2007), dado que este método de solução têm vantagens quando aborda problemas que podem ser representados na forma de grafos.

Também são variadas as metaheurísticas bioinspiradas baseadas em enxames e, dentro deste grupo, estão as metaheurísticas baseadas em enxames de abelhas. Cada método difere na forma como os autores procuraram modelar o comportamento das abelhas. Além disso, várias atividades ou tarefas realizadas pelas abelhas são passíveis de utilização para a confecção das metaheurísticas. Exemplos de tarefas das abelhas que foram modeladas como metaheurísticas são: o processo evolutivo das abelhas baseado na reprodução da rainha (queen-bee evolution) de Jung (2003), a comunicação entre as abelhas (bee system) 
de Sato e Hagiwara (1997), a busca por alimento (bee algorithm de Pham et al. (2005), entre outras.

Todos estes métodos baseados na inteligência de enxame das abelhas foram aplicados a variados problemas da literatura. Desde problemas de otimização à problemas de controle de troca de mensagens em redes de computadores e controle de buscas na internet, já foram abordados. Na otimização, estes métodos foram aplicados para os problemas de localização de facilidades (WEDDE et al., 2007), de sequenciamento de máquinas (CHONG et al., 2006; PHAM et al., 2007), do caixeiro viajante (LUCIC, 2002), de roteamento de veículos (MARINAKIS et al., 2008), entre outras.

Uma revisão sobre metaheurísticas baseadas em enxame de abelhas pode ser encontrada em Karaboga e Akay (2009), onde os autores abordam inúmeros métodos e aplicações. Os métodos foram classificados de acordo com a tarefa das abelhas na qual eles se baseiam.

Neste trabalho, abordaremos uma destas metaheurísticas bioinspiradas no comportamento das abelhas, mais especificamente a forma como as abelhas procuram seus alimentos. Esta metaheurística foi denominada de algoritmo de abelhas (do inglês bee algorithm), por Pham et al. (2005).

O algoritmo de abelhas é uma metaheurística de enxame criada recentemente e ainda pouco aplicada em problemas da literatura. Esta metaheurística foi inicialmente proposta (PHAM et al., 2005) para problemas de otimização contínua, no entanto, alguns trabalhos que abordam problemas de otimização combinatória têm utilizado esta abordagem de solução. Exemplos de trabalho que aplicam o algoritmo de abelhas a problemas de otimização combinatória são Özbakir et al. (2010) e Dereli e Das (2011). Özbakir et al. (2010) trata o problema de designação generalizada e Dereli e Das (2011) aborda o problema de carregamento de contêineres aplicando um método híbrido composto por algoritmo de abelhas com uma heurística específica do problema.

Os autores Pham et al. (2005) basearam-se nos padrões de busca das abelhas por comida para propor a metaheurística. O objetivo das abelhas, quando estão procurando comida, é maximizar a quantidade de comida obtida dentro de um período de tempo. Para isto, dois fatores são levados em consideração na busca feita pelas abelhas, a distância da fonte de comida até a colmeia e a facilidade de aquisição desta comida.

A busca das abelhas pelo alimento é feita em duas partes. Na primeira parte, abelhas exploradoras são enviadas para encontrar os pontos de coleta de alimentos, inicialmente 
de forma aleatória. Elas retornam, depositam o pólen recolhido e fazem uma dança conhecida por waggle dance. Esta dança é utilizada para passar as informações sobre o local onde cada abelha exploradora fez sua coleta de pólen. Com a dança, elas indicam a distância da fonte de comida, a direção na qual ela se encontra e a quantidade de comida existente. No segundo passo, são recrutadas as abelhas seguidoras, que buscarão a comida nos locais indicados pelas abelhas exploradoras. Os pontos mais promissores recebem um número maior de abelhas seguidoras, ou seja, mais abelhas são enviadas para onde existe maior possibilidade de arrecadar mais comida. Cada vez que as abelhas retornam à colmeia, ocorre novamente a dança e outras abelhas seguidoras são enviadas para os locais promissores.

Dessa forma, o algoritmo é basicamente composto de duas formas de busca combinadas, uma busca exploratória (aleatória) inicial seguida de múltiplas buscas locais. As abelhas exploradoras fazem a busca aleatória pelo espaço de solução do problema. Após a busca aleatória, as abelhas seguidoras fazem uma busca local na vizinhança de cada um dos pontos escolhidos para a verificação. Em seguida, são escolhidos os melhores indivíduos de cada vizinhança para formar a nova população de abelhas exploradoras, e o algoritmo se repete até que um critério de parada seja satisfeito. Quando chegamos ao mínimo de um espaço de busca (vizinhança de busca sem melhorias), a busca local desta abelha pode ser substituída por uma busca aleatória, tentando assim sair deste mínimo local.

A associação destes dois tipos de buscas (busca exploratória e busca local) tem por intuito tentar evitar ótimos locais ou obter a melhor solução entre múltiplos ótimos locais. Por estas características, o algoritmo de abelhas foi escolhido como uma das abordagens averiguadas nesta dissertação. Além disso, se considerarmos a heurística fix-and-optimize como um método de busca local com vizinhança variável (a vizinhança varia de acordo com a partição liberada para otimização) podemos produzir um método híbrido que tome proveito das vantagens de cada submétodo, resolvendo subproblemas de forma eficiente como a heurística fix-and-optimize e tentando evitar mínimos locais como a metaheurística algoritmo de abelhas.

O algoritmo de abelhas conta com um conjunto de parâmetros que deve ser ajustado de acordo com as características do problema. Estes parâmetros são: o número de abelhas exploradoras $(n b)$, o número de abelhas exploradoras escolhidas para a busca local $(m b)$, as melhores abelhas exploradoras dentre as escolhidas $(e b)$, as abelhas seguidoras enviadas aos " $e b$ " melhores locais (nep), as abelhas seguidoras enviadas aos " $m b-e b$ " demais locais 
$(n s p)$ e o tamanho da vizinhança de busca $(n g h)$.

O Algoritmo 4.4 apresenta o pseudocódigo de um algoritmo de abelhas básico.

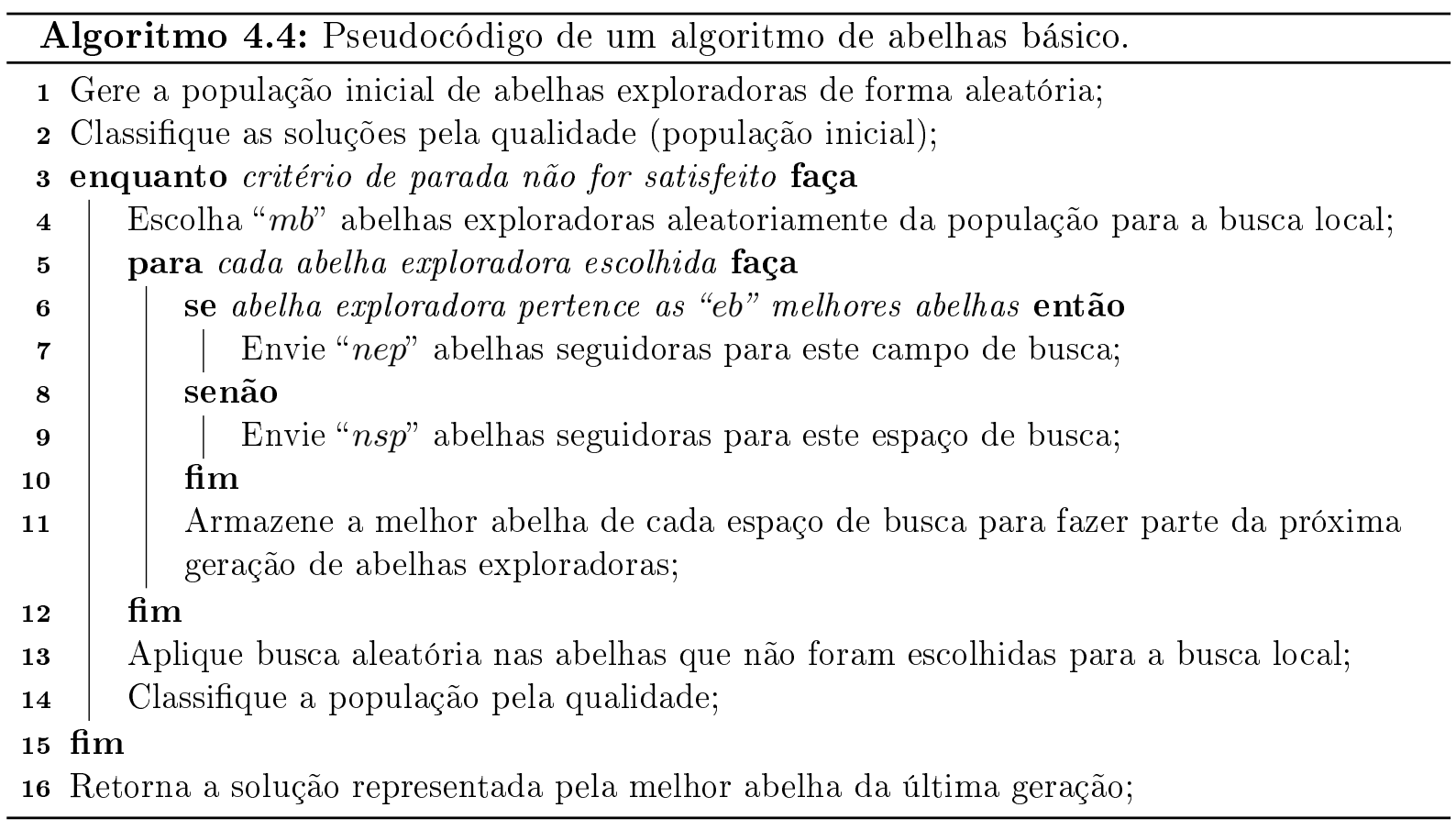

\section{Algoritmo de abelhas proposto}

Com o objetivo de resolver os problemas descritos no Capítulo 3, desenvolveu-se um método de algoritmo de abelhas com o uso da ferramenta CPLEX para resolver subproblemas. No nosso algoritmo, utiliza-se a heurística 4.2 para gerar a população inicial de soluções (abelhas exploradoras). Após este passo, o algoritmo de abelhas define a vizinhança de busca no entorno de cada abelha exploradora escolhida (vizinhança $k$-opt) e o CPLEX resolve o subproblema MIP gerado (busca local). Os passos de escolha das abelhas exploradoras e resolução dos subproblemas gerados são executados até que um critério de parada seja satisfeito.

Para a definição da vizinhança de busca $k$-opt, adicionamos uma nova família de restrições. Dada uma solução factível inicial (abelha exploradora) de preparação $\left(\bar{Y}_{i t} \forall i, t\right)$ definimos o conjunto $\bar{S}$ como sendo: $\bar{S}=\left\{(i, t) \mid \bar{Y}_{i t}=1, \quad i \in\{1, \ldots, N\}, t \in\{1, \ldots, T\}\right\}$, tal que $\bar{Y}_{i t}$ é o valor de preparação, na solução inicial, para o produto $i$ no período $t$. Com isto, podemos definir a vizinhança $k$-opt com a seguinte restrição: $\sum_{i=1}^{N} \sum_{t=1}^{T} A_{i t} \leq k$, onde $A_{i t}=1-Y_{i t}$ se $(i, t) \in \bar{S}$ e $A_{i t}=Y_{i t}$, caso contrário. Esta restrição garante que no máximo k preparações serão alteradas em relação a solução inicial da busca. Estas mudanças podem ser tanto do valor zero para um, como o contrário. O parâmetro ngh do 
algoritmo de abelhas, que indica o tamanho da vizinhança de busca, foi utilizado como valor de $k$ na definição do tamanho da vizinhança k-opt.

A solução do subproblema é limitado no tempo de resolução de acordo com a qualidade da abelha exploradora, dado o multiplicador "nep" (para as "eb" melhores abelhas exploradoras) ou "nsp" (para as "mb-eb" demais abelhas exploradoras) de acordo com o algoritmo de abelhas. O tempo limite é de TL*(nep ou $n s p)$, onde o parâmetro TL é passado a priori para o método e indica o multiplicador do tempo limite.

O algoritmo de abelhas proposto é descrito no Algoritmo 4.5. Para este algoritmo, considere $l$ o contador de iterações, $l^{\text {max }}$ o limite de iterações, melhoria o valor do desvio percentual entre a melhor solução da população atual e a melhor solução da população anterior, e $\epsilon$ o limite mínimo de melhora para continuar com o método de busca.

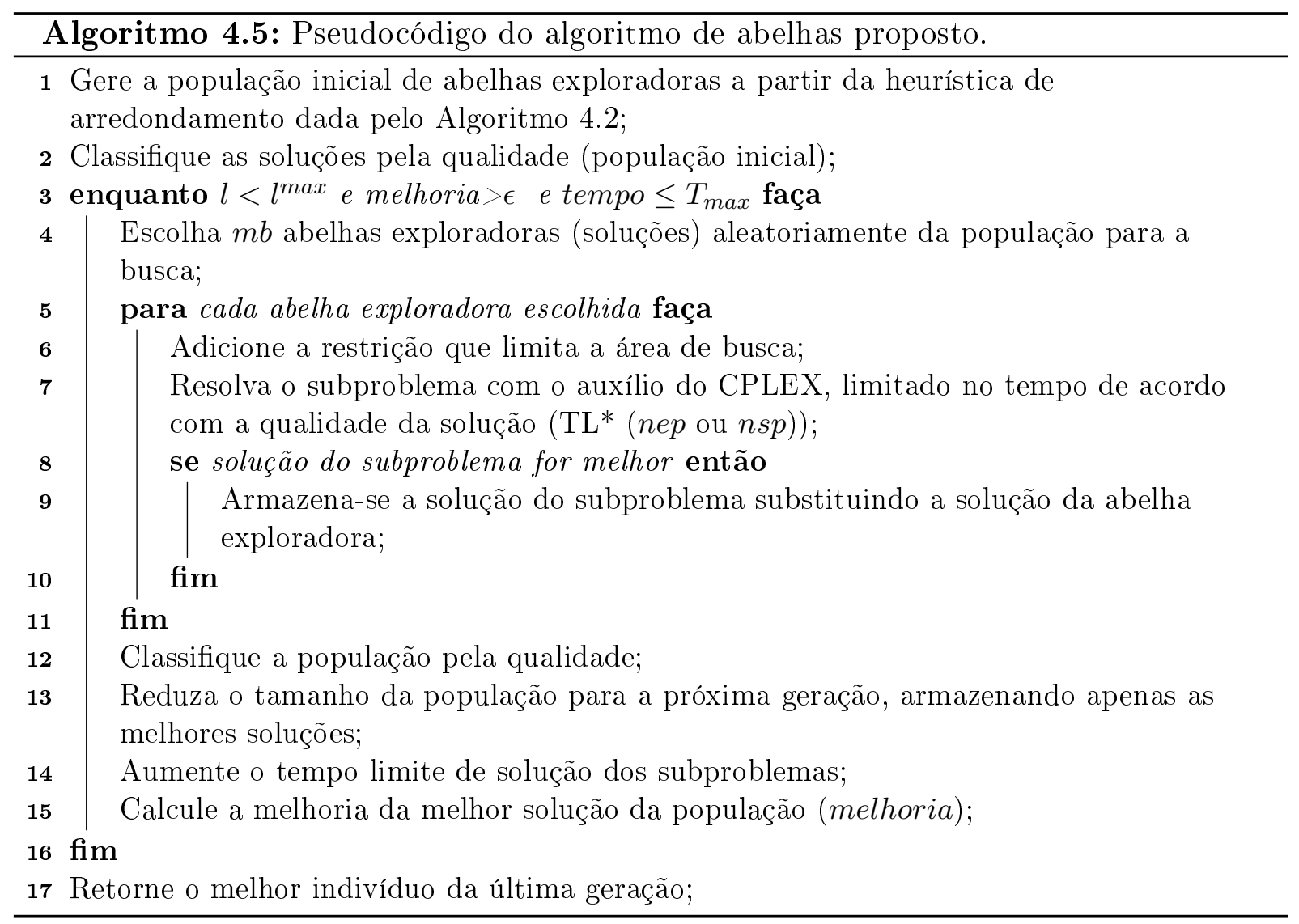

Com o objetivo de intensificar a busca nos locais mais promissores, optamos por aumentar o tempo limite das buscas nas vizinhanças a cada geração de abelhas. Este fato, porém, acarretaria um aumento de tempo para a resolução do subproblema de cada geração, com o passar das iterações. Para contornar este problema, ao mesmo tempo em que aumenta o tempo de busca, reduz-se o número de buscas locais executadas. Para isto, a cada iteração reduzimos a população de abelhas exploradoras, armazenando apenas as 
melhores soluções.

Um critério de parada utilizado foi o limite máximo de $l^{\text {max }}$ iterações (cada iteração corresponde a uma geração ou população de abelhas). Um segundo critério de parada utilizado foi a interrupção do processo devido a melhoria nas gerações: se o método não obtiver uma melhoria relativa maior do que $\epsilon$ na solução incumbente, o mesmo termina. Um outro critério de parada que pode ser utilizado é um limite máximo de tempo de execução para o algoritmo de abelhas.

\subsection{Métodos híbridos}

Métodos híbridos são métodos de solução construídos com a mistura ou cooperação entre dois ou mais métodos de solução. Estes métodos podem ser compostos por heurísticas, metaheurísticas e métodos exatos. Um método híbrido tem como objetivo associar as vantagens dos métodos que o compõe e assim agregar qualidades desejadas a solução, como por exemplo, um método heurístico pode gerar melhores limitantes e desta forma tentar reduzir o tempo de solução dos métodos exatos. Além disso, métodos sabidamente conhecidos por resolver de forma muito boa certos problemas da literatura podem ser usados em métodos híbridos para resolução de subproblemas.

Em Puchinger e Raidl (2005) e Jourdan et al. (2009) foram feitas duas classificações para métodos híbridos. Em Puchinger e Raidl (2005) os métodos são divididos entre colaborativos e integrados. Os colaborativos se distinguem devido a forma de interação dos sub-métodos, podendo ser executado sequencialmente ou em paralelo. Os integrados são separados pela forma de integração, ou seja, se o método exato incorpora a metaheurística ou o contrário. Em Jourdan et al. (2009) além de uma classificação, os autores propuseram uma taxonomia para a classificação deste tipo de métodos híbridos. Esta classificação se baseia em duas características, o nível de cooperação e a forma desta cooperação. A cooperação pode ser de baixo ou alto nível, e isso indica se os métodos são independentes (alto nível) ou se um deles faz parte do outro, substituindo um passo deste (baixo nível). A segunda característica está relacionada a ordem com que os métodos são executados, de forma sequencial ou paralela. Dentro desta classificação é feita uma revisão da literatura com os métodos de solução propostos para inúmeros problemas que seguem essa vertente híbrida. A Figura 14 apresenta a hierarquia de classificação de Puchinger e Raidl (2005).

Com o objetivo de desenvolver métodos que gerem boas soluções, foram desenvolvidas duas heurísticas híbridas de algoritmo de abelhas e fix-and-optimize para os problemas 


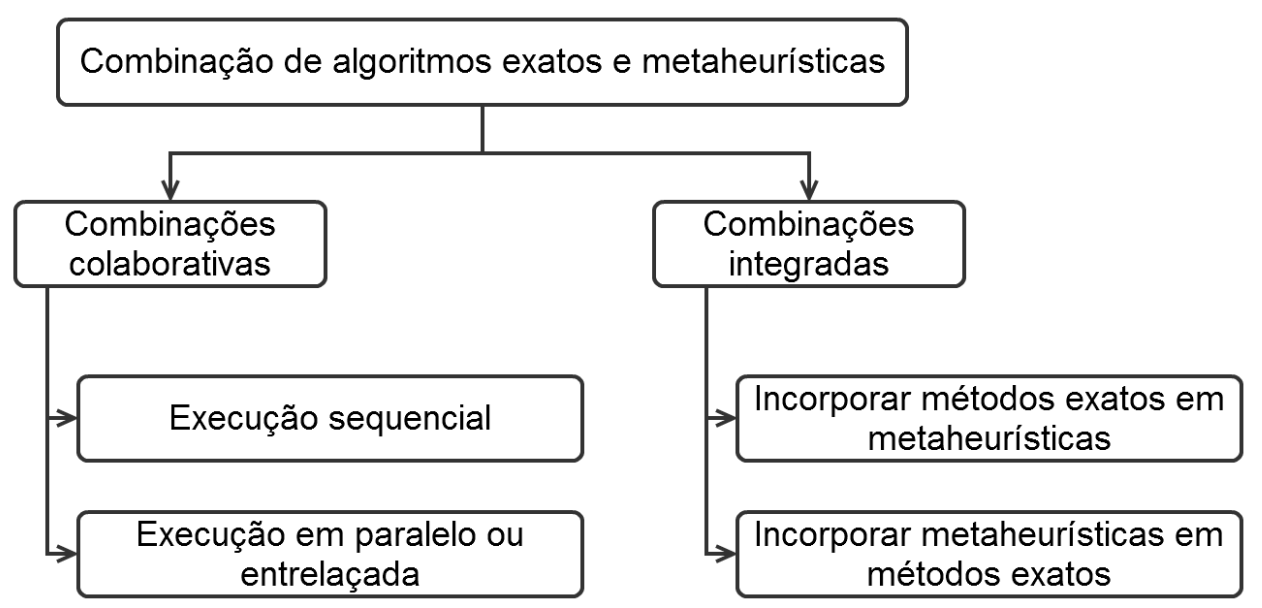

Figura 14: Classificação de métodos híbridos. Imagem adaptada de Puchinger e Raidl (2005).

considerados. Segundo a classificação de Jourdan et al. (2009), pode-se definir ambas as heurísticas como sendo métodos iterativos, pois apenas um método é executado por vez. A diferença entre os dois métodos híbridos se encontra na forma como a composição é feita, as posições de mestre e escravo se invertem. Ambos os métodos híbridos propostos são métodos de baixo nível, onde um dos métodos substitui um dos passos do outro, ou seja, um método faz parte do outro.

No primeiro método híbrido proposto neste trabalho, a metaheurística algoritmo de abelhas substitui o passo de definição das partições da heurística fix-and-optimize, além de definir qual partição será aplicada a cada passo. No segundo método, a composição é feita de forma inversa, a heurística fix-and-optimize substitui a busca local do algoritmo de abelhas.

\subsubsection{Primeira heurística híbrida: fix-and-optimize com algoritmo de abelhas}

Métodos do tipo fix-and-optmize, como descrito anteriormente, se baseiam fortemente no particionamento das variáveis do problema (variáveis inteiras). A escolha destes agrupamentos muitas vezes é feita segundo premissas para liberar variáveis que estejam relacionadas, como por exemplo, particionamento por período, onde cada partição tem todas as variáveis de preparação de um período ou de períodos subsequentes. O objetivo desta metodologia é tentar escolher partições que gerem subproblemas de rápida solução e que resultem na maior melhoria geral possível para a solução do problema original. Esse tipo de particionamento normalmente é feito segundo regras estabelecidas, como partição por 
períodos, por produtos ou por recursos, por exemplo.

Com o intuito de desenvolver um método que gerasse partições não intuitivas, mas de forma bem estabelecida, propõe-se a hibridização da heurística fix-and-optimize com um outro método que pudesse gerar partições diferentes das verificadas na literatura. Com esta intenção, utilizou-se a metaheurística algoritmo de abelhas para gerar partições não intuitivas. Desta forma, o primeiro método híbrido proposto neste trabalho consiste na heurística fix-and-optimize com particionamento definido pela metaheurística algoritmo de abelhas.

Basicamente, o método consiste de uma heurística fix-and-optimize onde as variáveis de cada partição (neste caso cada "abelha exploradora" define uma partição diferente) são inicialmente escolhidas aleatoriamente. A Figura 15 apresenta uma comparação entre uma partição por itens (Figura 15.a) e uma partição aleatória (Figura 15.b). Neste caso, a Figura 15.a é composta pelas variáveis de preparação do item 2. Como nos exemplos anteriores de particionamento com fixação de variáveis, na Figuras 15 e 16 as variáveis representadas por cinza claro serão fixadas, enquanto que as variáveis representadas por cinza escuro serão otimizadas.

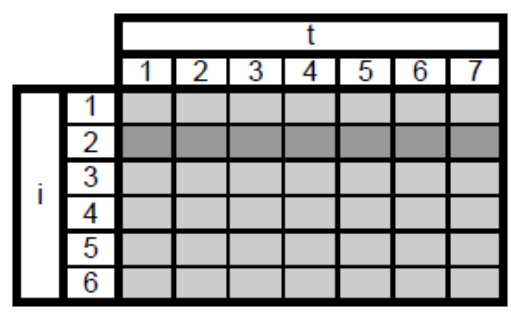

a) Particionamento por itens

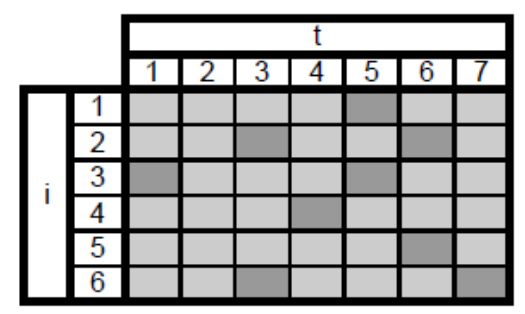

b) Particionamento aleatório

Figura 15: Partição do item 2 e partição aleatória.

Para a geração das abelhas seguidoras, as partições são modificadas também de forma aleatória adicionando/removendo variáveis nesta partição de acordo com um parâmetro do algoritmo de abelhas que define o tamanho da vizinhança $(n g h)$. Por exemplo, considere a partição aleatória da Figura 15.b (reapresentada na Figura 16.a) como a abelha exploradora e o tamanho de vizinhança $(n g h)$ igual a três. A partir disto, modificaremos a partição inicial da abelha exploradora adicionando/removendo variáveis escolhidas aleatoriamente na partição. A Figura 16.b apresenta uma possível abelha seguidora gerada por esse tipo de particionamento, onde são adicionadas as variáveis $(1,2)$ e $(2,5)$ e é removida a variável $(2,3)$, com as coordenadas dadas por $(i, t)$.

Desta forma, o algoritmo proposto fará buscas locais com o auxílio do CPLEX que 


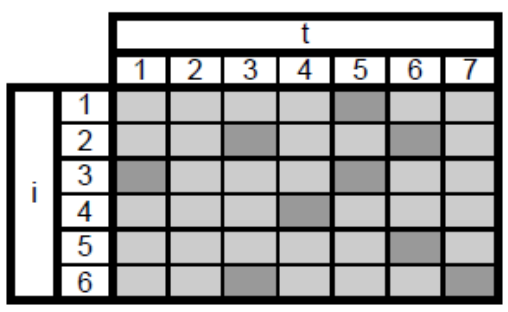

a) Abelha exploradora

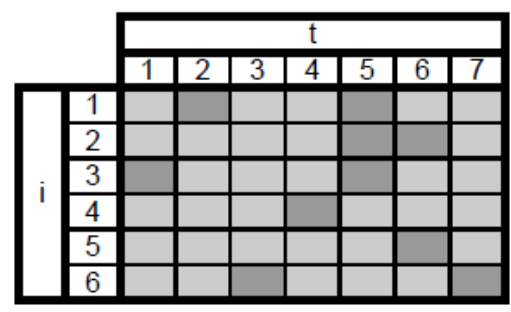

b) Abelha seguidora

Figura 16: Criação de uma abelha seguidora.

resolverá os subproblemas fixados. De acordo com a melhoria aplicada por cada abelha exploradora (partição base), um número nep ou nsp de abelhas seguidoras (novas partições criadas como descrito acima) serão geradas e seus subproblemas serão resolvidos.

Para evitar que o método se torne computacionalmente demorado, ou que partições com muitas variáveis livres possam deixar o algoritmo lento, adicionou-se um limite de tempo na resolução de cada subproblema. Após a resolução de todos os subproblemas gerados pelas abelhas seguidoras, a abelha que resultar em maior ganho em cada região do espaço de busca, será escolhida para fazer parte da próxima geração. Como critérios de parada, utilizamos um número máximo de iterações, tempo limite da heurística e uma geração da heurística sem melhoria da solução. Neste método híbrido, em particular, não foi aplicada uma busca aleatória nas abelhas exploradoras que não foram escolhidas para a busca local.

O Algoritmo 4.6 apresenta o Pseudocódigo deste primeiro método híbrido. A solução inicial é obtida a partir da heurística de arredondamento 4.2.

\subsubsection{Segunda heurística híbrida: algoritmo de abelhas com fix- and-optimize}

O algoritmo fix-and-optimize é um método de melhoria que pode ser visto como um algoritmo de busca local. Neste caso, a vizinhança se refere a partição de variáveis que são liberadas. Como a cada iteração altera-se a partição a ser liberada, a vizinhança também é alterada. As vizinhanças (partições) comumentes utilizadas são relativamente pequenas, pois os subproblemas gerados devem ser resolvidos rapidamente. Neste trabalho, como abordou-se partições com um número um pouco maior de variáveis (particionamento por períodos), limitou-se o tempo de resolução de cada subproblema. O tempo limite para a resolução de cada subproblema é proporcional ao número de variáveis livres do subproblema resolvido, ou seja, se o subproblema tem 10 variáveis livres para otimização, 


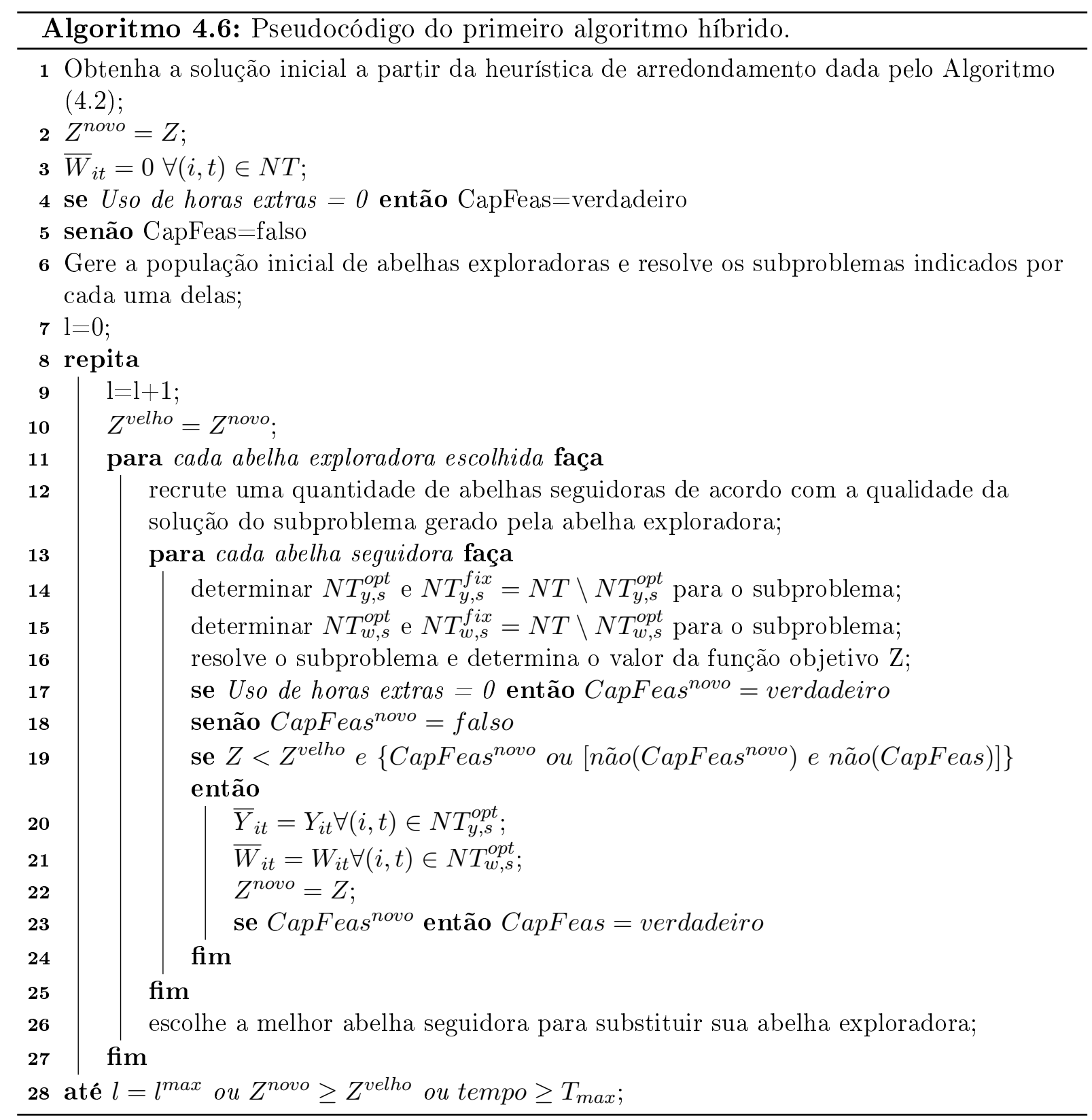

seu tempo de solução será limitado em $\alpha * 10$, onde $\alpha$ é o tempo limite para a solução do subproblema por variável "livre".

Neste método híbrido, propõe-se um algoritmo de abelhas onde a busca local implementada se trata de aplicação de partições do método fix-and-optimize. O método de busca é aplicado da seguinte forma: para uma solução (abelha exploradora) que foi escolhida para a busca local são aplicadas algumas partições escolhidas aleatoriamente e estas partições são retiradas do conjunto de partições que ainda não foram aplicadas a esta abelha. O número de partições aplicadas é definido segundo os parâmetros do algoritmo de abelhas, para as "eb" melhores soluções são aplicadas "nep" partições e para as " $m b-e b$ " demais soluções escolhidas são aplicadas " $n s p$ " partições. 


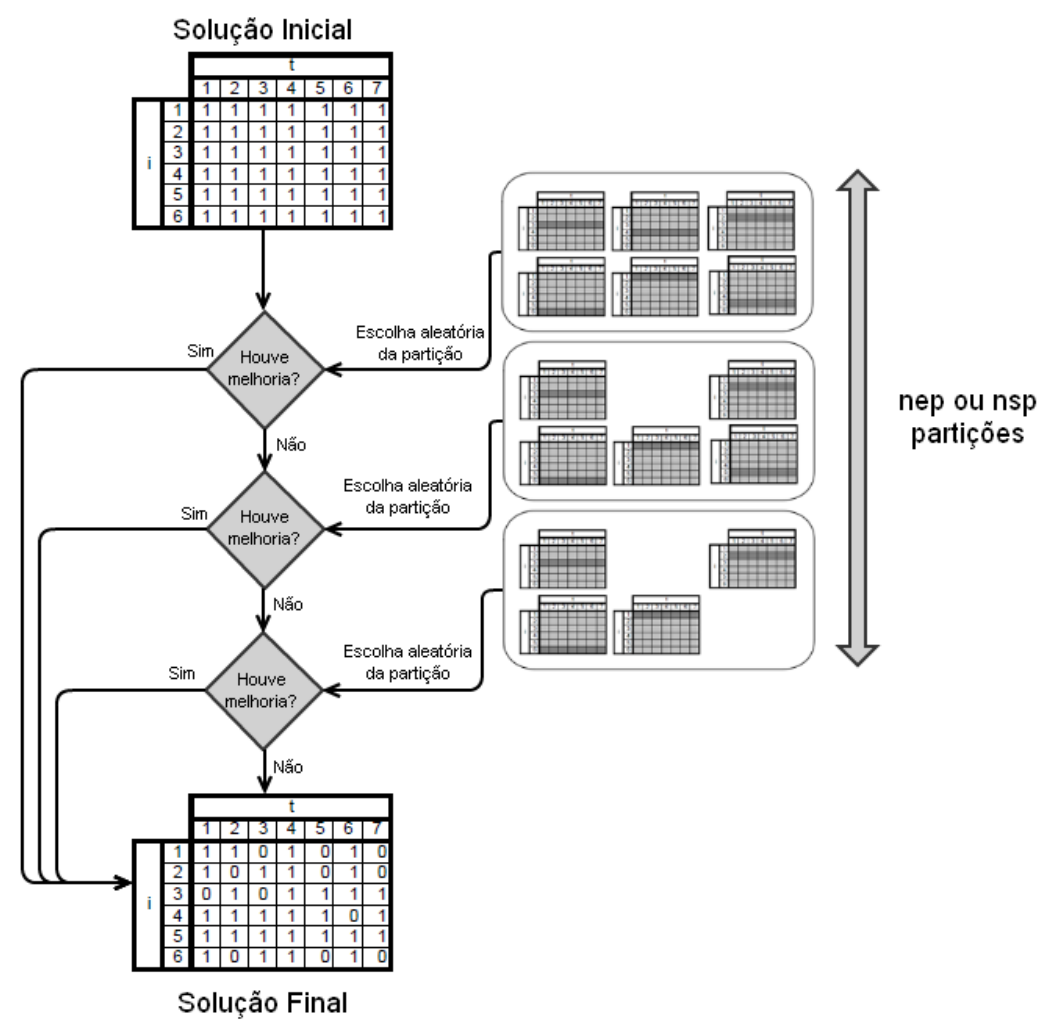

Figura 17: Exemplo de um passo do método de busca local.

A Figura 17 apresenta um exemplo de utilização da busca local proposta neste método híbrido. Neste exemplo, a solução inicial segue a política de produção lote-por-lote. A solução final da busca local é obtida, assim que "nep" ou "nsp" partições forem aplicadas a solução incumbente ou assim que uma partição gerar melhoria. Desta forma, se nenhuma partição apresentar melhoria, a solução é mantida e na próxima iteração outras partições são aplicadas. Caso haja uma melhoria em alguma partição, esta nova solução é passível de aplicação de qualquer uma das partições novamente, visto que, com a mudança da solução, as partições já aplicadas agora podem vir a gerar novas melhorias, portanto, todas as partições são novamente adicionadas ao conjunto de partições não aplicadas. Caso o conjunto de partições aplicáveis a uma solução se torne vazio, esta solução é considerada um ótimo local e então uma busca aleatória é aplicada a este ponto. Se a busca aleatória obtiver uma melhoria da solução, novamente todas as partições são adicionadas e o método de busca local recomeça.

A busca aleatória aplicada as soluções estagnadas (ótimos locais), consiste em modificar $n g h$ variáveis de decisão. Para cada variável escolhida aleatoriamente, muda-se o valor atual pelo inverso, ou seja, modificamos zero por um e um por zero. A seguir, resolvemos um subproblema linear, onde todas as variáveis de decisão estão fixadas. Se o subproblema for infactível, ignoramos o passo, caso contrário, a solução é armazenada, 
mesmo sendo pior que a solução anterior.

Nesta abordagem, utilizamos três critérios de parada: um número máximo de iterações $\left(l_{\max }\right)$; um tempo limite de execução; se todas as abelhas exploradoras se encontrarem em ótimos locais. O Algoritmo 4.7 apresenta a segunda heurística híbrida de algoritmo de abelhas com a heurística fix-and-optimize proposta neste trabalho.

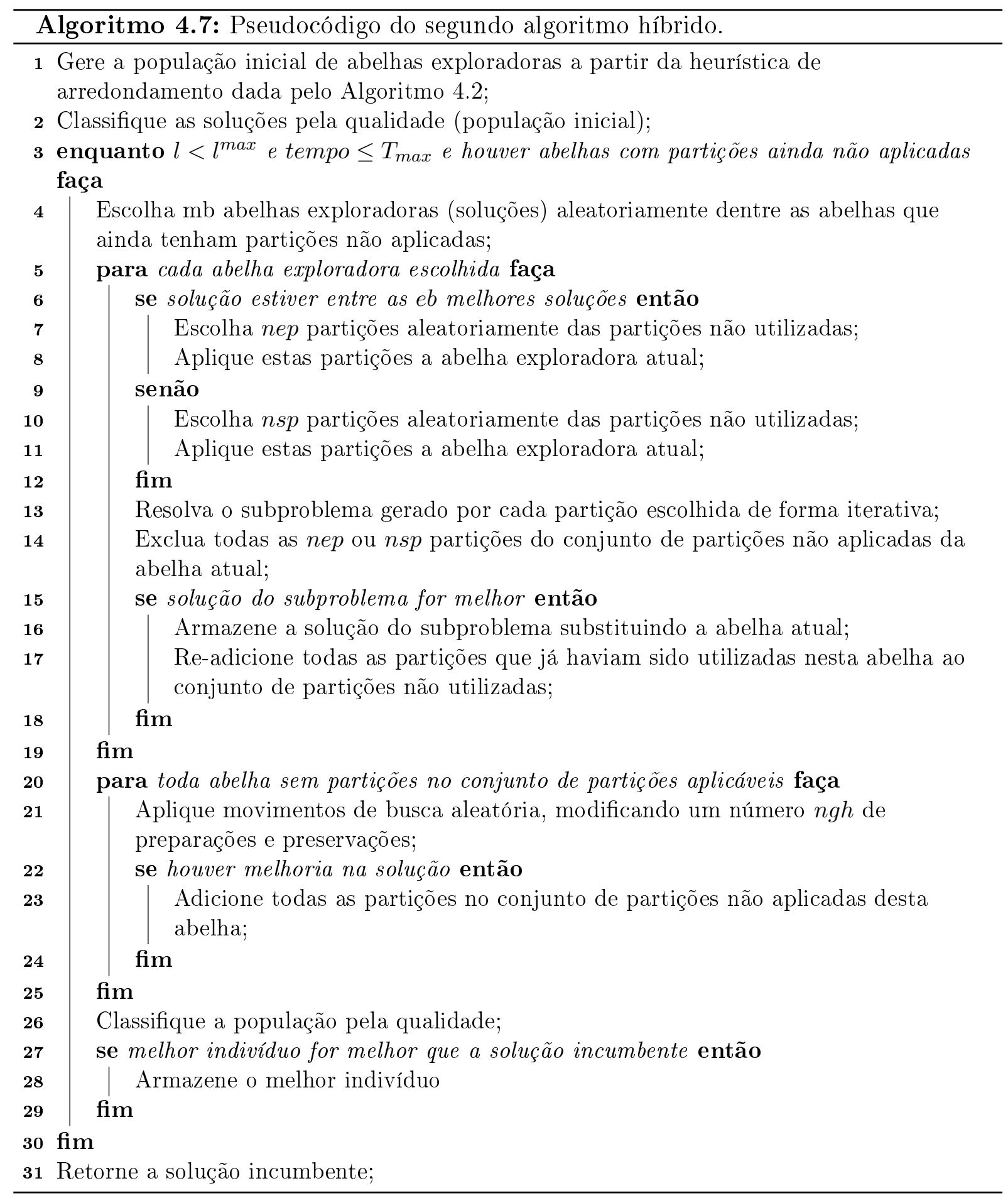




\section{CAPÍTULO 5}

\section{TESTES COMPUTACIONAIS}

Neste trabalho abordamos dois problemas de dimensionamento de lotes multiestágio, como descrito no Capítulo 3. O primeiro é um problema de dimensionamento de lotes multiestágio com limitações da capacidade, com possibilidade de utilização de horas extras e com custos e tempos de preparações não nulos. Além das características anteriores, o segundo problema considera preservação da preparação, lead-time positivo de um período para componentes e estoques iniciais também positivos.

Os testes computacionais foram executados considerando todas as abordagens de solução apresentadas no Capítulo 4, para cada uma das três formulações apresentadas no Capítulo 3 e, para cada um dos dois problemas considerados na dissertação.

Apresentaremos a seguir as características dos dois conjuntos de teste da literatura que foram utilizados. Em seguida, apresentaremos os resultados computacionais para cada um dos problemas abordados.

\subsection{Instâncias de Teste}

Dois grupos de instâncias de teste foram utilizados neste trabalho, sendo um grupo para cada problema abordado. Primeiramente, apresentaremos as instâncias do problema sem preservação da preparação e com lead-time nulo, desenvolvidas e documentadas em detalhes por Tempelmeier e Derstroff (1996) e Stadtler e Sürie (2000). Em seguida, 
apresentaremos as instâncias do problema com preservação da preparação e lead-time não nulo, desenvolvidas e documentadas por Tempelmeier e Buschkühl (2009). As instâncias dos dois grupos de testes foram fornecidas pelos respectivos autores.

\subsubsection{Instâncias de Tempelmeier e Derstroff (1996) e Stadtler e Sürie (2000)}

As instâncias geradas por Tempelmeier e Derstroff (1996) e Stadtler e Sürie (2000) foram divididas em 8 classes de instâncias, no entanto, neste trabalho abordaremos apenas 2 destas classes. As instâncias de teste foram divididas de acordo com o número de produtos, de períodos e de recursos, além da consideração ou não dos tempos de preparações, como pode ser visto na Tabela 1. Estas instâncias de teste possuem as seguintes características:

1. Tamanho das instâncias

O tamanho das instâncias varia com número de recursos, produtos e períodos, e elas foram divididos em classes conforme a Tabela 1.

Tabela 1: Características das instâncias de teste de Stadtler e Sürie (2000)

\begin{tabular}{||c||c|c|c|c|c||}
\hline Classe & No Produtos & No Períodos $^{\text {o }}$ & No Recursos & $\begin{array}{c}\text { Tempo de preparação } \\
\text { positivo }\end{array}$ & $\begin{array}{c}\text { Qtde de } \\
\text { Exemplos }\end{array}$ \\
\hline $\mathrm{A}+$ & 10 & 24 & 3 & Não & 120 \\
$\mathrm{~B}+$ & 10 & 24 & 3 & Sim & 312 \\
\hline
\end{tabular}

2. Estrutura de produto

As estruturas de produto das instâncias são divididas em quatro: geral e acíclica, geral e cíclica, montagem e acíclica, e montagem e cíclica, sendo que a questão de ciclicidade está relacionada ao uso de um mesmo recurso, por itens predecessores e sucessores. As estruturas geral e de montagem são representadas na Figura 18. Nesta figura são apresentadas todos os tipos de estruturas utilizadas neste conjunto de testes, estrutura geral cíclica (Figura 18.a), estrutura de montagem cíclica (Figura 18.b), estrutura geral acíclica (Figura 18.c) e estrutura de montagem acíclica (Figura 18.d). A classe B+também considera as mesmas estruturas de produto e recurso, variando apenas na consideração do tempo de preparação.

3. Perfil de demanda dos itens finais

Nestas instâncias não foram consideradas demandas externas para itens componentes. As demandas para itens finais foram geradas segundo o número de períodos, a 


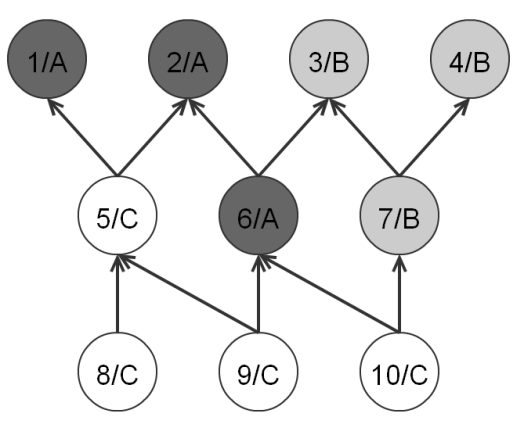

a) Estrutura de produto geral cíclica

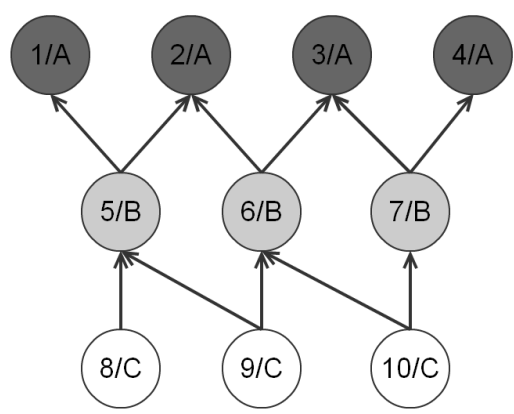

c) Estrutura de produto geral acíclica
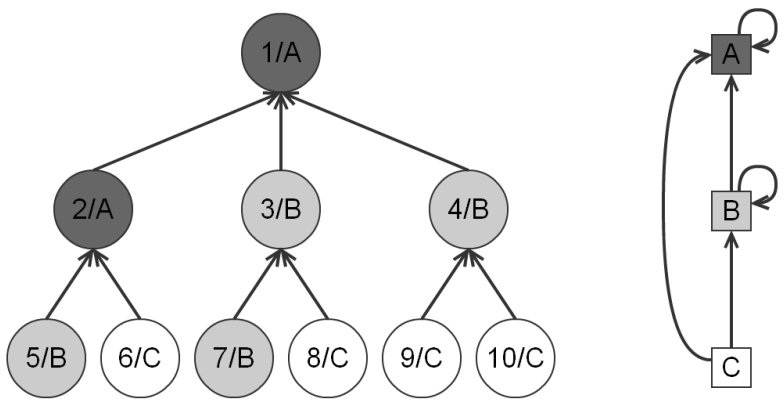

b) Estrutura de produto de montagem cíclica
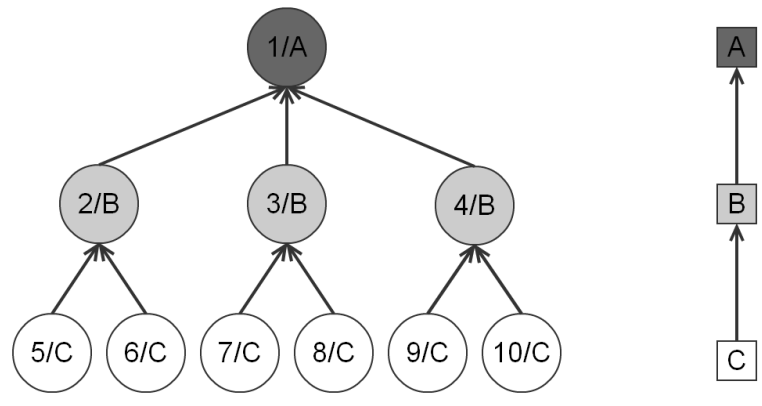

d) Estrutura de produto de montagem acíclica

Figura 18: Estruturas de produtos da classe A+. Imagem adaptada de Stadtler e Sürie (2000)

amplitude da demanda sazonal e um coeficiente de variação. A sazonalidade varia entre 0 (sem sazonalidade), 0,1 (pequena sazonalidade) e 0,2 (grande sazonalidade). O coeficiente de variação tem valor de 0,1 (pequena variação) ou 0,2 (grande variação). Segundo os autores, estes três fatores em conjunto fazem com que reflita uma variação estocástica na demanda.

4. Tempos de preparações

Os tempos de preparações variam de acordo com os itens. Como pode ser visto na Tabela 1, apenas a classe B + considera tempos de preparações positivos. A Tabela 2 apresenta os tempos de preparações utilizados na classe $\mathrm{B}+$, segundo o perfil de preparação e o item.

5. A proporção entre custos de preparação e de estoque

Esta é a proporção que demonstra o conflito de escolha natural que ocorre entre os custos de preparação e de estoque, pois sempre que um aumenta, o outro reduz e vice-versa. Esta proporção é calculada a seguir. 
Tabela 2: Tempos de preparações da classe $\mathrm{B}+$.

\begin{tabular}{||c||c|c|c||}
\hline \multicolumn{1}{||c||}{} & \multicolumn{3}{c||}{ Produto i } \\
\hline $\begin{array}{c}\text { Perfil de } \\
\text { preparação }\end{array}$ & $1,2,5,6$ & 3,4 & $7 \ldots 10$ \\
\hline 1 & $t s_{i}=10$ & $t s_{i}=15$ & $t s_{i}=5$ \\
2 & $t s_{i}=10$ & $t s_{i}=5$ & $t s_{i}=15$ \\
3 & $t s_{i}=30$ & $t s_{i}=45$ & $t s_{i}=15$ \\
4 & $t s_{i}=30$ & $t s_{i}=15$ & $t s_{i}=45$ \\
\hline
\end{tabular}

Considere a demanda de escalão $D_{i}$, dada por: $D_{i}=d_{i}+\sum_{j \in S(i)} r_{i j} * D_{j}$, onde $d_{i}$ é a demanda primária do item $i$ e $\sum_{j \in S(i)} r_{i j} * D_{j}$ é a soma das demandas do item $i$, como componente, para a produção de seus sucessores (demanda dependente).Considere também os tempos entre pedidos $(T B O)$ que são dados pela Tabela 3. O TBO define a janela de tempo entre cada pedido do item $i$, por exemplo, se temos $T B O_{1}=$ 2 , então se a demanda do item 1 ocorre no período $t$, a demanda do item 1 poderá ocorrer novamente apenas no período $t+2$.

Tabela 3: Tempos entre pedidos das classes $\mathrm{A}+\mathrm{e} \mathrm{B}+$.

\begin{tabular}{||c||c|c|c|c||}
\hline \multicolumn{1}{||c||}{} & & \multicolumn{3}{c||}{ Produto i } \\
\hline $\begin{array}{c}\text { Estrutura de } \\
\text { Produto }\end{array}$ & $\begin{array}{c}\text { Perfil } \\
\text { de } T B O\end{array}$ & $T B O=2$ & $T B O=4$ & $T B O=6$ \\
\hline Geral & 3 & & $1 \ldots 10$ & \\
Geral & 4 & $1 \ldots 4$ & $5 \ldots 7$ & $8 \ldots 10$ \\
Montagem & 3 & & $1 \ldots 10$ & \\
Montagem & 4 & 1 & $2 \ldots 4$ & $5 \ldots 10$ \\
\hline
\end{tabular}

Os custos de preparações são calculados pela seguinte fórmula:

$s_{i}=0.5 * e_{i} * \bar{D}_{i} *\left(T B O_{i}\right)^{2}$, onde $e_{i}$ representa o custo de estoque marginal do produto $i$. Custo de estoque marginal é a diferença entre o custo de estoque do item $i$ e o custo de estoque de todos os componentes de $i$ necessários para a produção de uma unidade de $i$, ou seja, é a diferença no custo de estoque do item montado para o item não montado. Neste conjunto de testes foi considerado $e_{i}$ igual a um para todos os itens. $\bar{D}_{i}=\sum_{t=1}^{T} D_{i t}$ representa a demanda de escalão acumulada do item $i$ durante todo o horizonte de planejamento.

6. A capacidade dos recursos

Para obter instâncias com certa variabilidade em relação a capacidade, foram consideradas diferentes porcentagens de utilização da capacidade $\left(R U_{m}\right)$. Os perfis de utilização dos recursos utilizados são apresentados na Tabela 4. 
Tabela 4: Porcentagem de utilização dos recursos das classes $\mathrm{A}+\mathrm{e} \mathrm{B}+$.

\begin{tabular}{||c||c|c|c||}
\hline $\begin{array}{c}\text { Perfil de } \\
\text { Utilização }\end{array}$ & Recurso 1 & Recurso 2 & Recurso 3 \\
\hline 1 & $90 \%$ & $90 \%$ & $90 \%$ \\
2 & $70 \%$ & $70 \%$ & $70 \%$ \\
3 & $50 \%$ & $50 \%$ & $50 \%$ \\
4 & $90 \%$ & $70 \%$ & $50 \%$ \\
5 & $50 \%$ & $70 \%$ & $90 \%$ \\
\hline
\end{tabular}

A capacidade de cada recurso é calculada pela seguinte fórmula:

$$
C_{m t}=\frac{\sum_{i \in K_{m}}\left(a_{i} * \bar{D}_{i}+s t_{i}\right)}{R U_{m}} \quad \forall t
$$

\subsubsection{Instâncias de teste de Tempelmeier e Buschkühl (2009)}

As instâncias de teste geradas e utilizadas em Tempelmeier e Buschkühl (2009) foram divididas em 6 classes de instâncias, de acordo com o número de produtos, de períodos e de recursos das instâncias, como pode ser visto na Tabela 5. Para a construção das instâncias de teste, os autores levaram em consideração seis propriedades que os autores de Tempelmeier e Derstroff (1996) e Stadtler e Sürie (2000) consideraram com ligeiras modificações.

1. Tamanho do problema

Varia com número de recursos, produtos e períodos, e estes foram divididos em classes conforme a Tabela 5.

Tabela 5: Características das instâncias de teste de Tempelmeier e Buschkühl (2009)

\begin{tabular}{||c||c|c|c|c||}
\hline Classe & $\mathrm{N}^{\circ}$ Produtos & $\mathrm{N}^{\circ}$ Períodos & $\mathrm{N}^{\circ}$ Recursos & Qtde de Exemplos \\
\hline 1 & 10 & 4 & 3 & 480 \\
2 & 10 & 8 & 3 & 480 \\
3 & 20 & 8 & 6 & 240 \\
4 & 20 & 16 & 6 & 240 \\
5 & 40 & 8 & 6 & 240 \\
6 & 40 & 16 & 6 & 240 \\
\hline
\end{tabular}

2. Estrutura de produto

As estruturas das instâncias são divididas em quatro: geral e acíclica, geral e cíclica, montagem e acíclica, e montagem e cíclica. As estruturas são representadas na Figura 19. Nesta figura, a primeira linha apresenta estruturas cíclicas e a segunda linha apresenta estruturas acíclicas. As estruturas da coluna da esquerda são 
estruturas gerais e as estruturas da direita são estruturas de montagem.

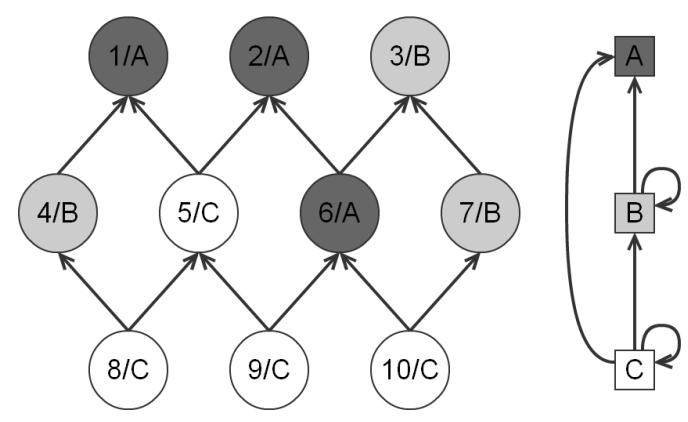

a) Estrutura de produto geral cíclica
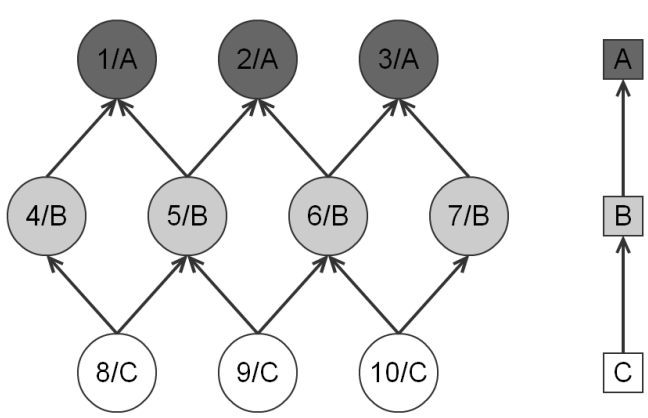

c) Estrutura de produto geral acíclica

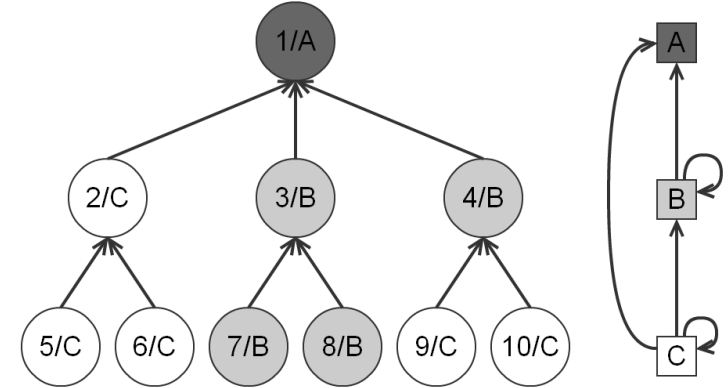

b) Estrutura de produto de montagem cíclica

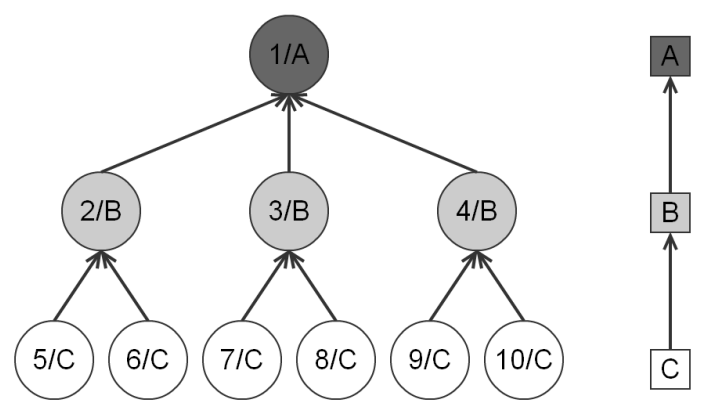

d) Estrutura de produto de montagem acíclica

Figura 19: Estruturas de produtos da classe 1. Imagem adaptada de Tempelmeier e Buschkühl (2009)

3. Perfil de demanda dos itens finais

A demanda externa foi gerada seguindo uma distribuição normal. Os valores das demandas foram gerados utilizando o algoritmo Mersenne Twister como descrito em Matsumoto e Nishimura (1998). Para assegurar a factibilidade do problema, um estoque inicial foi calculado para suprir a demanda de componentes no primeiro período, dado que o lead-time é igual a um para todos os componentes.

4. Tempos de preparação

Os tempos de preparação variam entre 5, 10 e 20 unidades de tempo para refletir o impacto causado. A Tabela 6 apresenta a distribuição destes tempos de acordo com o número de itens de cada classe de testes.

5. A proporção entre custos de preparação e de estoque

Os autores utilizaram a abordagem de cálculo do caso anterior, modificando apenas os perfis de TBO, como apresentados na Tabela 7 . 
Tabela 6: Tempos de preparações por número de itens.

\begin{tabular}{||c||c||c|c|c||}
\hline $\begin{array}{c}\text { Número de } \\
\text { Itens }\end{array}$ & $\begin{array}{c}\text { Perfil de } \\
\text { preparação }\end{array}$ & $t s_{i}=5$ & $t s_{i}=10$ & $t s_{i}=20$ \\
\hline 10 & 1 & $1,2,3$ & $4,5,6,7$ & $8,9,10$ \\
10 & 2 & $8,9,10$ & $4,5,6,7$ & $1,2,3$ \\
20 & 1 & $1, \ldots, 6$ & $7, \ldots, 14$ & $15, \ldots, 20$ \\
20 & 2 & $15, \ldots, 20$ & $7, \ldots, 14$ & $1, \ldots, 6$ \\
40 & 1 & $1, \ldots, 13$ & $14, \ldots, 27$ & $28, \ldots, 40$ \\
40 & 2 & $28, \ldots, 40$ & $14, \ldots, 27$ & $1, \ldots, 13$ \\
\hline
\end{tabular}

Tabela 7: Tempos entre pedidos por número de itens.

\begin{tabular}{|c|c|c|c|c|}
\hline & & \multicolumn{3}{|c|}{ Produto i } \\
\hline $\begin{array}{l}\text { Número de } \\
\text { Itens }\end{array}$ & $\begin{array}{c}\text { Perfil } \\
\text { de } T B O\end{array}$ & $T B O=1$ & $T B O=2$ & $T B O=4$ \\
\hline 10 & 1 & $1, \ldots, 10$ & & \\
\hline 10 & 2 & & $1, \ldots, 10$ & \\
\hline 10 & 3 & & & $1, \ldots, 10$ \\
\hline 10 (assembly) & 4 & 1 & $2, \ldots, 4$ & $5, \ldots, 10$ \\
\hline 10 (general) & 4 & $1, \ldots, 3$ & $4, \ldots, 7$ & $8, \ldots, 10$ \\
\hline 20 & 1 & & $1, \ldots, 20$ & \\
\hline 20 & 2 & $1, \ldots, 3$ & $4, \ldots, 10$ & $11, \ldots, 20$ \\
\hline 40 & 1 & & $1, \ldots, 40$ & \\
\hline 40 (assembly) & 2 & $1, \ldots, 4$ & $5, \ldots, 16$ & $17, \ldots, 40$ \\
\hline 40 (general) & 2 & $1, \ldots, 6$ & $7, \ldots, 19$ & $20, \ldots, 40$ \\
\hline
\end{tabular}

6. A capacidade utilizada

Como anteriormente considerado, as porcentagens de capacidade utilizadas foram de $50 \%, 70 \%$ e 90\%, como apresentado na Tabela 8 , onde cada letra representa um recurso diferente.

Tabela 8: Porcentagem de utilização por número de recursos.

\begin{tabular}{||c||c||c|c|c||}
\hline & & \multicolumn{3}{||}{ Produto i } \\
\hline $\begin{array}{c}\text { Número de } \\
\text { Recursos }\end{array}$ & $\begin{array}{c}\text { Perfil de } \\
\text { Utilização }\end{array}$ & $R U_{m}=50 \%$ & $R U_{m}=70 \%$ & $R U_{m}=90 \%$ \\
\hline 3 & 1 & $\mathrm{~A}, \mathrm{~B}, \mathrm{C}$ & $\mathrm{A}, \mathrm{B}, \mathrm{C}$ & \\
3 & 2 & & & $\mathrm{~A}, \mathrm{~B}, \mathrm{C}$ \\
3 & 3 & $\mathrm{~A}$ & $\mathrm{~B}$ & $\mathrm{C}$ \\
3 & 4 & $\mathrm{C}$ & $\mathrm{B}$ & $\mathrm{A}$ \\
3 & 5 & $\mathrm{~A}, \ldots, \mathrm{F}$ & & \\
6 & 1 & & $\mathrm{~A}, \ldots, \mathrm{F}$ & \\
6 & 2 & $\mathrm{~A}, \mathrm{D}$ & $\mathrm{B}, \mathrm{E}$ & $\mathrm{C}, \mathrm{F}$ \\
6 & 3 & $\mathrm{~A}, \mathrm{~B}$ & $\mathrm{C}, \mathrm{D}$ & $\mathrm{E}, \mathrm{F}$ \\
6 & 4 & &
\end{tabular}

A porcentagem de utilização foi calculada pela seguinte fórmula: 


$$
R U_{m}=\frac{\sum_{i \in K_{m}} \sum_{t=1}^{T}\left(a_{i} * X_{i t}+t s_{i} * Y_{i t}\right)}{\sum_{t=1}^{T} C_{m t}}
$$

\subsection{Resultados Computacionais}

Os resultados computacionais foram divididos em duas partes, uma para cada problema abordado. Cada parte apresenta primeiramente uma análise comparativa dos resultados computacionais de cada abordagem de solução em relação as três formulações apresentadas no Capítulo 3. Em seguida, apresenta um comparativo entre os métodos, considerando a melhor formulação para cada abordagem. Para estas comparações, utilizamos cinco métricas que são definida a seguir:

\section{- Desvio percentual médio}

O desvio percentual médio $\left(\right.$ Desvio $\left.=\frac{S o l-U B}{U B}\right)$ é calculado com relação ao limitante superior. O limitante superior foi obtido por meio da resolução do problema com a ferramenta CPLEX, considerando um tempo limite de uma hora, no caso das classes de instâncias propostas por Tempelmeier e Buschkühl (2009). No caso das instâncias de Tempelmeier e Derstroff (1996) e Stadtler e Sürie (2000) foram utilizados os limitantes disponibilizados pelos autores.

\section{- Desvio padrão percentual}

O desvio padrão percentual foi obtido a partir da variação dos desvios percentuais de cada instância com relação ao desvio percentual médio da classe. No caso das heurísticas probabilísticas, cada instância foi executada cinco vezes e o desvio padrão foi calculado com relação a todas as execuções de forma conjunta.

\section{- Tempo computacional médio}

\section{- Percentual de melhoria}

O percentual de melhoria define qual a proporção de instâncias de cada classe que obtiveram soluções iguais ou melhores que o limitante superior utilizado.

\section{- Percentual de factibilidade}

O percentual de factibilidade define qual a proporção de instâncias de cada classe que não utilizaram horas extras.

$\mathrm{Na}$ apresentação dos resultados computacionais, utilizaremos as siglas para definir cada abordagem. Estas siglas foram apresentadas no Capítulo 4 e serão listadas abaixo. 
Além disso, elas também foram adicionadas a lista de Abreviaturas e Siglas.

Para os testes computacionais desta dissertação, utilizamos o seguinte conjunto de parâmetros:

1. LPF (Heurística do tipo LP-and-fix)

(a) $T_{\max }=600$ segundos ( $T_{\max }$ é o tempo máximo para execução de toda heurística);

(b) $\alpha=0,17$ ( $\alpha$ define o intervalo de arredondamento e fixação da heurística).

2. RF1 (Heurística do tipo relax-and-fix com particionamento por períodos)

(a) $T_{\max }=600$ segundos;

(b) $\mathrm{TF}=2$ ( $\mathrm{TF}$ é o número de períodos ou itens que serão fixados a cada iteração);

(c) $\mathrm{TS}=4$ (TS é o número de períodos ou itens considerados inteiros a cada iteração);

(d) $T_{\operatorname{maxp}}=15$ segundos $*$ TF $\left(T_{\operatorname{maxp}}\right.$ é o tempo máximo para resolução de uma partição).

3. RF2 (Heurística do tipo relax-and-fix com particionamento por nível da estrutura de produto)

(a) $T_{\max }=600$ segundos;

(b) $T_{\operatorname{maxp}}=15$ segundos $*$ número de item considerados inteiros.

4. RF3 (Heurística do tipo relax-and-fix com particionamento por itens)

(a) $T_{\max }=600$ segundos;

(b) $\mathrm{TF}=3$;

(c) $\mathrm{TS}=5$;

(d) $T_{\operatorname{maxp}}=15$ segundos $* \mathrm{TF}$.

5. FO (Heurísticas do tipo fix-and-optimize)

FO-P1 (heurísticas do tipo fix-and-optimize com particionamento por itens);

FO-P2 (heurísticas do tipo fix-and-optimize com particionamento por períodos);

FO-P3 (heurísticas do tipo fix-and-optimize com particionamento por itens e depois por períodos);

FO-P4 (heurísticas do tipo fix-and-optimize com particionamento por períodos e depois por itens); 
(a) $T_{\max }=600$ segundos;

(b) $l_{\max }=1000$ (número máximo de iterações do método);

(c) $T_{\operatorname{maxp}}=0,1$ segundos por variável livre para otimização.

6. BA (Metaheurística algoritmo de abelhas)

(a) $T_{\max }=600$ segundos;

(b) $T_{\operatorname{maxp}}=0,3$ segundos $+0,1$ segundos por iteração;

(c) $\mathrm{nb}=9$ (número de abelhas exploradoras);

(d) $\mathrm{mb}=9$ (número de abelhas exploradoras escolhidas para busca local);

(e) $\mathrm{eb}=9$ (melhores abelhas entre as mb abelhas exploradoras escolhidas);

(f) nep=11 (número de abelhas seguidoras enviadas com as eb melhores abelhas exploradoras escolhidas);

(g) $n s p=5$ (número de abelhas seguidoras enviadas com as mb-eb demais abelhas exploradoras escolhidas);

(h) $n g h=23$ (tamanho da vizinhança de busca);

(i) $l_{\max }=1000$;

(j) $\epsilon=0,0005$ (melhoria mínima entre as gerações de abelhas para que o método continue);

7. BFO1 e BFO2 (métodos híbridos)

BFO1 (primeiro método híbrido proposto);

BFO2-P1 (segundo método híbrido proposto com particionamento por itens);

BFO2-P1 (segundo método híbrido proposto com particionamento por períodos);

BFO2-P1 (segundo método híbrido proposto com particionamento por itens e períodos);

(a) $T_{\max }=600$ segundos;

(b) $T_{\operatorname{maxp}}=0,1$ segundos por variável livre para otimização;

(c) $\mathrm{nb}=9$;

(d) $\mathrm{mb}=9$;

(e) $\mathrm{eb}=9$;

(f) nep=11;

(g) $\mathrm{nsp}=5$; 
(h) $\mathrm{ngh}=23$;

(i) $l_{\max }=1000$.

\section{Ambiente de testes}

Os testes foram executados em um microcomputador com processador Intel Core 2 Duo E6550 de 2.33 Ghz, memória L2 cache de 4MB e 3GB de memória RAM sob o sistema operacional Debian 4.1.1-21. Todos os algoritmos foram implementados em $\mathrm{C}++$ e para a resolução de problemas de programação inteira mista foi utilizada a ferramenta IBM ILOG CPLEX 11.2, com o auxílio da biblioteca de funções CPLEX Concert Technology.

\subsubsection{Problema de dimensionamento de lotes multiestágio com limitação de capacidade}

Os resultados computacionais são analisados primeiramente considerando as formulações matemáticas e em uma segunda etapa, analisando as abordagens de solução. Para cada uma das etapas analisadas, os resultados computacionais para o problema de dimensionamento de lotes multiestágio com limitação de capacidade são apresentados em quatro partes. Na primeira parte são apresentados os resultados obtidos pelos procedimentos baseados em relaxação linear (heurísticas LP-and-fix e relax-and-fix). Na segunda parte os resultados obtidos pelas heurísticas puras do tipo fix-and-optimize são discutidos e analisados. Na terceira parte são apresentados os resultados obtidos pela metaheurística algoritmo de abelhas e finalmente, na última parte, apresentamos os resultados obtidos pelas heurísticas híbridas.

\subsubsection{Análise dos resultados com foco na formulação utilizada}

\section{Heurísticas baseadas em relaxação linear}

As Tabelas 9 e 10 apresentam os resultados de desvio percentual médio e desvio padrão percentual, respectivamente. A primeira verificação que podemos fazer é que mesmo sendo heurísticas baseadas em relaxação linear, com características em comum, os resultados não foram similares quando utilizamos uma mesma formulação.

A heurística LPF obteve melhores resultados com a formulação SPL (formulação por localização de facilidades, ver Apêndice A) quando consideramos o desvio percentual médio, mas quando consideramos o desvio padrão os resultados foram numericamente próximos aos obtidos para a formulação Agregada. Na heurística RF1, os resultados para 
a formulação SPL foram melhores tanto no desvio percentual quanto no desvio padrão, de forma geral. Para a heurística RF2, os resultados das formulações Agregada e Mista foram bem próximos, tanto nos desvios percentuais quanto nos desvios padrões, com pequena vantagem para a formulação Mista quando consideramos as instâncias da classe $\mathrm{B}+$. Na heurística RF3, os resultados para a formulação SPL foram piores que os resultados obtidos para as formulações Agregada e Mista na classe de testes A+, no entanto, os resultados foram consideravelmente melhores na classe de testes $\mathrm{B}+$, fazendo com que a formulação SPL tenha um resultado médio melhor que as demais.

Tabela 9: Desvio percentual médio - Heurísticas baseadas em relaxação linear

\begin{tabular}{||c||c|r|r||r|r|r||}
\hline \multicolumn{1}{||c||}{} & \multicolumn{3}{c||}{ LPF } & \multicolumn{1}{c||}{ RF1 } \\
\hline Classe & SPL & Agregada & Mista & SPL & Agregada & \multicolumn{1}{c||}{ Mista } \\
\hline A + & $\mathbf{1 , 3 5 \%}$ & $2,22 \%$ & $4,06 \%$ & $\mathbf{1 , 6 5 \%}$ & $2,34 \%$ & $2,52 \%$ \\
B + & $\mathbf{1 , 4 8 \%}$ & $1,61 \%$ & $3,90 \%$ & $\mathbf{1 4 1 , 6 9 \%}$ & $251,74 \%$ & $255,15 \%$ \\
\hline \hline \multicolumn{1}{||}{} & \multicolumn{5}{|c||}{ RF2 } & \multicolumn{3}{c||}{ RF3 } \\
\hline Classe & SPL & Agregada & Mista & SPL & Agregada & \multicolumn{1}{c||}{ Mista } \\
\hline A + & $9,06 \%$ & $\mathbf{5 , 9 1 \%}$ & $6,18 \%$ & $6,62 \%$ & $\mathbf{4 , 4 7 \%}$ & $4,81 \%$ \\
B + & $267,80 \%$ & $200,61 \%$ & $\mathbf{1 9 8 , 9 6 \%}$ & $\mathbf{7 9 , 2 9 \%}$ & $132,38 \%$ & $138,51 \%$ \\
\hline
\end{tabular}

Tabela 10: Desvio padrão percentual - Heurísticas baseadas em relaxação linear

\begin{tabular}{||c||r|r|r||r|r|r||}
\hline \multicolumn{1}{||c||}{} & \multicolumn{3}{c||}{ LPF } & \multicolumn{1}{c||}{ RF1 } \\
\hline Classe & SPL & Agregada & Mista & SPL & Agregada & \multicolumn{1}{c||}{ Mista } \\
\hline A + & $\mathbf{1 , 7 5 \%}$ & $1,89 \%$ & $2,36 \%$ & $2,25 \%$ & $\mathbf{1 , 7 2 \%}$ & $1,84 \%$ \\
B + & $2,20 \%$ & $\mathbf{2 , 0 5 \%}$ & $2,10 \%$ & $\mathbf{2 3 6 , 0 3 \%}$ & $500,54 \%$ & $501,71 \%$ \\
\hline \hline \multicolumn{1}{||c||}{} & \multicolumn{3}{c||}{ RF2 } & \multicolumn{3}{c||}{ RF3 } \\
\hline Classe & SPL & Agregada & Mista & SPL & Agregada & \multicolumn{1}{c||}{ Mista } \\
\hline A + & $7,13 \%$ & $\mathbf{4 , 6 6 \%}$ & $4,82 \%$ & $4,30 \%$ & $3,65 \%$ & $\mathbf{3 , 1 9 \%}$ \\
B + & $420,96 \%$ & $393,57 \%$ & $\mathbf{3 9 3 , 0 4 \%}$ & $\mathbf{1 9 0 , 2 5 \%}$ & $276,87 \%$ & $271,59 \%$ \\
\hline
\end{tabular}

A Tabela 11 apresenta os resultados dos tempos computacionais médios de todas as heurísticas para todas as formulações. Observe que as heurísticas RF1, RF2 e RF3 quando utilizam a formulação Agregada, apresentam os menores tempos computacionais médios. A heurística LPF, para quase todas as instâncias e todas as formulações, foi interrompida pelo critério de limite de tempo. Esta interrupção não aconteceu apenas para algumas instâncias da classe A+ e quando se utilizou a formulação Agregada.

Para um grande número de instâncias em todas as formulações utilizadas, as heurísticas não foram capazes de obter soluções ótimas ou melhores das que existiam na literatura conforme podemos observar na Tabela 12. Porém, podemos verificar que com a formulação SPL, as heurísticas LPF, RF1 e RF2, conseguiram obter desempenho melhor do que as mesmas heurísticas utilizando outras formulações. No caso da heurística RF3, os resultados foram melhores utilizando a formulação Agregada. 
Tabela 11: Tempo computacional médio - Heurísticas baseadas em relaxação linear

\begin{tabular}{||c||c|r|c||c|r|c||}
\hline \multicolumn{1}{||c||}{} & \multicolumn{3}{c||}{ LPF } & \multicolumn{3}{c||}{ RF1 } \\
\hline Classe & SPL & Agregada & Mista & SPL & Agregada & Mista \\
A + & 600,77 & $\mathbf{5 9 6 , 8 2}$ & 601,43 & 196,52 & $\mathbf{2 2 , 5 4}$ & 153,08 \\
B + & 600,80 & $\mathbf{6 0 0 , 7 1}$ & 601,43 & 193,68 & $\mathbf{2 5 , 1 7}$ & 152,58 \\
\hline \hline \multicolumn{1}{||}{} & \multicolumn{3}{c||}{ RF2 } & \multicolumn{3}{c||}{ RF3 } \\
\hline Classe & SPL & Agregada & Mista & SPL & Agregada & Mista \\
A + & 121,79 & $\mathbf{6 7 , 2 7}$ & 100,72 & 122,91 & $\mathbf{8 3 , 1 4}$ & 117,93 \\
B + & 125,19 & $\mathbf{6 1 , 0 5}$ & 100,45 & 120,22 & $\mathbf{9 1 , 5 0}$ & 123,11 \\
\hline
\end{tabular}

Tabela 12: Percentual de melhoria - Heurísticas baseadas em relaxação linear

\begin{tabular}{||c||c|r|r||r|r|r||}
\hline \multicolumn{1}{|c||}{} & \multicolumn{3}{c||}{ LPF } & \multicolumn{3}{c||}{ RF1 } \\
\hline Classe & SPL & Agregada & Mista & SPL & Agregada & Mista \\
\hline A + & $\mathbf{2 1 , 6 7 \%}$ & $11,67 \%$ & $5,00 \%$ & $\mathbf{1 8 , 3 3 \%}$ & $5,00 \%$ & $5,83 \%$ \\
B + & $\mathbf{2 1 , 7 9 \%}$ & $18,59 \%$ & $1,28 \%$ & $\mathbf{1 6 , 3 5 \%}$ & $9,62 \%$ & $9,29 \%$ \\
\hline \hline \multicolumn{1}{||}{} & \multicolumn{3}{c||}{ RF2 } & \multicolumn{3}{c||}{ RF3 } \\
\hline Classe & SPL & Agregada & Mista & SPL & Agregada & Mista \\
\hline A+ & $\mathbf{4 , 1 7 \%}$ & $2,50 \%$ & $2,50 \%$ & $1,67 \%$ & $\mathbf{7 , 5 0 \%}$ & $4,17 \%$ \\
B + & $\mathbf{5 , 1 3 \%}$ & $0,96 \%$ & $1,28 \%$ & $1,92 \%$ & $\mathbf{5 , 1 3 \%}$ & $2,56 \%$ \\
\hline
\end{tabular}

A Tabela 13 apresenta o percentual de factibilidade de cada conjunto de teste. Vale lembrar aqui que na classe $\mathrm{A}+$, apenas $90 \%$ das instâncias são factíveis sem a utilização de horas extras. A heurística LPF, para as formulações SPL e Agregada obteve o mesmo percentual de factibilidade. A heurística RF1 com a formulação Agregada obteve melhores resultados em termos de factibilidade do que as outras formulações, enquanto que para as heurísticas RF2 e RF3, a média geral de factibilidade foi melhor quando utilizamos a formulação SPL.

Os percentuais de factibilidade obtidos pelas heurísticas RF1, RF2 e RF3, para a classe $\mathrm{B}+$ foram reduzidos, o que demonstra que os métodos tiveram dificuldades em encontrar soluções sem utilização de horas extras, quando considera que os tempos das preparações são positivos. Um motivo para a qualidade dos resultados apresentados nas Tabelas 9 e 10, principalmente para a classe $\mathrm{B}+$, é a alta utilização de horas extras nas soluções obtidas. A utilização de horas extras leva a um aumento do custo total, e consequentemente, a um desvio percentual elevado, o que demonstra que estas abordagens não foram eficientes para este conjunto de teste.

Apesar da formulação Agregada ter obtido tempos computacionais melhores, como apresentado na Tabela 11, as abordagens baseadas em relaxação linear obtiveram soluções de melhor qualidade quando utilizamos a formulação SPL (ver Tabelas 9 e 10). Porém, a heurística RF2 obteve melhores resultados com a formulação Mista do que os obtidos com outras formulações. Desta forma, optamos pela formulação SPL para as heurísticas 
Tabela 13: Percentual de factibilidade - Heurísticas baseadas em relaxação linear

\begin{tabular}{||c||c|r|r||r|r|r||}
\hline \multicolumn{1}{||c||}{} & \multicolumn{3}{c||}{ LPF } & \multicolumn{3}{c||}{ RF1 } \\
\hline Classe & SPL & Agregada & Mista & SPL & Agregada & Mista \\
\hline A + & $\mathbf{9 0 , 0 0 \%}$ & $\mathbf{9 0 , 0 0 \%}$ & $\mathbf{9 0 , 0 0 \%}$ & $87,50 \%$ & $\mathbf{9 0 , 0 0 \%}$ & $\mathbf{9 0 , 0 0 \%}$ \\
B + & $\mathbf{9 9 , 6 8 \%}$ & $\mathbf{9 9 , 6 8 \%}$ & $99,36 \%$ & $58,33 \%$ & $\mathbf{6 5 , 7 1 \%}$ & $64,10 \%$ \\
\hline \hline \multicolumn{1}{||}{} & \multicolumn{3}{c||}{ RF2 } & \multicolumn{3}{c||}{ RF3 } \\
\hline Classe & SPL & Agregada & Mista & SPL & Agregada & Mista \\
\hline A + & $\mathbf{9 0 , 0 0 \%}$ & $89,17 \%$ & $89,17 \%$ & $89,17 \%$ & $\mathbf{9 0 , 0 0 \%}$ & $\mathbf{9 0 , 0 0 \%}$ \\
B + & $\mathbf{5 5 , 7 7 \%}$ & $53,85 \%$ & $\mathbf{5 5 , 7 7 \%}$ & $\mathbf{7 4 , 6 8 \%}$ & $65,06 \%$ & $64,42 \%$ \\
\hline
\end{tabular}

LPF, RF1 e RF3 e, para a heurística RF2, optamos pela formulação Mista.

\section{Heurísticas do tipo fix-and-optimize}

As Tabelas 14 e 15 apresentam os desvios percentuais e desvios padrões para as soluções obtidas pelas heurísticas do tipo fix-and-optimize. As heurísticas com a formulação SPL obtiveram resultados melhores em todos os testes, no caso do desvio percentual, e em quase todos os resultados, no caso do desvio padrão.

Tabela 14: Desvio percentual médio - Heurísticas do tipo fix-and-optimize

\begin{tabular}{||c||c|r|c||c|r|r||}
\hline \multicolumn{1}{||}{} & \multicolumn{3}{c||}{ FO-P1 } & \multicolumn{3}{c||}{ FO-P2 } \\
\hline Classe & SPL & Agregada & Mista & SPL & Agregada & Mista \\
\hline A + & $\mathbf{2 , 9 4 \%}$ & $4,64 \%$ & $4,48 \%$ & $\mathbf{1 , 3 7 \%}$ & $3,16 \%$ & $3,05 \%$ \\
B + & $\mathbf{2 , 7 4 \%}$ & $4,06 \%$ & $4,09 \%$ & $\mathbf{0 , 9 1 \%}$ & $2,32 \%$ & $2,47 \%$ \\
\hline \hline \multicolumn{1}{||}{} & \multicolumn{3}{c||}{ FO-P3 } & \multicolumn{3}{c||}{ FO-P4 } \\
\hline Classe & SPL & Agregada & Mista & SPL & Agregada & Mista \\
\hline A + & $\mathbf{1 , 0 8 \%}$ & $2,75 \%$ & $2,77 \%$ & $\mathbf{0 , 9 6 \%}$ & $2,59 \%$ & $2,49 \%$ \\
B + & $\mathbf{0 , 6 6 \%}$ & $2,16 \%$ & $2,20 \%$ & $\mathbf{0 , 4 0 \%}$ & $1,82 \%$ & $1,87 \%$ \\
\hline
\end{tabular}

Tabela 15: Desvio padrão percentual - Heurísticas do tipo fix-and-optimize

\begin{tabular}{||c||c|r|r||c|r|r||}
\hline \multicolumn{1}{||c||}{} & \multicolumn{3}{c||}{ FO-P1 } & \multicolumn{3}{c||}{ FO-P2 } \\
\hline Classe & SPL & Agregada & Mista & SPL & Agregada & Mista \\
\hline A + & $\mathbf{2 , 3 4 \%}$ & $2,63 \%$ & $2,46 \%$ & $\mathbf{1 , 6 8 \%}$ & $2,22 \%$ & $2,14 \%$ \\
B + & $2,30 \%$ & $\mathbf{2 , 1 1 \%}$ & $2,21 \%$ & $\mathbf{2 , 0 7 \%}$ & $2,19 \%$ & $2,31 \%$ \\
\hline \hline \multicolumn{1}{||}{} & \multicolumn{3}{c||}{ FO-P3 } & \multicolumn{3}{c||}{ FO-P4 } \\
\hline Classe & SPL & Agregada & Mista & SPL & Agregada & Mista \\
\hline A + & $\mathbf{1 , 6 5 \%}$ & $1,96 \%$ & $1,98 \%$ & $\mathbf{1 , 5 4 \%}$ & $1,81 \%$ & $1,72 \%$ \\
B + & $\mathbf{1 , 8 0 \%}$ & $2,06 \%$ & $2,08 \%$ & $\mathbf{1 , 7 3 \%}$ & $1,90 \%$ & $1,91 \%$ \\
\hline
\end{tabular}

Nos tempos computacionais, no entanto, as heurísticas com a formulação Agregada apresentaram os menores tempos computacionais em todos os casos de teste, como apresentado na Tabela 16. As heurísticas com a formulação SPL demandaram maiores tempos computacionais, isso pode ter ocorrido devido ao número de variáveis e restrições desta formulação. 
Tabela 16: Tempo computacional médio - Heurísticas do tipo fix-and-optimize

\begin{tabular}{||c||c|r|r||r|r|r||}
\hline \multicolumn{1}{|c||}{} & \multicolumn{3}{c||}{ FO-P1 } & \multicolumn{3}{c||}{ FO-P2 } \\
\hline Classe & SPL & Agregada & Mista & SPL & Agregada & Mista \\
\hline A + & 12,38 & $\mathbf{1 , 7 2}$ & 4,41 & 23,15 & $\mathbf{5 , 2 6}$ & 12,10 \\
B + & 12,93 & $\mathbf{1 , 8 1}$ & 4,65 & 22,76 & $\mathbf{5 , 5 3}$ & 12,57 \\
\hline \hline \multicolumn{1}{||}{} & \multicolumn{3}{c||}{ FO-P3 } & \multicolumn{3}{c||}{ FO-P4 } \\
\hline Classe & SPL & Agregada & Mista & SPL & Agregada & Mista \\
\hline A + & 31,46 & $\mathbf{5 , 7 3}$ & 13,27 & 26,98 & $\mathbf{5 , 6 6}$ & 12,57 \\
B + & 31,41 & $\mathbf{5 , 9 8}$ & 13,93 & 27,13 & $\mathbf{5 , 8 6}$ & 13,42 \\
\hline
\end{tabular}

O percentual de melhoria, neste tipo de abordagem, foi melhor do que para as heurísticas anteriores como apresentado na Tabela 17, porém, não apresentam desempenho na obtenção de soluções melhores. Podemos verificar que as heurísticas com a formulação SPL obtiveram melhores resultados em todos os casos.

Tabela 17: Percentual de melhoria - Heurísticas do tipo fix-and-optimize

\begin{tabular}{||c||c|r|c||r|r|c||}
\hline \multicolumn{1}{||c||}{} & \multicolumn{3}{c||}{ FO-P1 } & \multicolumn{3}{c||}{ FO-P2 } \\
\hline Classe & SPL & Agregada & Mista & SPL & Agregada & Mista \\
\hline A + & $\mathbf{6 , 6 7 \%}$ & $0,83 \%$ & $0,83 \%$ & $\mathbf{1 6 , 6 7 \%}$ & $3,33 \%$ & $3,33 \%$ \\
B + & $\mathbf{8 , 3 3 \%}$ & $2,56 \%$ & $2,88 \%$ & $\mathbf{2 8 , 2 1 \%}$ & $10,90 \%$ & $9,62 \%$ \\
\hline \hline \multicolumn{1}{||}{} & \multicolumn{3}{c||}{ FO-P3 } & \multicolumn{3}{c||}{ FO-P4 } \\
\hline Classe & SPL & Agregada & Mista & SPL & Agregada & Mista \\
\hline A + & $\mathbf{2 5 , 0 0 \%}$ & $5,83 \%$ & $5,83 \%$ & $\mathbf{2 6 , 6 7 \%}$ & $4,17 \%$ & $3,33 \%$ \\
B+ & $\mathbf{3 3 , 0 1 \%}$ & $12,82 \%$ & $12,82 \%$ & $\mathbf{3 7 , 5 0 \%}$ & $14,74 \%$ & $14,74 \%$ \\
\hline
\end{tabular}

As heurísticas fix-and-optimize, para todas formulações, obtiveram bons resultados quanto ao percentual de factibilidade como mostrado na Tabela 18, ou seja, conseguem soluções sem a utilização de horas extras para quase todas as instâncias. Não houve expressiva variação nos resultados das heurísticas para as formulações, o que indica que esta métrica não influencia a escolha da formulação mais adequada para a abordagem fix-and-optimize.

As heurísticas com a formulação SPL apresentaram melhores resultados quanto a qualidade de solução e percentual de melhoria, enquanto as heurísticas com a formulação Agregada apresentaram menores tempos computacionais. Deste modo, a formulação SPL foi escolhida para as heurísticas fix-and-optimize, pois os tempos computacionais foram muitas vezes menores que o tempo limite. Convém observar que as heurísticas com a formulação SPL apresentaram os maiores tempos computacionais, como apresentado na Tabela 16, porém nas outras métricas apresentaram desempenho melhor, o que justifica a escolha. 
Tabela 18: Percentual de factibilidade - Heurísticas do tipo fix-and-optimize

\begin{tabular}{||c||c|r|r||r|r|r||}
\multicolumn{1}{||c||}{} & \multicolumn{3}{c||}{ FO-P1 } & \multicolumn{3}{c||}{ FO-P2 } \\
\hline Classe & SPL & Agregada & \multicolumn{1}{c|}{ Mista } & SPL & Agregada & Mista \\
A + & $\mathbf{9 0 , 0 0 \%}$ & $89,17 \%$ & $\mathbf{9 0 , 0 0 \%}$ & $\mathbf{9 0 , 0 0 \%}$ & $\mathbf{9 0 , 0 0 \%}$ & $\mathbf{9 0 , 0 0 \%}$ \\
B + & $99,36 \%$ & $\mathbf{1 0 0 , 0 0 \%}$ & $\mathbf{1 0 0 , 0 0 \%}$ & $\mathbf{9 9 , 6 8 \%}$ & $\mathbf{9 9 , 6 8 \%}$ & $\mathbf{9 9 , 6 8 \%}$ \\
\hline \hline \multicolumn{1}{||c||}{} & \multicolumn{3}{|c||}{ FO-P3 } & \multicolumn{3}{c||}{ FO-P4 } \\
\hline Classe & SPL & Agregada & Mista & SPL & Agregada & Mista \\
\hline A + & $\mathbf{9 0 , 0 0 \%}$ & $\mathbf{9 0 , 0 0 \%}$ & $\mathbf{9 0 , 0 0 \%}$ & $\mathbf{9 0 , 0 0 \%}$ & $\mathbf{9 0 , 0 0 \%}$ & $\mathbf{9 0 , 0 0 \%}$ \\
B + & $99,68 \%$ & $\mathbf{1 0 0 , 0 0 \%}$ & $99,68 \%$ & $\mathbf{1 0 0 , 0 0 \%}$ & $99,68 \%$ & $99,68 \%$ \\
\hline
\end{tabular}

\section{Metaheurística algoritmo de abelhas}

A Tabela 19 apresenta os desvios resultantes dos testes computacionais com a metaheurística algoritmo de abelhas (BA). Como podemos verificar na tabela, a metaheurística com a formulação Agregada obteve os melhores desempenhos médios, sendo superior às demais formulações nas duas classes. A metaheurística com a formulação SPL obteve melhores resultados do que com a formulação Mista, considerando o desvio percentual médio, no entanto, ao considerarmos o desvio padrão médio, a metaheurística com a formulação Mista foi melhor. Portanto, a metaheurística com a formulação SPL obtém melhores resultados gerais que a metaheurística com a formulação Mista, mas a formulação Mista é mais robusta que a formulação SPL.

Tabela 19: Desvio percentual médio e desvio padrão percentual - Metaheurística algoritmo de abelhas

\begin{tabular}{|c|c|c|c|c|c|c|}
\hline & \multicolumn{3}{|c|}{ Desvio percentual médio } & \multicolumn{3}{|c|}{ Desvio padrão percentual } \\
\hline Classe & SPL & Agregada & Mista & SPL & Agregada & Mista \\
\hline $\mathrm{A}+$ & $6,79 \%$ & $4,06 \%$ & $8,78 \%$ & $4,47 \%$ & $2,19 \%$ & $3,62 \%$ \\
\hline $\mathrm{B}+$ & $8,70 \%$ & $4,05 \%$ & $10,27 \%$ & $7,39 \%$ & $2,27 \%$ & $4,53 \%$ \\
\hline
\end{tabular}

O tempo computacional médio, em segundos, apresentado na Tabela 20, mostra que a metaheurística com a formulação SPL obteve os melhores resultados, ao contrário do que ocorreu com as abordagens anteriores. Isto se deve a forma de busca local implementada, que gera subproblemas mais "apertados" quando utilizamos a formulação SPL. Logo, o subproblema pode ser resolvido mais rapidamente.

Tabela 20: Tempo computacional médio - Metaheurística algoritmo de abelhas

\begin{tabular}{||c||c|r|c||}
\hline Classe & SPL & Agregada & Mista \\
A + & $\mathbf{1 2 9 , 1 3}$ & 141,71 & 144,87 \\
B + & $\mathbf{1 2 1 , 8 9}$ & 139,42 & 141,00 \\
\hline
\end{tabular}


O percentual de melhoria, como pode ser visto na Tabela 21, foi não nulo somente para a metaheurística com a formulação Agregada em todas as classes e para a metaheurística com a formulação SPL na classe $\mathrm{B}+$, o que mostra a dificuldade da metaheurística, para qualquer formulação, em melhorar as melhores soluções. Podemos verificar na mesma tabela, que o percentual de factibilidade variou pouco, gerando no máximo 5 soluções que utilizam horas extras na classe $\mathrm{B}+$, considerando as 312 instâncias multiplicado pelas 5 execuções de cada instância. Com uma variação tão pequena, esta medida de desempenho não será considerada na escolha da formulação.

Tabela 21: Percentual de melhoria e percentual de factibilidade - Metaheurística algoritmo de abelhas

\begin{tabular}{||c||c|r|r||r|r|r||}
\hline \multicolumn{1}{||c||}{} & \multicolumn{3}{c||}{ Percentual de melhoria } & \multicolumn{3}{c||}{ Percentual de factibilidade } \\
\hline Classe & SPL & Agregada & Mista & SPL & Agregada & Mista \\
\hline A + & $0,00 \%$ & $\mathbf{3 , 5 0 \%}$ & $0,00 \%$ & $\mathbf{8 9 , 8 3 \%}$ & $89,50 \%$ & $\mathbf{8 9 , 8 3 \%}$ \\
B + & $0,26 \%$ & $\mathbf{3 , 0 1 \%}$ & $0,00 \%$ & $98,85 \%$ & $\mathbf{9 9 , 1 7 \%}$ & $\mathbf{9 9 , 1 7 \%}$ \\
\hline
\end{tabular}

Novamente temos que decidir qual a melhor formulação para a metaheurística, considerando o tempo computacional médio e a qualidade de solução. Com a formulação Agregada, a metaheurística obteve melhores resultados quanto a qualidade e com a formulação SPL, a metaheurística obteve melhores tempos médios. Como nas decisões anteriores, optamos pela melhor qualidade dentro do limite de tempo estipulado, ou seja, a metaheurística com a formulação Agregada foi escolhida como mais adequada para a metaheurística algoritmo de abelhas.

\section{Heurísticas híbridas}

As Tabelas 22 e 23 apresentam os desvios percentuais e a variação do desvio padrão para cada caso de teste. O desvio percentual demonstra que a primeira abordagem híbrida (BFO1) gera melhores resultados quando utilizamos a formulação Agregada. Já a segunda heurística híbrida (BFO2), apresenta melhores resultados quando utilizamos a formulação SPL, independente da partição que foi utilizada. No caso do desvio padrão, as mesmas regras se estabelecem.

No tempo computacional médio, apresentado na Tabela 24, os melhores resultados foram obtidos com a formulação Agregada. No caso da heurística BFO2, a diferença para as demais formulações foi maior, passando de duas vezes em todos os casos.

O percentual de melhoria foi maior que o demonstrado pelas abordagens anteriores, chegando a mais de $50 \%$ das instâncias no caso da heurística BFO2-P3 resolvendo a classe de testes $\mathrm{B}+$, como pode ser visto na Tabela 25. A formulação SPL foi superior as demais, 
Tabela 22: Desvio percentual médio - Heurísticas híbridas

\begin{tabular}{||c||c|r|r||r|r|r||}
\hline \multicolumn{1}{||}{} & \multicolumn{3}{c||}{ BFO1 } & \multicolumn{3}{c||}{ BFO2-P1 } \\
\hline Classe & SPL & Agregada & Mista & SPL & Agregada & Mista \\
\hline A + & $1,77 \%$ & $\mathbf{1 , 3 7 \%}$ & $2,43 \%$ & $\mathbf{2 , 2 8 \%}$ & $3,86 \%$ & $3,87 \%$ \\
B + & $2,61 \%$ & $\mathbf{0 , 7 1 \%}$ & $2,73 \%$ & $\mathbf{1 , 7 9 \%}$ & $3,28 \%$ & $3,20 \%$ \\
\hline \hline \multicolumn{1}{||}{} & \multicolumn{3}{c||}{ BFO2-P2 } & \multicolumn{3}{c||}{ BFO2-P3 } \\
\hline Classe & SPL & Agregada & Mista & SPL & Agregada & Mista \\
\hline A + & $\mathbf{0 , 5 2 \%}$ & $2,11 \%$ & $2,07 \%$ & $\mathbf{0 , 0 9 \%}$ & $1,69 \%$ & $1,66 \%$ \\
B + & $\mathbf{- 0 , 1 3 \%}$ & $1,31 \%$ & $1,35 \%$ & $\mathbf{- 0 , 4 9 \%}$ & $0,90 \%$ & $0,93 \%$ \\
\hline
\end{tabular}

Tabela 23: Desvio padrão percentual - Heurísticas híbridas

\begin{tabular}{|c|c|c|c|c|c|c|}
\hline & \multicolumn{3}{|c|}{$\overline{\mathrm{BFO} 1}$} & \multicolumn{3}{|c|}{ BFO2-P1 } \\
\hline Classe & SPL & Agregada & Mista & SPL & Agregada & Mista \\
\hline $\mathrm{A}+$ & $2,51 \%$ & $1,57 \%$ & $2,02 \%$ & $2,22 \%$ & $2,51 \%$ & $2,53 \%$ \\
\hline $\mathrm{B}+$ & $4,46 \%$ & $1,90 \%$ & $2,36 \%$ & $2,04 \%$ & $2,21 \%$ & $2,20 \%$ \\
\hline & \multicolumn{3}{|c|}{ BFO2-P2 } & \multicolumn{3}{|c|}{ BFO2-P3 } \\
\hline Classe & SPL & Agregada & Mista & SPL & Agregada & Mista \\
\hline $\mathrm{A}+$ & $1,23 \%$ & $1,64 \%$ & $1,62 \%$ & $1,23 \%$ & $1,63 \%$ & $1,62 \%$ \\
\hline $\mathrm{B}+$ & $1,66 \%$ & $1,92 \%$ & $1,92 \%$ & $1,60 \%$ & $1,87 \%$ & $1,87 \%$ \\
\hline
\end{tabular}

Tabela 24: Tempo computacional médio - Heurísticas híbridas

\begin{tabular}{||c||c|r|c||c|r|r||}
\hline \multicolumn{1}{||c||}{} & \multicolumn{3}{c||}{ BFO1 } & \multicolumn{3}{c||}{ BFO2-P1 } \\
\hline Classe & SPL & Agregada & Mista & SPL & Agregada & Mista \\
\hline A + & 589,01 & $\mathbf{5 1 1 , 9 4}$ & 593,19 & 137,12 & $\mathbf{2 1 , 1 3}$ & 51,15 \\
B + & 585,01 & $\mathbf{5 2 3 , 1 5}$ & 600,99 & 156,72 & $\mathbf{2 3 , 9 2}$ & 57,85 \\
\hline \hline \multicolumn{1}{|||}{} & \multicolumn{3}{c||}{ BFO2-P2 } & \multicolumn{3}{c||}{ BFO2-P3 } \\
\hline Classe & SPL & Agregada & Mista & SPL & Agregada & Mista \\
\hline A + & 208,14 & $\mathbf{4 8 , 1 3}$ & 116,77 & 267,15 & $\mathbf{5 3 , 1 6}$ & 131,00 \\
B + & 214,58 & $\mathbf{5 1 , 8 7}$ & 120,64 & 269,79 & $\mathbf{5 6 , 0 3}$ & 134,38 \\
\hline
\end{tabular}

obtendo percentuais maiores em quase todos os casos. A exceção ocorreu na resolução da classe $\mathrm{B}+$ pela heurística BFO1. Neste caso, a heurística híbrida BFO1 com a formulação Agregada foi melhor.

Tabela 25: Percentual de melhoria - Heurísticas híbridas

\begin{tabular}{||c||c|r|r||r|r|c||}
\hline \multicolumn{1}{||c||}{} & \multicolumn{3}{c||}{ BFO1 } & \multicolumn{3}{c||}{ BFO2-P1 } \\
\hline Classe & SPL & Agregada & Mista & SPL & Agregada & Mista \\
\hline A + & $\mathbf{2 0 , 3 3 \%}$ & $16,00 \%$ & $7,17 \%$ & $\mathbf{9 , 0 0 \%}$ & $4,50 \%$ & $3,83 \%$ \\
B + & $21,09 \%$ & $\mathbf{3 0 , 1 3 \%}$ & $8,65 \%$ & $\mathbf{1 4 , 3 6 \%}$ & $4,49 \%$ & $4,62 \%$ \\
\hline \hline \multicolumn{1}{||c||}{} & \multicolumn{3}{c||}{ BFO2-P2 } & \multicolumn{3}{c||}{ BFO2-P3 } \\
\hline Classe & SPL & Agregada & Mista & SPL & Agregada & Mista \\
\hline A + & $\mathbf{3 0 , 5 0 \%}$ & $8,33 \%$ & $8,83 \%$ & $\mathbf{4 3 , 8 3 \%}$ & $10,50 \%$ & $10,33 \%$ \\
B + & $\mathbf{4 6 , 8 6 \%}$ & $19,94 \%$ & $20,32 \%$ & $\mathbf{5 7 , 9 5 \%}$ & $26,03 \%$ & $26,09 \%$ \\
\hline
\end{tabular}

O percentual de factibilidade foi geralmente bem próximo à factibilidade máxima de cada classe de testes, sendo que em nenhum caso esta diferença foi superior a $1,5 \%$.

A formulação Agregada foi escolhida como mais adequada para a heurística BFO1, por 
Tabela 26: Percentual de factibilidade - Heurísticas híbridas

\begin{tabular}{||c||c|r|c||r|r|c||}
\hline \multicolumn{1}{||}{} & \multicolumn{3}{c||}{ BFO1 } & \multicolumn{3}{c||}{ BFO2-P1 } \\
\hline Classe & SPL & Agregada & Mista & SPL & Agregada & Mista \\
\hline A + & $89,67 \%$ & $\mathbf{9 0 , 0 0 \%}$ & $89,83 \%$ & $89,83 \%$ & $\mathbf{9 0 , 0 0 \%}$ & $\mathbf{9 0 , 0 0 \%}$ \\
B + & $99,36 \%$ & $98,97 \%$ & $\mathbf{9 9 , 6 2 \%}$ & $\mathbf{9 9 , 8 7 \%}$ & $\mathbf{9 9 , 8 7 \%}$ & $99,68 \%$ \\
\hline \hline \multicolumn{1}{||}{} & \multicolumn{3}{|c||}{ BFO2-P2 } & \multicolumn{3}{c||}{ BFO2-P3 } \\
\hline Classe & SPL & Agregada & Mista & SPL & Agregada & Mista \\
\hline A + & $89,83 \%$ & $89,83 \%$ & $\mathbf{9 0 , 0 0 \%}$ & $\mathbf{9 0 , 0 0 \%}$ & $\mathbf{9 0 , 0 0 \%}$ & $\mathbf{9 0 , 0 0 \%}$ \\
B + & $99,29 \%$ & $99,49 \%$ & $\mathbf{9 9 , 6 2 \%}$ & $\mathbf{9 9 , 8 1 \%}$ & $99,55 \%$ & $99,55 \%$ \\
\hline
\end{tabular}

obter melhores soluções, dentro do limite de tempo estipulado, de forma mais robusta, ou seja, com desvio padrão menor e com percentual médio de otimalidade maior que as demais formulações. A formulação SPL foi escolhida para a abordagem BFO2 pelos mesmos motivos.

\subsubsection{Análise dos resultados com foco nas abordagens de solução}

Com a análise focada na formulação, definimos as melhores formulações para cada tipo de abordagem de solução. A formulação SPL obteve melhores resultados para as abordagens LPF, RF1, RF3, FO-P1, FO-P2, FO-P3, FO-P4, BFO2-P1, BFO2-P2 e BFO2-P3. A formulação Agregada foi escolhida para as heurísticas BA e BFO1. Já a formulação Mista foi escolhida para a abordagem RF2.

O gráfico apresentado na Figura 20 mostra a dispersão dos resultados médios das heurísticas com as formulações escolhidas. As médias apresentadas neste gráfico se referem a média aritmética dos valores obtidos nas duas classes de teste abordadas (classes $\mathrm{A}+$ e $\mathrm{B}+$ ). Para cada ponto, no Eixo $\mathrm{X}$ podemos verificar o tempo computacional médio (em segundos), enquanto que no Eixo Y obtemos o desvio percentual médio. As linhas verticais representam a faixa de erro, que neste caso é obtida pela média do desvio padrão das classes $\mathrm{A}+$ e $\mathrm{B}+$ das soluções heurísticas. A linha de erro se estende do valor da média menos o desvio padrão até o valor da média mais o desvio padrão. Desta forma, obtemos a faixa de qualidade de soluções que cada heurística obterá em $68 \%$ dos casos, de acordo com a distribuição normal (DEGROOT; SCHERVISH, 2002). Se estendermos a faixa de erros com o dobro do desvio padrão, como apresentado na Figura 21, temos $95 \%$ dos casos ocorrendo dentro desta faixa. Cabe lembrar que o eixo X de todos os gráficos se encontram em escala logarítmica. Por exemplo, na Figura 20, para a heurística RF2, o desvio percentual médio é de 102,57\% e o desvio padrão médio de 198,93\%. Por isso, a faixa de erros se extende do valor da média do desvio percentual menos o desvio padrão $(-96,36 \%)$ até o valor da soma destes desvios (301,50\%). 


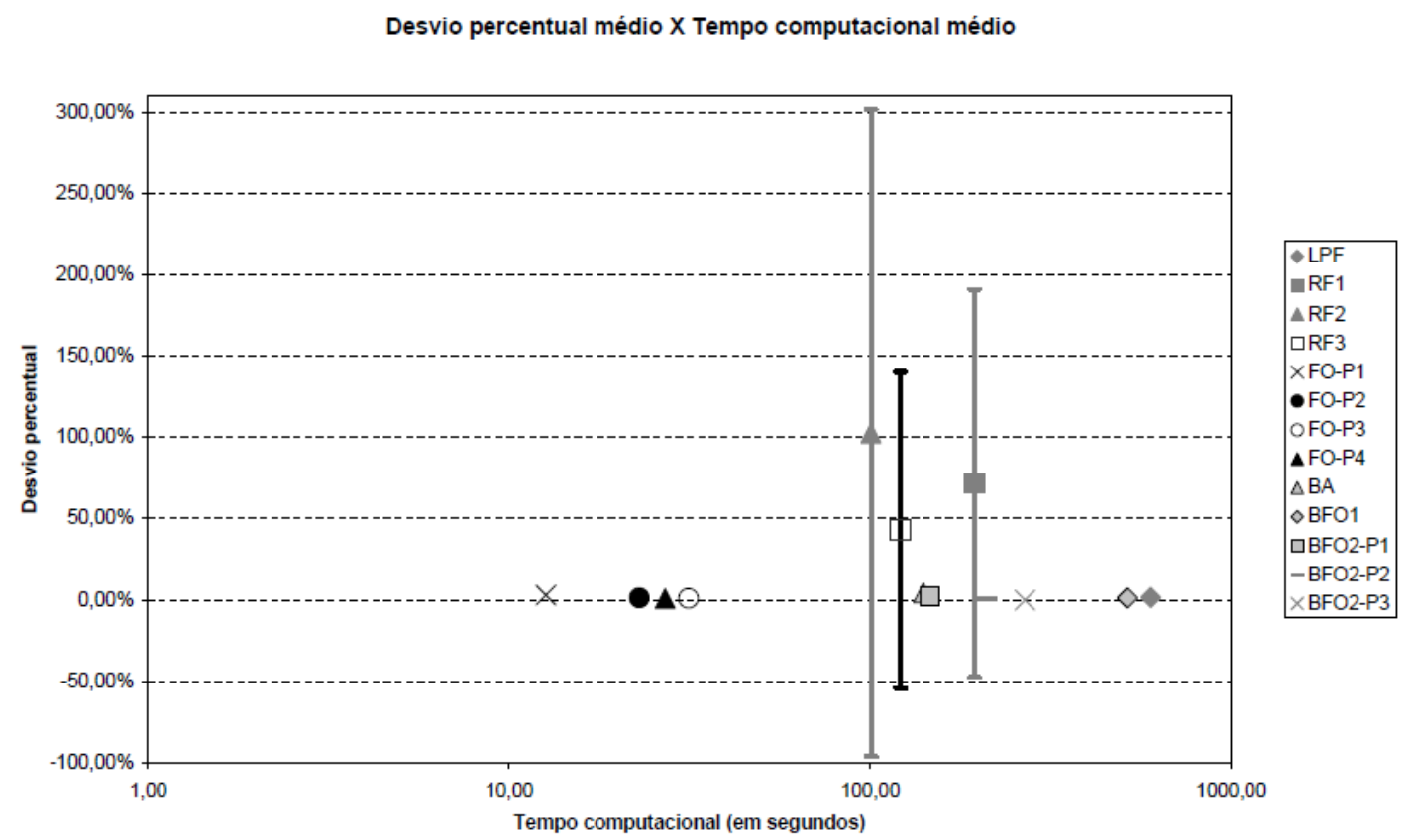

Figura 20: Gráfico de qualidade de solução com barra de erros igual ao desvio padrão.

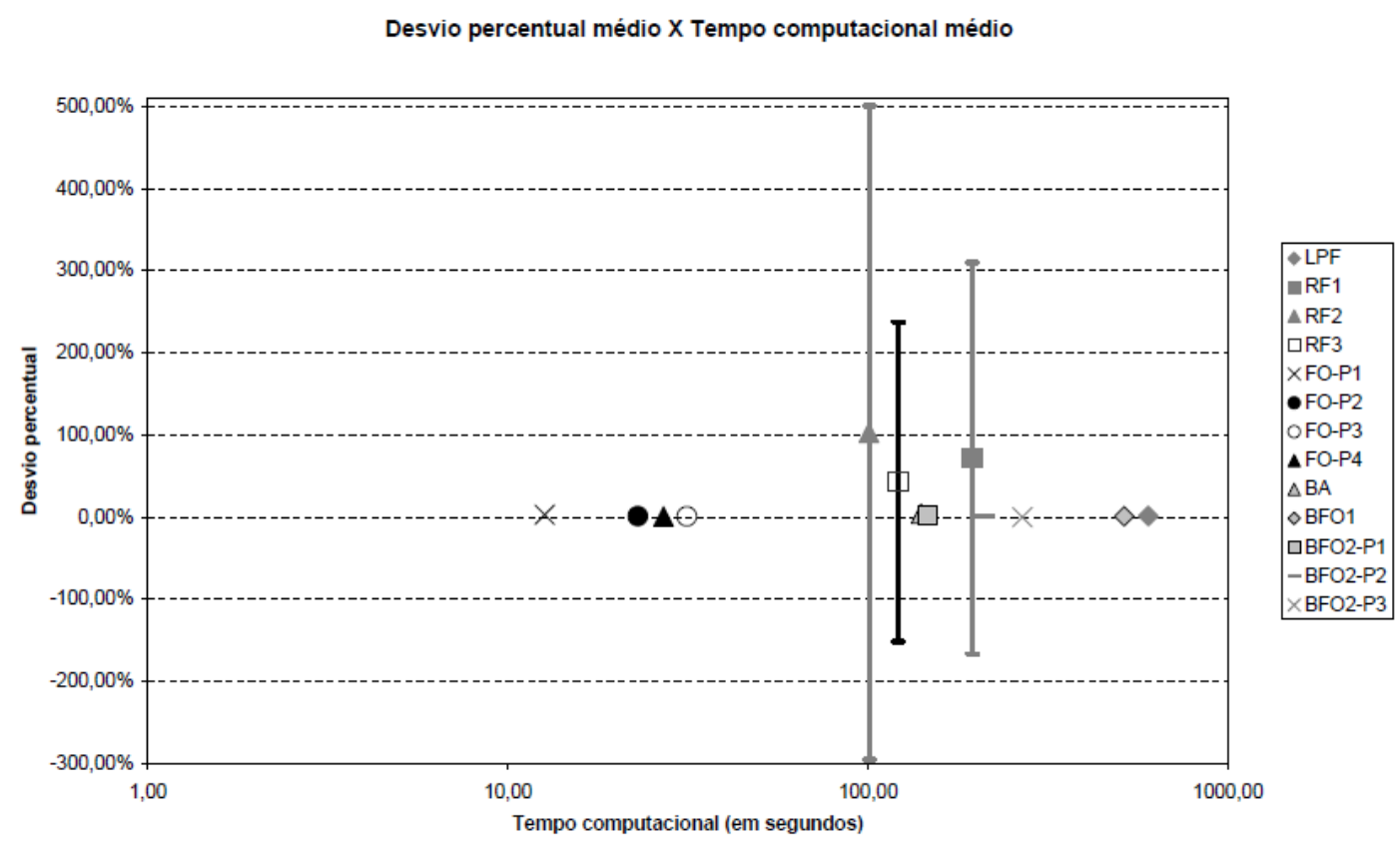

Figura 21: Gráfico de qualidade de solução com barra de erros igual ao dobro do desvio padrão.

Como as heurísticas RF1, RF2 e RF3 obtiveram resultados muito piores do que as demais heurísticas, neste conjunto de testes, a visualização do desempenho das demais abordagens nos gráficos das Figuras 20 e 21 foi comprometido. Por este motivo, optamos por gerar os gráficos apresentados nas Figuras 22 e 23, onde estas heurísticas foram omitidas da comparação. 


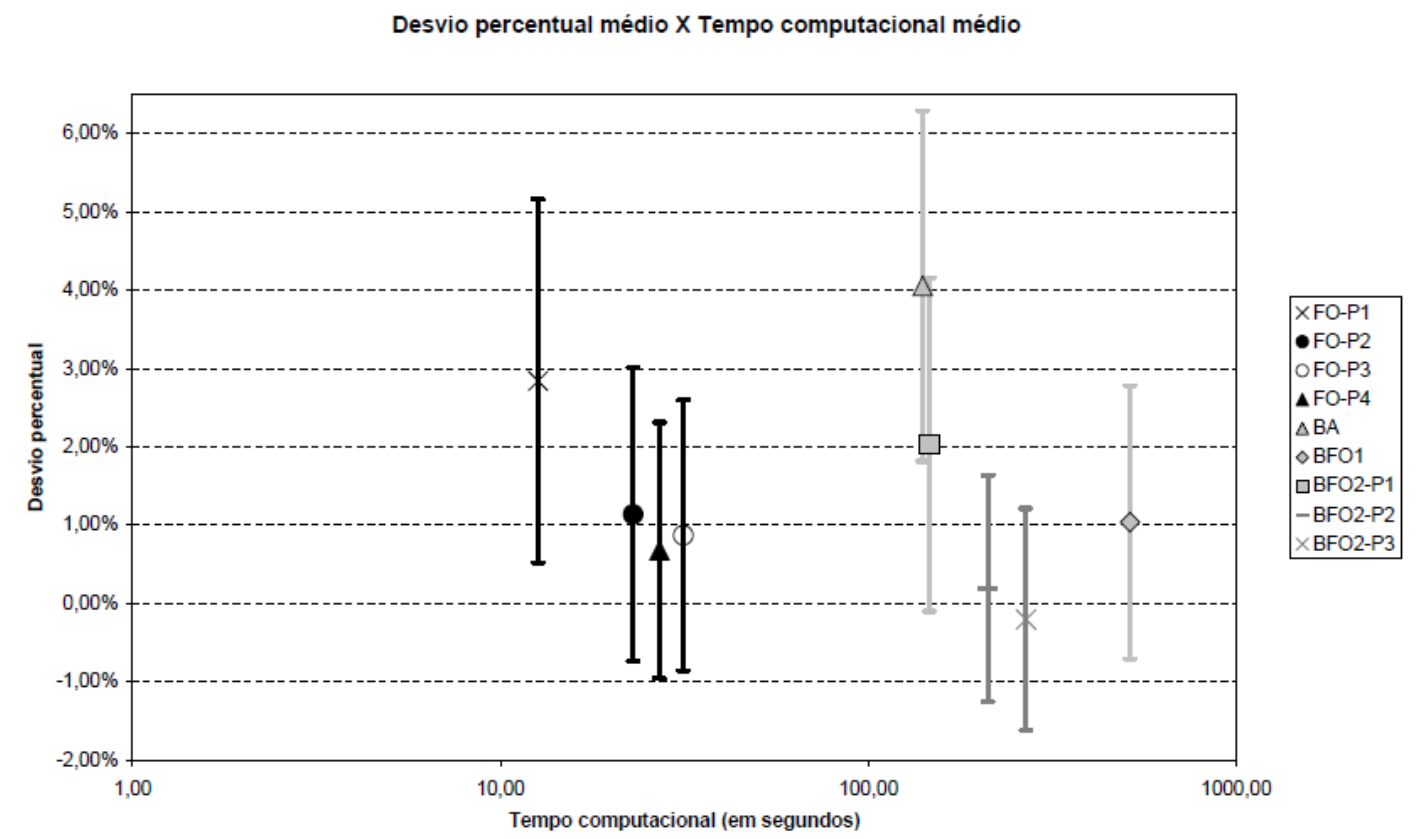

Figura 22: Gráfico de qualidade de solução com barra de erros igual ao desvio padrão.

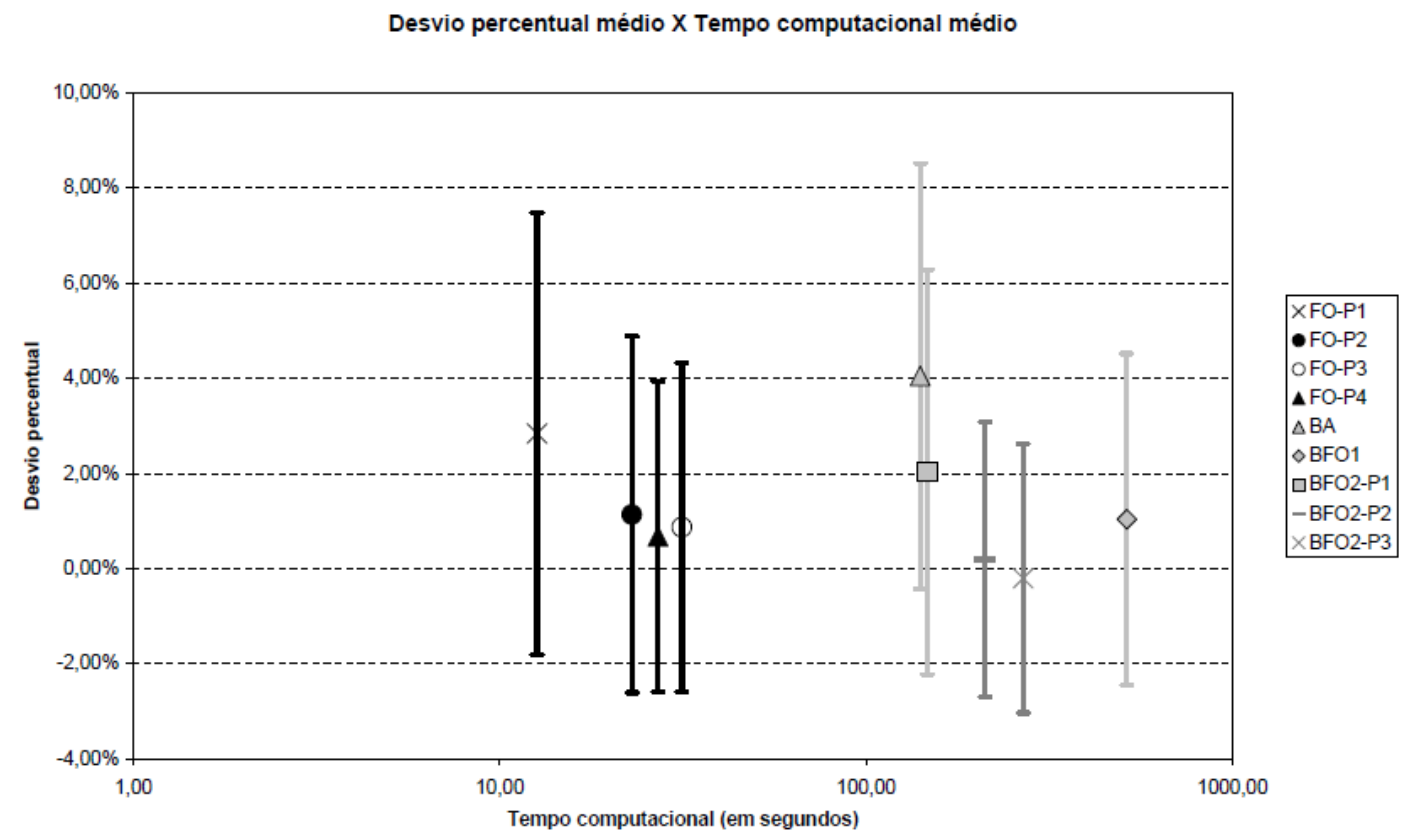

Figura 23: Gráfico de qualidade de solução com barra de erros igual ao dobro do desvio padrão.

Com o auxílio das Figuras 22 e 23, podemos verificar que ao avaliar o tempo computacional, as heurísticas do tipo fix-and-optimize(FO-P1, FO-P2, FO-P3 e FO-P4) foram as mais eficientes, seguidas pela metaheurística e, por último, os métodos híbridos. Em relação a qualidade de solução, a heurística BFO2-P3 é a melhor, dominando todas as demais heurísticas e obtendo soluções em média $0,20 \%$ melhores que o limitante supe- 
rior utilizado. Outras duas abordagens se destacam, as abordagens FO-P4 e BFO2-P2. Sendo que a abordagem FO-P4 tem tempo computacional da ordem de 10 vezes menor que as abordagens BFO2-P2 e BFO2-P3 e possui qualidade inferior somente a estas duas abordagens.

O gráfico da Figura 24 apresenta o percentual médio de otimalidade obtido em cada abordagem de solução. Observe que as três abordagens que obtiveram melhor qualidade de solução (FO-P4, BFO2-P2 e BFO2-P3), também geraram maior percentual de melhoria. A abordagem de solução BFO2-P3 obteve os melhores resultados, neste conjunto de testes, seguida das heurísticas BFO2-P3 e FO-P4.

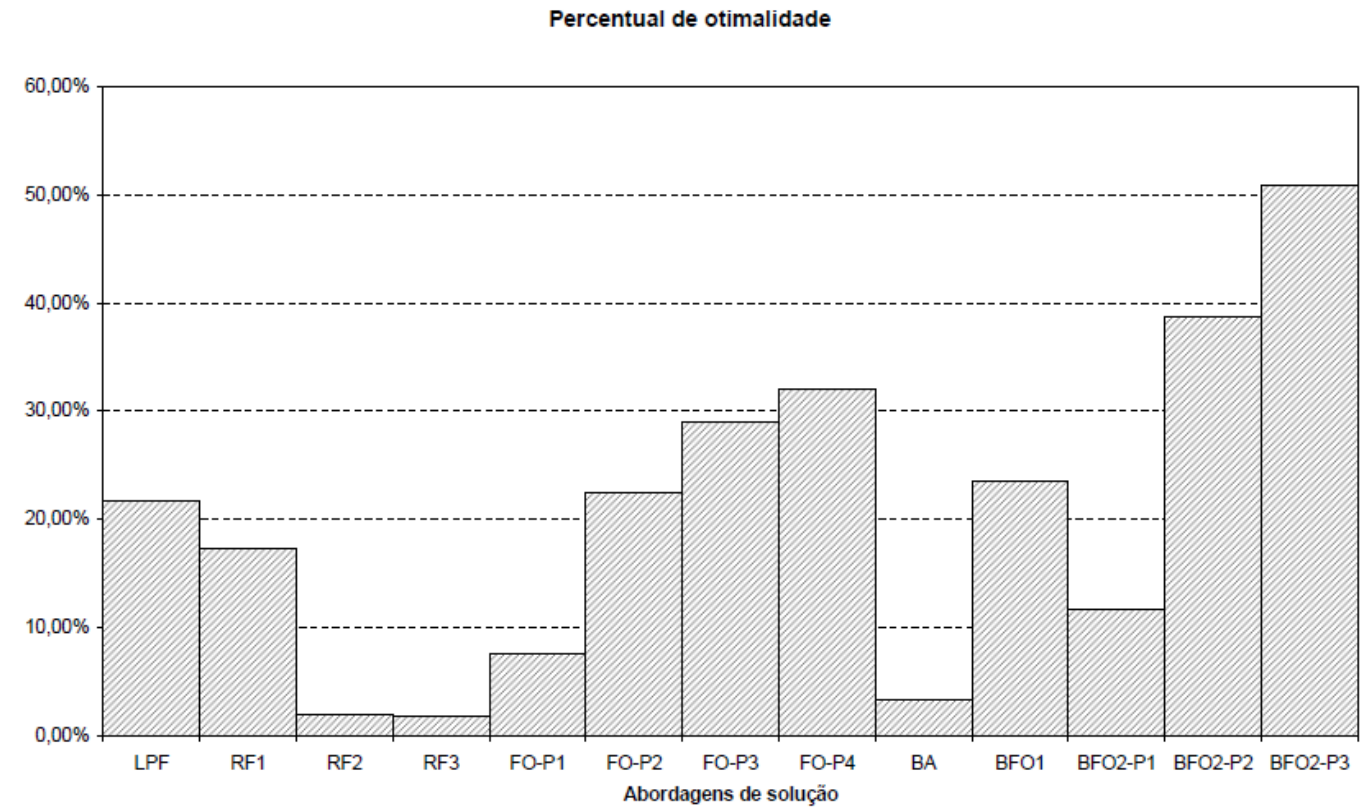

Figura 24: Gráfico de otimalidade média.

As heurísticas híbridas se mostraram eficientes, pois obtiveram resultados de alta qualidade quando observamos o desvio percentual, desvio padrão e percentual de melhoria, mesmo necessitando de maior tempo computacional médio. A heurística FO-P4 também se apresenta como um bom método, caso o tempo para a obtenção das solução seja menor que o estipulado para estes testes, pois também obteve soluções de boa qualidade.

\subsubsection{Problema de dimensionamento de lotes multiestágio com limitação de capacidade e preservação da preparação}

Da mesma forma que na seção anterior, os resultados computacionais são analisados primeiramente considerando as formulações matemáticas e em seguida analisando as abordagens de solução. Para cada uma das etapas analisadas, os resultados computacionais 
para o problema de dimensionamento de lotes multiestágio com limitação de capacidade e preservação da preparação são apresentados em quatro partes, como feito na análise de resultados do problema anterior. Na primeira parte apresentamos os resultados obtidos pelas heurísticas $L P$-and-fix e relax-and-fix. Na segunda parte os resultados obtidos pelas heurísticas puras do tipo fix-and-optimize são analisados. Na terceira parte apresentamos os resultados obtidos pela metaheurística algoritmo de abelhas e na última parte apresentamos os resultados obtidos pelas heurísticas híbridas.

\subsubsection{Análise dos resultados com foco na formulação utilizada}

\section{Heurísticas baseadas em relaxação linear}

A Tabela 27 apresenta os desvios percentuais médios para as abordagens baseadas em relaxação linear. Como podemos verificar, as heurísticas com a formulação SPL obtiveram melhores resultados gerais, com algumas exceções pontuais. Na Tabela 28 podemos verificar que o desvio padrão percentual apresentado pelas heurísticas com a formulação SPL também foi geralmente menor, sendo superado apenas nas heurísticas LPF, RF2 e RF3 com a formulação Mista, em alguns casos.

Tabela 27: Desvio percentual médio - Heurísticas baseadas em relaxação linear

\begin{tabular}{||c||r|r|r||r|r|r||}
\hline \multicolumn{1}{||c||}{} & \multicolumn{3}{|c||}{ LPF } & \multicolumn{3}{c||}{ RF1 } \\
\hline Classe & SPL & Agregada & Mista & SPL & Agregada & Mista \\
\hline 1 & $1,00 \%$ & $2,06 \%$ & $\mathbf{0 , 8 6 \%}$ & $\mathbf{0 , 0 0 \%}$ & $\mathbf{0 , 0 0 \%}$ & $\mathbf{0 , 0 0 \%}$ \\
2 & $\mathbf{1 , 1 1 \%}$ & $18,44 \%$ & $3,39 \%$ & $\mathbf{0 , 1 2 \%}$ & $0,22 \%$ & $0,22 \%$ \\
3 & $\mathbf{1 , 0 5 \%}$ & $5,84 \%$ & $2,66 \%$ & $\mathbf{0 , 0 5 \%}$ & $0,20 \%$ & $0,20 \%$ \\
4 & $\mathbf{0 , 7 4 \%}$ & $10,94 \%$ & $2,62 \%$ & $\mathbf{0 , 0 6 \%}$ & $0,12 \%$ & $0,12 \%$ \\
5 & $\mathbf{0 , 4 6 \%}$ & $3,39 \%$ & $2,39 \%$ & $\mathbf{0 , 0 6 \%}$ & $0,25 \%$ & $0,26 \%$ \\
6 & $\mathbf{0 , 3 6 \%}$ & $5,69 \%$ & $4,98 \%$ & $\mathbf{0 , 0 6 \%}$ & $0,12 \%$ & $0,16 \%$ \\
\hline \hline \multicolumn{7}{||c|}{ RF2 } \\
\hline Classe & SPL & Agregada & Mista & SPL & Agregada & Mista \\
\hline 1 & $\mathbf{1 , 3 1 \%}$ & $1,43 \%$ & $1,41 \%$ & $\mathbf{0 , 9 0 \%}$ & $1,08 \%$ & $1,01 \%$ \\
2 & $\mathbf{0 , 9 3 \%}$ & $1,80 \%$ & $1,74 \%$ & $\mathbf{0 , 5 8 \%}$ & $1,10 \%$ & $1,10 \%$ \\
3 & $\mathbf{1 , 3 3 \%}$ & $1,78 \%$ & $1,72 \%$ & $\mathbf{1 , 0 9 \%}$ & $1,47 \%$ & $1,47 \%$ \\
4 & $\mathbf{0 , 6 4 \%}$ & $1,60 \%$ & $1,60 \%$ & $\mathbf{0 , 5 5 \%}$ & $1,29 \%$ & $1,34 \%$ \\
5 & $1,46 \%$ & $1,20 \%$ & $\mathbf{1 , 1 7 \%}$ & $\mathbf{1 , 6 0 \%}$ & $1,61 \%$ & $1,62 \%$ \\
6 & $\mathbf{0 , 7 7 \%}$ & $1,05 \%$ & $1,04 \%$ & $\mathbf{0 , 9 1 \%}$ & $1,31 \%$ & $1,30 \%$ \\
\hline
\end{tabular}

Quanto ao tempo computacional, os resultados foram variados, como é apresentado na Tabela 29. Para a heurística RF1, a formulação SPL demonstrou menores tempos computacionais médios. No caso da heurística LPF, os resultados foram bem variados, com leve predominância da formulação SPL. Nas outras duas heurísticas, a formulação agregada demonstrou melhor tempo computacional. 
Tabela 28: Desvio padrão percentual - Heurísticas baseadas em relaxação linear

\begin{tabular}{||c||r|r|r||r|r|r||}
\hline \multicolumn{1}{||}{} & \multicolumn{3}{c||}{ LPF } & \multicolumn{3}{c||}{ RF1 } \\
\hline Classe & SPL & Agregada & \multicolumn{1}{|c|}{ Mista } & SPL & Agregada & Mista \\
\hline 1 & $1,71 \%$ & $2,68 \%$ & $\mathbf{1 , 6 3 \%}$ & $\mathbf{0 , 0 0 \%}$ & $\mathbf{0 , 0 0 \%}$ & $\mathbf{0 , 0 0 \%}$ \\
2 & $\mathbf{1 , 4 1 \%}$ & $12,12 \%$ & $3,84 \%$ & $\mathbf{0 , 4 8 \%}$ & $0,50 \%$ & $0,50 \%$ \\
3 & $1,32 \%$ & $1,80 \%$ & $\mathbf{1 , 1 5 \%}$ & $\mathbf{0 , 1 4 \%}$ & $0,42 \%$ & $0,42 \%$ \\
4 & $\mathbf{1 , 1 0 \%}$ & $4,66 \%$ & $1,36 \%$ & $\mathbf{0 , 1 2 \%}$ & $0,22 \%$ & $0,23 \%$ \\
5 & $\mathbf{0 , 4 5 \%}$ & $1,03 \%$ & $0,95 \%$ & $\mathbf{0 , 1 1 \%}$ & $0,31 \%$ & $0,33 \%$ \\
6 & $\mathbf{0 , 3 5 \%}$ & $1,47 \%$ & $1,54 \%$ & $\mathbf{0 , 0 9 \%}$ & $0,15 \%$ & $0,18 \%$ \\
\hline \hline \multicolumn{1}{||c|}{} & \multicolumn{1}{|c|}{ RF2 } & \multicolumn{3}{|c||}{ RF3 } \\
\hline Classe & SPL & Agregada & Mista & SPL & Agregada & Mista \\
\hline 1 & $2,72 \%$ & $2,75 \%$ & $\mathbf{2 , 6 9 \%}$ & $2,23 \%$ & $2,32 \%$ & $\mathbf{2 , 1 1 \%}$ \\
2 & $\mathbf{1 , 5 3 \%}$ & $3,13 \%$ & $2,92 \%$ & $\mathbf{1 , 0 6 \%}$ & $1,48 \%$ & $1,48 \%$ \\
3 & $\mathbf{1 , 3 1 \%}$ & $2,03 \%$ & $1,84 \%$ & $\mathbf{1 , 0 9 \%}$ & $1,56 \%$ & $1,56 \%$ \\
4 & $\mathbf{0 , 8 0 \%}$ & $2,45 \%$ & $2,45 \%$ & $\mathbf{0 , 5 9 \%}$ & $1,75 \%$ & $1,87 \%$ \\
5 & $1,22 \%$ & $1,18 \%$ & $\mathbf{1 , 1 7 \%}$ & $\mathbf{1 , 2 6 \%}$ & $\mathbf{1 , 2 6 \%}$ & $1,27 \%$ \\
6 & $\mathbf{0 , 6 2 \%}$ & $1,07 \%$ & $1,07 \%$ & $\mathbf{0 , 6 2 \%}$ & $1,01 \%$ & $1,01 \%$ \\
\hline
\end{tabular}

Tabela 29: Tempo computacional médio - Heurísticas baseadas em relaxação linear

\begin{tabular}{||c||r|r|r||r|r|r||}
\hline \multicolumn{1}{||}{} & \multicolumn{3}{c||}{ LPF } & \multicolumn{3}{c||}{ RF1 } \\
\hline Classe & SPL & Agregada & Mista & SPL & Agregada & Mista \\
1 & $\mathbf{0 , 0 2}$ & $\mathbf{0 , 0 2}$ & $\mathbf{0 , 0 2}$ & $\mathbf{0 , 0 3}$ & 0,04 & 0,06 \\
2 & 0,64 & $\mathbf{0 , 3 5}$ & 1,88 & 0,94 & $\mathbf{0 , 5 5}$ & 2,04 \\
3 & $\mathbf{0 , 5 5}$ & 0,58 & 1,50 & $\mathbf{2 , 7 6}$ & 2,81 & 6,08 \\
4 & $\mathbf{1 1 , 1 7}$ & 66,18 & 159,89 & 12,45 & $\mathbf{8 , 2 5}$ & 42,84 \\
5 & 2,37 & $\mathbf{1 , 7 0}$ & 5,93 & $\mathbf{1 5 , 0 0}$ & 18,21 & 22,69 \\
6 & $\mathbf{2 5 , 3 8}$ & 70,90 & 179,61 & $\mathbf{3 4 , 6 9}$ & 41,61 & 113,41 \\
\hline \hline \multicolumn{1}{||c||}{} & \multicolumn{3}{|c||}{ RF 2} & \multicolumn{3}{|c||}{ RF3 } \\
\hline Classe & \multicolumn{1}{|c|}{ SPL } & Agregada & \multicolumn{1}{|c|}{ Mista } & SPL & Agregada & Mista \\
\hline 1 & 0,04 & $\mathbf{0 , 0 3}$ & 0,05 & $\mathbf{0 , 0 4}$ & $\mathbf{0 , 0 4}$ & 0,05 \\
2 & 0,37 & $\mathbf{0 , 2 6}$ & 0,57 & 0,52 & $\mathbf{0 , 3 4}$ & 0,91 \\
3 & 1,11 & $\mathbf{0 , 5 9}$ & 1,20 & 0,87 & $\mathbf{0 , 7 3}$ & 1,51 \\
4 & 13,80 & $\mathbf{9 , 9 9}$ & 23,37 & 12,58 & $\mathbf{9 , 0 6}$ & 29,94 \\
5 & 5,36 & $\mathbf{1 , 3 7}$ & 3,00 & 2,93 & $\mathbf{1 , 4 8}$ & 3,20 \\
6 & 29,14 & $\mathbf{1 1 , 1 6}$ & 30,29 & 16,89 & $\mathbf{8 , 1 3}$ & 30,15 \\
\hline
\end{tabular}

Como pode ser visto na Tabela 30, a formulação SPL tem maior percentual de melhoria para as heurísticas LPF, RF1 e RF3. Na heurística RF2, os resultados foram variados, com predominância da formulação Mista. Convém salientar que para todas as formulações a heurística RF1, que é baseada na decomposição por períodos, obteve soluções melhores para todos os exemplos da classe 1 . Observando as Tabelas 27 e 28, podemos dizer que as soluções obtidas pela RF1 é ótima para esta classe. Isto ocorreu pois o número de períodos integralizados para a otimização é igual ao número de períodos no problema, ou seja, o único subproblema resolvido é igual ao problema original.

O percentual de factibilidade foi máximo para todos as heurísticas baseadas em relaxação, utilizando qualquer uma das formulações, como apresentado na Tabela 31. É 
Tabela 30: Percentual de melhoria - Heurísticas baseadas em relaxação linear

\begin{tabular}{|c|c|c|c|c|c|c|}
\hline & \multicolumn{3}{|c|}{ LPF } & \multicolumn{3}{|c|}{ RF1 } \\
\hline Classe & SPL & Agregada & Mista & SPL & Agregada & Mista \\
\hline 1 & $54,17 \%$ & $23,33 \%$ & $43,33 \%$ & $100,00 \%$ & $100,00 \%$ & $100,00 \%$ \\
\hline 2 & $32,50 \%$ & $0,00 \%$ & $9,38 \%$ & $77,92 \%$ & $61,88 \%$ & $62,08 \%$ \\
\hline 3 & $11,25 \%$ & $0,00 \%$ & $0,00 \%$ & $79,58 \%$ & $42,50 \%$ & $42,08 \%$ \\
\hline 4 & $25,83 \%$ & $0,00 \%$ & $0,42 \%$ & $64,58 \%$ & $56,25 \%$ & $55,00 \%$ \\
\hline 5 & $5,83 \%$ & $0,00 \%$ & $0,00 \%$ & $64,58 \%$ & $30,83 \%$ & $29,58 \%$ \\
\hline 6 & $6,25 \%$ & $0,00 \%$ & $0,00 \%$ & $41,25 \%$ & $27,08 \%$ & $27,92 \%$ \\
\hline & \multicolumn{3}{|c|}{$\overline{\mathrm{RF} 2}$} & \multicolumn{3}{|c|}{$\overline{\text { RF3 }}$} \\
\hline Classe & SPL & Agregada & Mista & SPL & Agregada & Mista \\
\hline 1 & $52,29 \%$ & $46,04 \%$ & $46,67 \%$ & $58,54 \%$ & $53,54 \%$ & $52,08 \%$ \\
\hline 2 & $45,00 \%$ & $28,54 \%$ & $28,54 \%$ & $45,63 \%$ & $20,83 \%$ & $20,42 \%$ \\
\hline 3 & $7,08 \%$ & $10,83 \%$ & $10,83 \%$ & $10,83 \%$ & $10,00 \%$ & $9,58 \%$ \\
\hline 4 & $9,58 \%$ & $18,75 \%$ & $19,17 \%$ & $7,50 \%$ & $14,17 \%$ & $13,75 \%$ \\
\hline 5 & $0,00 \%$ & $1,67 \%$ & $1,67 \%$ & $0,00 \%$ & $0,00 \%$ & $0,00 \%$ \\
\hline 6 & $0,00 \%$ & $2,08 \%$ & $2,08 \%$ & $0,00 \%$ & $0,00 \%$ & $0,00 \%$ \\
\hline
\end{tabular}

importante lembrar, que neste conjunto de testes, todas as instâncias têm ao menos uma solução factível sem a utilização de horas extras.

Tabela 31: Percentual de factibilidade - Heurísticas baseadas em relaxação linear

\begin{tabular}{||c||c|c|c||c|c|c||}
\hline \multicolumn{1}{||c||}{} & \multicolumn{3}{c||}{ LPF } & \multicolumn{3}{c||}{ RF1 } \\
\hline Classe & SPL & Agregada & Mista & SPL & Agregada & Mista \\
\hline 1 & $100,00 \%$ & $100,00 \%$ & $100,00 \%$ & $100,00 \%$ & $100,00 \%$ & $100,00 \%$ \\
3 & $100,00 \%$ & $100,00 \%$ & $100,00 \%$ & $100,00 \%$ & $100,00 \%$ & $100,00 \%$ \\
4 & $100,00 \%$ & $100,00 \%$ & $100,00 \%$ & $100,00 \%$ & $100,00 \%$ & $100,00 \%$ \\
5 & $100,00 \%$ & $100,00 \%$ & $100,00 \%$ & $100,00 \%$ & $100,00 \%$ & $100,00 \%$ \\
6 & $100,00 \%$ & $100,00 \%$ & $100,00 \%$ & $100,00 \%$ & $100,00 \%$ & $100,00 \%$ \\
\hline \hline \multicolumn{1}{||c||c|c|c||c|c||c||}{} \\
\hline Classe & SPL & Agregada & Mista & SPL & Agregada & Mista \\
\hline 1 & $100,00 \%$ & $100,00 \%$ & $100,00 \%$ & $100,00 \%$ & $100,00 \%$ & $100,00 \%$ \\
2 & $100,00 \%$ & $100,00 \%$ & $100,00 \%$ & $100,00 \%$ & $100,00 \%$ & $100,00 \%$ \\
3 & $100,00 \%$ & $100,00 \%$ & $100,00 \%$ & $100,00 \%$ & $100,00 \%$ & $100,00 \%$ \\
4 & $100,00 \%$ & $100,00 \%$ & $100,00 \%$ & $100,00 \%$ & $100,00 \%$ & $100,00 \%$ \\
5 & $100,00 \%$ & $100,00 \%$ & $100,00 \%$ & $100,00 \%$ & $100,00 \%$ & $100,00 \%$ \\
6 & $100,00 \%$ & $100,00 \%$ & $100,00 \%$ & $100,00 \%$ & $100,00 \%$ & $100,00 \%$ \\
\hline
\end{tabular}

A partir destes resultados, podemos verificar que as heurísticas com a formulação SPL obtiveram melhores resultados médios que as heurísticas com as demais formulações. Com esta formulação, o tempo computacional foi maior em alguns casos, mas isto não foi impactante para este conjunto de testes. Quando foi utilizada a formulação SPL, em alguns casos, um menor percentual de melhoria foi obtido (heurísticas RF2 e RF3). No entanto, a formulação SPL adicionou maior robustez às heurísticas dado que o desvio percentual médio e o desvio padrão foram menores (ver Tabelas 27 e 28), e desta forma, podemos dizer que os métodos obtiveram soluções mais próximas da média da classe, 
independentemente da instância abordada dentro de cada classe. As heurísticas com a formulação Mista apresentaram soluções com desvios percentuais próximos aos obtidos pelas heurísticas com a formulação agregada, porém, obtiveram soluções melhores em alguns poucos casos (ver Tabela 27). Os tempos computacionais médios, no entanto, das heurísticas com a formulação Mista foram mais elevados que os obtidos pelas heurísticas com as outras duas formulações.

Neste contexto de conjunto de testes e abordagens de solução, a formulação SPL se mostrou mais eficiente.

\section{Heurísticas do tipo fix-and-optimize}

A Tabela 32 apresenta os desvios percentuais médios com relação as heurísticas do tipo fix-and-optimize. Como podemos verificar, as heurísticas, em relação as formulações, se alternam na obtenção dos melhores desvios médios. No entanto, o valor da variação entre a melhor e a pior formulação é relativamente pequeno, variando no máximo em 0,06\%, no caso da classe 1 utilizando a heurística FO-P1. Além disso, a variação do desvio padrão percentual também se mostrou pequena, como pode ser visto na Tabela 33, variando no máximo 0,25\%. Isto demonstra que, neste tipo de abordagem, a qualidade das soluções não foi afetada pela formulação utilizada.

Tabela 32: Desvio percentual médio - Heurísticas do tipo fix-and-optimize

\begin{tabular}{||c||c|r|r||r|r|r||}
\hline \multicolumn{1}{||}{} & \multicolumn{3}{|c||}{ FO-P1 } & \multicolumn{3}{c||}{ FO-P2 } \\
\hline Classe & SPL & Agregada & \multicolumn{1}{c|}{ Mista } & SPL & Agregada & Mista \\
\hline 1 & $0,60 \%$ & $\mathbf{0 , 5 9 \%}$ & $0,65 \%$ & $0,21 \%$ & $0,21 \%$ & $\mathbf{0 , 2 0 \%}$ \\
2 & $0,78 \%$ & $0,78 \%$ & $\mathbf{0 , 7 7 \%}$ & $0,45 \%$ & $0,45 \%$ & $\mathbf{0 , 4 4 \%}$ \\
3 & $\mathbf{0 , 5 6 \%}$ & $0,59 \%$ & $0,59 \%$ & $\mathbf{0 , 2 9 \%}$ & $\mathbf{0 , 2 9 \%}$ & $0,30 \%$ \\
4 & $\mathbf{0 , 5 5 \%}$ & $0,57 \%$ & $0,58 \%$ & $0,19 \%$ & $0,19 \%$ & $\mathbf{0 , 1 8 \%}$ \\
5 & $\mathbf{0 , 6 9 \%}$ & $0,71 \%$ & $0,71 \%$ & $\mathbf{0 , 2 4 \%}$ & $0,25 \%$ & $0,25 \%$ \\
6 & $\mathbf{0 , 4 2 \%}$ & $0,44 \%$ & $0,44 \%$ & $\mathbf{0 , 1 1 \%}$ & $\mathbf{0 , 1 1 \%}$ & $\mathbf{0 , 1 1 \%}$ \\
\hline \hline \multicolumn{3}{||c||}{ FO-P3 } & \multicolumn{3}{|c||}{ FO-P } \\
\hline Classe & SPL & Agregada & Mista & SPL & Agregada & Mista \\
\hline 1 & $\mathbf{0 , 2 0 \%}$ & $\mathbf{0 , 2 0 \%}$ & $0,23 \%$ & $0,20 \%$ & $0,20 \%$ & $\mathbf{0 , 1 9 \%}$ \\
2 & $0,32 \%$ & $0,32 \%$ & $\mathbf{0 , 3 1 \%}$ & $\mathbf{0 , 3 2 \%}$ & $\mathbf{0 , 3 2 \%}$ & $\mathbf{0 , 3 2 \%}$ \\
3 & $0,29 \%$ & $0,32 \%$ & $\mathbf{0 , 2 6 \%}$ & $0,25 \%$ & $\mathbf{0 , 2 4 \%}$ & $0,25 \%$ \\
4 & $0,22 \%$ & $\mathbf{0 , 1 9 \%}$ & $0,20 \%$ & $0,13 \%$ & $\mathbf{0 , 1 2 \%}$ & $0,13 \%$ \\
5 & $\mathbf{0 , 2 6 \%}$ & $0,27 \%$ & $0,27 \%$ & $\mathbf{0 , 2 2 \%}$ & $0,23 \%$ & $0,23 \%$ \\
6 & $\mathbf{0 , 1 6 \%}$ & $\mathbf{0 , 1 6 \%}$ & $\mathbf{0 , 1 6 \%}$ & $0,10 \%$ & $\mathbf{0 , 0 9 \%}$ & $\mathbf{0 , 0 9 \%}$ \\
\hline
\end{tabular}

A Tabela 34 apresenta os tempos computacionais médios das abordagens do tipo fixand-optimize. Nestes resultados, podemos verificar que as heurísticas com a formulação Agregada levam vantagens com relação as heurísticas com as demais formulações. Os resultados obtidos com esta formulação, neste tipo de abordagem, foram sempre melhores 
Tabela 33: Desvio padrão percentual - Heurísticas do tipo fix-and-optimize

\begin{tabular}{||c||c|r|r||r|r|r||}
\hline \multicolumn{1}{|c||}{} & \multicolumn{3}{c||}{ FO-P1 } & \multicolumn{3}{c||}{ FO-P2 } \\
\hline Classe & SPL & Agregada & Mista & SPL & Agregada & Mista \\
\hline 1 & $1,32 \%$ & $\mathbf{1 , 0 7 \%}$ & $1,13 \%$ & $0,73 \%$ & $0,74 \%$ & $\mathbf{0 , 7 2 \%}$ \\
2 & $\mathbf{1 , 3 1 \%}$ & $1,32 \%$ & $1,32 \%$ & $\mathbf{0 , 9 1 \%}$ & $\mathbf{0 , 9 1 \%}$ & $\mathbf{0 , 9 1 \%}$ \\
3 & $\mathbf{0 , 7 8 \%}$ & $0,87 \%$ & $0,86 \%$ & $\mathbf{0 , 5 4 \%}$ & $\mathbf{0 , 5 4 \%}$ & $0,56 \%$ \\
4 & $\mathbf{0 , 8 1 \%}$ & $0,85 \%$ & $0,86 \%$ & $\mathbf{0 , 2 7 \%}$ & $\mathbf{0 , 2 7 \%}$ & $\mathbf{0 , 2 7 \%}$ \\
5 & $0,65 \%$ & $0,65 \%$ & $\mathbf{0 , 6 4 \%}$ & $\mathbf{0 , 2 7 \%}$ & $\mathbf{0 , 2 7 \%}$ & $\mathbf{0 , 2 7 \%}$ \\
6 & $\mathbf{0 , 4 2 \%}$ & $0,44 \%$ & $0,45 \%$ & $0,13 \%$ & $\mathbf{0 , 1 2 \%}$ & $0,13 \%$ \\
\hline \hline \multicolumn{5}{||c||c|c||c||c|c||}{} \\
\hline Classe & SPL & Agregada & Mista & SPL & Agregada & Mista \\
\hline 1 & $\mathbf{0 , 7 8 \%}$ & $\mathbf{0 , 7 8 \%}$ & $0,82 \%$ & $0,72 \%$ & $0,73 \%$ & $\mathbf{0 , 7 1 \%}$ \\
2 & $\mathbf{0 , 6 3 \%}$ & $\mathbf{0 , 6 3 \%}$ & $\mathbf{0 , 6 3 \%}$ & $\mathbf{0 , 8 2 \%}$ & $0,83 \%$ & $0,83 \%$ \\
3 & $0,53 \%$ & $0,57 \%$ & $\mathbf{0 , 4 7 \%}$ & $0,50 \%$ & $\mathbf{0 , 4 8 \%}$ & $0,49 \%$ \\
4 & $0,48 \%$ & $\mathbf{0 , 3 3 \%}$ & $0,34 \%$ & $0,26 \%$ & $\mathbf{0 , 2 5 \%}$ & $0,26 \%$ \\
5 & $\mathbf{0 , 3 4 \%}$ & $\mathbf{0 , 3 4 \%}$ & $0,36 \%$ & $\mathbf{0 , 2 8 \%}$ & $\mathbf{0 , 2 8 \%}$ & $\mathbf{0 , 2 8 \%}$ \\
6 & $0,21 \%$ & $\mathbf{0 , 2 0 \%}$ & $0,21 \%$ & $0,13 \%$ & $\mathbf{0 , 1 2 \%}$ & $0,13 \%$ \\
\hline
\end{tabular}

ou iguais aos resultados obtidos com as demais formulações.

Tabela 34: Tempo computacional médio - Heurísticas do tipo fix-and-optimize

\begin{tabular}{||c||r|r|r||r|r|r||}
\hline \multicolumn{1}{||c||}{} & \multicolumn{3}{c||}{ FO-P1 } & \multicolumn{3}{c||}{ FO-P2 } \\
\hline Classe & SPL & Agregada & Mista & SPL & Agregada & Mista \\
\hline 1 & 0,08 & $\mathbf{0 , 0 7}$ & 0,09 & $\mathbf{0 , 0 5}$ & $\mathbf{0 , 0 5}$ & 0,06 \\
2 & 0,29 & $\mathbf{0 , 2 1}$ & 0,29 & 0,32 & $\mathbf{0 , 2 6}$ & 0,39 \\
3 & 1,15 & $\mathbf{0 , 6 6}$ & 0,90 & 0,71 & $\mathbf{0 , 5 4}$ & 0,85 \\
4 & 5,62 & $\mathbf{1 , 7 1}$ & 2,78 & 5,05 & $\mathbf{2 , 3 5}$ & 4,84 \\
5 & 4,57 & $\mathbf{2 , 3 9}$ & 3,46 & 2,05 & $\mathbf{1 , 4 1}$ & 2,27 \\
6 & 24,73 & $\mathbf{6 , 6 4}$ & 10,99 & 14,20 & $\mathbf{6 , 0 1}$ & 10,95 \\
\hline \hline \multicolumn{3}{||c||r|r||r||r||}{ FO-P3 } & \multicolumn{3}{|c||}{ FO-P4 } \\
\hline Classe & SPL & Agregada & Mista & SPL & Agregada & Mista \\
\hline 1 & $\mathbf{0 , 1 2}$ & $\mathbf{0 , 1 2}$ & 0,14 & 0,12 & $\mathbf{0 , 1 1}$ & 0,14 \\
2 & 0,54 & $\mathbf{0 , 4 1}$ & 0,58 & 0,53 & $\mathbf{0 , 4 0}$ & 0,59 \\
3 & 1,62 & $\mathbf{1 , 0 6}$ & 1,58 & 1,46 & $\mathbf{0 , 9 9}$ & 1,45 \\
4 & 9,62 & $\mathbf{3 , 5 3}$ & 6,02 & 8,95 & $\mathbf{3 , 3 8}$ & 6,36 \\
5 & 5,45 & $\mathbf{3 , 2 4}$ & 4,92 & 4,95 & $\mathbf{2 , 9 4}$ & 4,36 \\
6 & 34,25 & $\mathbf{1 0 , 1 5}$ & 17,39 & 31,05 & $\mathbf{9 , 2 9}$ & 17,51 \\
\hline
\end{tabular}

O percentual de melhoria, apresentado na Tabela 35, demonstra a predominância da formulação Mista, nas heurísticas FO-P2, FO-P3 e FO-P4. No caso da heurística FO-P1, a formulação SPL foi melhor, quando se observa o percentual de melhoria.

A Tabela 36 demonstra que não houve problemas com relação a factibilidade das instâncias de teste verificadas, pois em todos os casos a factibilidade foi de 100\%, ou seja, as soluções obtidas pelas heurísticas não utilizam horas extras.

Apesar da dominância das heurísticas com as formulações SPL e Mista em casos específicos, como no percentual de melhoria, esta dominância não foi demonstrada quando ob- 
Tabela 35: Percentual de melhoria - Heurísticas do tipo fix-and-optimize

\begin{tabular}{|c|c|c|c|c|c|c|}
\hline & \multicolumn{3}{|c|}{ FO-P1 } & \multicolumn{3}{|c|}{ FO-P2 } \\
\hline Classe & SPL & Agregada & Mista & SPL & Agregada & Mista \\
\hline 1 & $56,88 \%$ & $53,54 \%$ & $53,13 \%$ & $89,38 \%$ & $89,38 \%$ & $89,58 \%$ \\
\hline 2 & $49,17 \%$ & $46,46 \%$ & $46,88 \%$ & $51,67 \%$ & $50,83 \%$ & $51,67 \%$ \\
\hline 3 & $24,17 \%$ & $24,17 \%$ & $24,17 \%$ & $38,33 \%$ & $34,17 \%$ & $36,67 \%$ \\
\hline 4 & $25,42 \%$ & $22,08 \%$ & $22,50 \%$ & $16,25 \%$ & $16,67 \%$ & $16,67 \%$ \\
\hline 5 & $3,33 \%$ & $2,92 \%$ & $2,92 \%$ & $12,92 \%$ & $12,92 \%$ & $12,92 \%$ \\
\hline 6 & $2,92 \%$ & $2,08 \%$ & $2,08 \%$ & $15,42 \%$ & $15,83 \%$ & $16,25 \%$ \\
\hline & \multicolumn{3}{|c|}{ "FO-P3 } & \multicolumn{3}{|c|}{ FO-P4 } \\
\hline Classe & SPL & Agregada & Mista & SPL & Agregada & Mista \\
\hline 1 & $90,83 \%$ & $90,83 \%$ & $89,79 \%$ & $90,00 \%$ & $90,21 \%$ & $90,21 \%$ \\
\hline 2 & $63,75 \%$ & $63,33 \%$ & $64,79 \%$ & $67,08 \%$ & $68,33 \%$ & $68,13 \%$ \\
\hline 3 & $47,92 \%$ & $47,50 \%$ & $49,17 \%$ & $54,58 \%$ & $51,67 \%$ & $54,58 \%$ \\
\hline 4 & $52,08 \%$ & $52,50 \%$ & $52,92 \%$ & $55,42 \%$ & $57,08 \%$ & $57,08 \%$ \\
\hline 5 & $25,00 \%$ & $24,17 \%$ & $24,58 \%$ & $24,17 \%$ & $23,75 \%$ & $24,17 \%$ \\
\hline 6 & $24,17 \%$ & $23,75 \%$ & $24,58 \%$ & $25,83 \%$ & $25,42 \%$ & $28,33 \%$ \\
\hline
\end{tabular}

Tabela 36: Percentual de factibilidade - Heurísticas do tipo fix-and-optimize

\begin{tabular}{||c||c|c|c||c|c|c||}
\hline \multicolumn{1}{||c||}{} & \multicolumn{3}{c||}{ FO-P1 } & \multicolumn{3}{c||}{ FO-P2 } \\
\hline Classe & SPL & Agregada & Mista & SPL & Agregada & Mista \\
\hline 1 & $100,00 \%$ & $100,00 \%$ & $100,00 \%$ & $100,00 \%$ & $100,00 \%$ & $100,00 \%$ \\
2 & $100,00 \%$ & $100,00 \%$ & $100,00 \%$ & $100,00 \%$ & $100,00 \%$ & $100,00 \%$ \\
3 & $100,00 \%$ & $100,00 \%$ & $100,00 \%$ & $100,00 \%$ & $100,00 \%$ & $100,00 \%$ \\
4 & $100,00 \%$ & $100,00 \%$ & $100,00 \%$ & $100,00 \%$ & $100,00 \%$ & $100,00 \%$ \\
5 & $100,00 \%$ & $100,00 \%$ & $100,00 \%$ & $100,00 \%$ & $100,00 \%$ & $100,00 \%$ \\
6 & $100,00 \%$ & $100,00 \%$ & $100,00 \%$ & $100,00 \%$ & $100,00 \%$ & $100,00 \%$ \\
\hline \hline \multicolumn{1}{||c|}{} & \multicolumn{3}{|c||}{ FO-P3 } & \multicolumn{3}{c||}{ FO-P4 } \\
\hline Classe & SPL & Agregada & Mista & SPL & Agregada & Mista \\
\hline 1 & $100,00 \%$ & $100,00 \%$ & $100,00 \%$ & $100,00 \%$ & $100,00 \%$ & $100,00 \%$ \\
2 & $100,00 \%$ & $100,00 \%$ & $100,00 \%$ & $100,00 \%$ & $100,00 \%$ & $100,00 \%$ \\
3 & $100,00 \%$ & $100,00 \%$ & $100,00 \%$ & $100,00 \%$ & $100,00 \%$ & $100,00 \%$ \\
4 & $100,00 \%$ & $100,00 \%$ & $100,00 \%$ & $100,00 \%$ & $100,00 \%$ & $100,00 \%$ \\
5 & $100,00 \%$ & $100,00 \%$ & $100,00 \%$ & $100,00 \%$ & $100,00 \%$ & $100,00 \%$ \\
6 & $100,00 \%$ & $100,00 \%$ & $100,00 \%$ & $100,00 \%$ & $100,00 \%$ & $100,00 \%$ \\
\hline
\end{tabular}

servamos os desvios percentuais médios e desvios padrões percentuais, onde os resultados foram bem próximos para todas as formulações. Além disso, os tempos computacionais das heurísticas com a formulação Agregada foram menores ou iguais em todas as classes de testes.

Portanto, a formulação agregada se mostrou mais efetiva em abordagens do tipo fix-and-optimize. Como ocorreu com as heurísticas anteriores, as soluções obtidas pelas heurísticas do tipo fix-and-optimize também não utilizaram horas extras para nenhuma classe. 


\section{Metaheurística algoritmo de abelhas}

O desvio percentual médio e o desvio padrão percentual dos testes computacionais referentes a metaheurística algoritmo de abelhas (BA) são apresentados na Tabela 37. A partir destes dados, podemos verificar que houve pouca variação entre os desvios da metaheurística com as formulações SPL e Agregada, porém a metaheurística com a formulação SPL apresentou soluções com desvios ligeiramente melhores na qualidade de solução. O desvio percentual variou no máximo $0,25 \%$ e o desvio padrão $1,99 \%$. No caso da metaheurística com a formulação Mista, no entanto, algumas dificuldades foram encontradas nas classes 4 e 6 , onde o método não conseguiu resolver algumas instâncias sem a utilização de horas extras, como pode ser verificado no percentual de factibilidade apresentado na Tabela 39.

Tabela 37: Desvio percentual médio e desvio padrão percentual - Metaheurística algoritmo de abelhas

\begin{tabular}{||c||r|r|r||r|r|r||}
\hline \multicolumn{1}{||c||}{} & \multicolumn{1}{c||}{ Desvio percentual médio } & \multicolumn{2}{c||}{ Desvio padrão percentual } \\
\hline Classe & SPL & Agregada & \multicolumn{1}{c|}{ Mista } & SPL & Agregada & \multicolumn{1}{c|}{ Mista } \\
\hline Class1 & $\mathbf{0 , 0 0 \%}$ & $\mathbf{0 , 0 0 \%}$ & $\mathbf{0 , 0 0 \%}$ & $\mathbf{0 , 0 0 \%}$ & $\mathbf{0 , 0 0 \%}$ & $\mathbf{0 , 0 0 \%}$ \\
Class2 & $0,01 \%$ & $\mathbf{0 , 0 0 \%}$ & $0,03 \%$ & $0,06 \%$ & $\mathbf{0 , 0 2 \%}$ & $0,14 \%$ \\
Class3 & $\mathbf{0 , 0 1 \%}$ & $0,02 \%$ & $0,04 \%$ & $\mathbf{0 , 0 5 \%}$ & $0,08 \%$ & $0,11 \%$ \\
Class4 & $\mathbf{0 , 1 4 \%}$ & $0,39 \%$ & $6,17 \%$ & $\mathbf{0 , 3 5 \%}$ & $2,34 \%$ & $45,72 \%$ \\
Class5 & $0,08 \%$ & $\mathbf{0 , 0 6 \%}$ & $0,16 \%$ & $0,14 \%$ & $\mathbf{0 , 1 3 \%}$ & $0,26 \%$ \\
Class6 & $\mathbf{0 , 9 1 \%}$ & $1,02 \%$ & $9,38 \%$ & $3,20 \%$ & $\mathbf{2 , 9 7 \%}$ & $55,10 \%$ \\
\hline
\end{tabular}

Os tempos computacionais médios também demonstram um certo equilíbrio entre as formulações SPL e Agregada, como pode ser visto na Tabela 38. Os tempos computacionais da formulação Mista, foram superiores aos tempos das outras duas formulações, em todos os casos.

Tabela 38: Tempo computacional médio - Metaheurística algoritmo de abelhas

\begin{tabular}{||c||r|r|r||}
\hline Classe & SPL & Agregada & Mista \\
\hline 1 & $\mathbf{0 , 6 2}$ & 0,78 & 1,06 \\
2 & 22,53 & $\mathbf{1 9 , 9 0}$ & 32,74 \\
3 & $\mathbf{2 9 , 7 6}$ & 33,48 & 44,92 \\
4 & 60,44 & $\mathbf{6 0 , 0 3}$ & 118,50 \\
5 & 62,32 & $\mathbf{5 7 , 1 8}$ & 84,13 \\
6 & $\mathbf{8 7 , 4 3}$ & 104,40 & 110,74 \\
\hline
\end{tabular}

No percentual de melhoria, apresentado na Tabela 39, também houve um certo equilíbrio entre os resultados obtidos com a utilização das formulações SPL e Agregada, com pequena vantagem da formulação SPL. 
Tabela 39: Percentual de melhoria e percentual de factibilidade - Metaheurística algoritmo de abelhas

\begin{tabular}{||c||r|r|r||c|c|c||}
\hline \multicolumn{1}{||c||}{} & \multicolumn{3}{c||}{ Percentual de melhoria } & \multicolumn{2}{c||}{ Percentual de factibilidade } \\
\hline Classe & SPL & Agregada & \multicolumn{1}{c|}{ Mista } & SPL & Agregada & Mista \\
\hline 1 & $\mathbf{1 0 0 , 0 0 \%}$ & $\mathbf{1 0 0 , 0 0 \%}$ & $\mathbf{1 0 0 , 0 0 \%}$ & $100,00 \%$ & $100,00 \%$ & $100,00 \%$ \\
2 & $96,13 \%$ & $\mathbf{9 9 , 0 4 \%}$ & $91,71 \%$ & $100,00 \%$ & $100,00 \%$ & $100,00 \%$ \\
3 & $\mathbf{9 0 , 6 7 \%}$ & $85,67 \%$ & $80,17 \%$ & $100,00 \%$ & $100,00 \%$ & $100,00 \%$ \\
4 & $\mathbf{7 6 , 2 5 \%}$ & $67,42 \%$ & $24,42 \%$ & $100,00 \%$ & $100,00 \%$ & $\mathbf{9 9 , 7 5 \%}$ \\
5 & $58,25 \%$ & $\mathbf{6 0 , 0 0 \%}$ & $49,92 \%$ & $100,00 \%$ & $100,00 \%$ & $100,00 \%$ \\
6 & $\mathbf{3 7 , 0 0 \%}$ & $31,42 \%$ & $0,42 \%$ & $100,00 \%$ & $100,00 \%$ & $\mathbf{9 9 , 2 5 \%}$ \\
\hline
\end{tabular}

Como visto, a metaheurística BA apresentou problemas de convergência apenas quando utilizamos a formulação Mista. Este fator está relacionado possivelmente ao tempo limite de solução dos subproblemas, dado que a formulação Mista demanda maior tempo para resolução. As demais formulações tiveram desempenho similar, segundo os fatores analisados.

\section{Heurísticas híbridas}

As Tabelas 40 e 41 apresentam o desvio percentual e o desvio padrão dos testes com as heurísticas híbridas. Com o auxílio destes testes, podemos verificar que a mudança de formulação não influencia de forma significativa a qualidade de solução obtidas pelas abordagens de solução.

Tabela 40: Desvio percentual médio - Heurísticas híbridas

\begin{tabular}{|c|c|c|c|c|c|c|}
\hline & \multicolumn{3}{|c|}{ BFO1 } & \multicolumn{3}{|c|}{ BFO2-P1 } \\
\hline Classe & SPL & Agregada & Mista & SPL & Agregada & Mista \\
\hline 1 & $0,06 \%$ & $0,05 \%$ & $0,06 \%$ & $0,30 \%$ & $0,32 \%$ & $0,30 \%$ \\
\hline 2 & $0,15 \%$ & $0,14 \%$ & $0,16 \%$ & $0,48 \%$ & $0,48 \%$ & $0,47 \%$ \\
\hline 3 & $0,11 \%$ & $0,13 \%$ & $0,12 \%$ & $0,37 \%$ & $0,38 \%$ & $0,35 \%$ \\
\hline 4 & $0,09 \%$ & $0,10 \%$ & $0,10 \%$ & $0,38 \%$ & $0,38 \%$ & $0,38 \%$ \\
\hline 5 & $0,15 \%$ & $0,14 \%$ & $0,14 \%$ & $0,49 \%$ & $0,48 \%$ & $0,48 \%$ \\
\hline 6 & $0,08 \%$ & $0,08 \%$ & $0,12 \%$ & $\mathbf{0 , 3 3 \%}$ & $0,34 \%$ & $0,34 \%$ \\
\hline & \multicolumn{3}{|c|}{ BFO2-P2 } & \multicolumn{3}{|c|}{ BFO2-P3 } \\
\hline Classe & SPL & Agregada & Mista & SPL & Agregada & Mista \\
\hline 1 & $0,13 \%$ & $0,14 \%$ & $0,13 \%$ & $0,12 \%$ & $0,12 \%$ & $0,10 \%$ \\
\hline 2 & $0,15 \%$ & $0,16 \%$ & $0,16 \%$ & $0,08 \%$ & $0,09 \%$ & $0,09 \%$ \\
\hline 3 & $0,13 \%$ & $0,14 \%$ & $0,14 \%$ & $0,10 \%$ & $0,09 \%$ & $0,10 \%$ \\
\hline 4 & $\mathbf{0 , 1 7 \%}$ & $0,17 \%$ & $0,18 \%$ & $0,09 \%$ & $0,08 \%$ & $0,09 \%$ \\
\hline 5 & $0,16 \%$ & $0,14 \%$ & $0,15 \%$ & $0,13 \%$ & $\mathbf{0 , 1 3 \%}$ & $0,13 \%$ \\
\hline 6 & $0,09 \%$ & $0,09 \%$ & $0,08 \%$ & $0,06 \%$ & $0,07 \%$ & $0,07 \%$ \\
\hline
\end{tabular}

Os tempos computacionais médios são apresentados na Tabela 42. Os resultados demonstram que as heurísticas com a formulação Agregada foram um pouco mais eficientes, pois os tempos computacionais das heurísticas com a formulação Agregada são sempre 
Tabela 41: Desvio padrão percentual - Heurísticas híbridas

\begin{tabular}{|c|c|c|c|c|c|c|}
\hline & \multicolumn{3}{|c|}{ BFO1 } & \multicolumn{3}{|c|}{ BFO2-P1 } \\
\hline Classe & SPL & Agregada & Mista & SPL & Agregada & Mista \\
\hline 1 & $0,28 \%$ & $0,27 \%$ & $0,26 \%$ & $0,91 \%$ & $0,92 \%$ & $0,88 \%$ \\
\hline 2 & $0,48 \%$ & $0,48 \%$ & $0,51 \%$ & $0,90 \%$ & $0,93 \%$ & $0,91 \%$ \\
\hline 3 & $0,30 \%$ & $0,33 \%$ & $0,32 \%$ & $0,63 \%$ & $0,63 \%$ & $0,59 \%$ \\
\hline 4 & $0,21 \%$ & $0,21 \%$ & $0,21 \%$ & $0,58 \%$ & $0,59 \%$ & $0,59 \%$ \\
\hline 5 & $0,23 \%$ & $0,20 \%$ & $0,22 \%$ & $0,46 \%$ & $0,44 \%$ & $0,44 \%$ \\
\hline 6 & $0,13 \%$ & $0,12 \%$ & $0,23 \%$ & $0,33 \%$ & $0,34 \%$ & $0,35 \%$ \\
\hline & \multicolumn{3}{|c|}{$\overline{\mathrm{BFO} 2-\mathrm{P} 2}$} & \multicolumn{3}{|c|}{$\overline{\mathrm{BFO} 2-\mathrm{P} 3}$} \\
\hline Classe & SPL & Agregada & Mista & SPL & Agregada & Mista \\
\hline 1 & $0,63 \%$ & $0,61 \%$ & $0,64 \%$ & $0,59 \%$ & $0,58 \%$ & $0,54 \%$ \\
\hline 2 & $0,49 \%$ & $0,43 \%$ & $0,45 \%$ & $0,28 \%$ & $0,33 \%$ & $0,32 \%$ \\
\hline 3 & $0,27 \%$ & $0,29 \%$ & $0,30 \%$ & $0,28 \%$ & $0,26 \%$ & $0,27 \%$ \\
\hline 4 & $0,25 \%$ & $0,25 \%$ & $0,26 \%$ & $0,21 \%$ & $0,19 \%$ & $0,21 \%$ \\
\hline 5 & $0,19 \%$ & $0,19 \%$ & $0,18 \%$ & $0,18 \%$ & $0,18 \%$ & $0,18 \%$ \\
\hline 6 & $0,10 \%$ & $0,10 \%$ & $0,10 \%$ & $0,09 \%$ & $0,09 \%$ & $0,10 \%$ \\
\hline
\end{tabular}

menores ou iguais ao valor obtido pelas heurísticas com as demais formulações.

Tabela 42: Tempo computacional médio - Heurísticas híbridas

\begin{tabular}{||c||r|r|r||r|r|r||}
\hline \multicolumn{1}{||c||}{} & \multicolumn{3}{|c||}{ BFO1 } & \multicolumn{3}{c||}{ BFO2-P1 } \\
\hline Classe & SPL & Agregada & \multicolumn{1}{c|}{ Mista } & SPL & Agregada & Mista \\
\hline 1 & 0,96 & $\mathbf{0 , 9 2}$ & 1,16 & 0,68 & $\mathbf{0 , 6 2}$ & 0,72 \\
2 & 4,18 & $\mathbf{3 , 2 7}$ & 5,84 & 2,41 & $\mathbf{1 , 7 1}$ & 2,30 \\
3 & 10,06 & $\mathbf{8 , 2 2}$ & 15,00 & 10,73 & $\mathbf{6 , 4 4}$ & 8,93 \\
4 & 69,65 & $\mathbf{4 9 , 7 4}$ & 174,29 & 51,16 & $\mathbf{1 6 , 0 5}$ & 26,23 \\
5 & 32,04 & $\mathbf{2 3 , 1 9}$ & 47,50 & 47,30 & $\mathbf{2 4 , 4 4}$ & 35,09 \\
6 & 226,47 & $\mathbf{1 8 4 , 2 1}$ & 401,63 & 235,06 & $\mathbf{6 0 , 5 6}$ & 108,77 \\
\hline \hline & \multicolumn{3}{||}{ BFO2-P2 } & \multicolumn{3}{c||}{ BFO2-P3 } \\
\hline Classe & SPL & Agregada & Mista & SPL & Agregada & Mista \\
\hline 1 & $\mathbf{0 , 2 7}$ & $\mathbf{0 , 2 7}$ & 0,33 & 0,88 & $\mathbf{0 , 8 4}$ & 1,05 \\
2 & 2,48 & $\mathbf{1 , 8 1}$ & 2,76 & 4,34 & $\mathbf{3 , 2 1}$ & 4,70 \\
3 & 5,26 & $\mathbf{3 , 8 4}$ & 6,31 & 13,42 & $\mathbf{8 , 7 0}$ & 12,91 \\
4 & 44,21 & $\mathbf{1 7 , 9 7}$ & 36,76 & 81,20 & $\mathbf{2 9 , 3 3}$ & 53,91 \\
5 & 15,47 & $\mathbf{1 0 , 5 9}$ & 17,26 & 47,17 & $\mathbf{2 7 , 1 7}$ & 43,23 \\
6 & 126,59 & $\mathbf{4 2 , 8 9}$ & 88,33 & 280,71 & $\mathbf{8 6 , 0 0}$ & 162,53 \\
\hline
\end{tabular}

O percentual de melhoria, apresentado na Tabela 43, demonstra equilíbrio entre as formulações abordadas, pois houve pouca variação entre as formulações.

Não houve problemas quanto a factibilidade das instâncias destas classes, pois todas as soluções obtidas pelas heurísticas híbridas foram soluções factíveis sem a utilização de horas extras, como pode ser verificado na Tabela 44.

Para este grupo de abordagens, o tempo computacional foi o fator de maior variação quanto a formulação utilizada, para as heurísticas híbridas. De acordo com o tempo computacional, a formulação Agregada foi a que se mostrou mais apropriada a este tipo 
Tabela 43: Percentual de melhoria - Heurísticas híbridas

\begin{tabular}{|c|c|c|c|c|c|c|}
\hline & \multicolumn{3}{|c|}{ BFO1 } & \multicolumn{3}{|c|}{ BFO2-P1 } \\
\hline Classe & SPL & Agregada & Mista & SPL & Agregada & Mista \\
\hline 1 & $89,29 \%$ & $89,96 \%$ & $90,50 \%$ & $75,63 \%$ & $75,25 \%$ & $74,88 \%$ \\
\hline 2 & $77,46 \%$ & $78,08 \%$ & $77,13 \%$ & $59,04 \%$ & $59,25 \%$ & $60,13 \%$ \\
\hline 3 & $67,42 \%$ & $66,17 \%$ & $67,08 \%$ & $38,67 \%$ & $39,17 \%$ & $38,75 \%$ \\
\hline 4 & $66,33 \%$ & $65,83 \%$ & $64,83 \%$ & $32,67 \%$ & $33,58 \%$ & $32,83 \%$ \\
\hline 5 & $40,42 \%$ & $39,58 \%$ & $42,17 \%$ & $5,67 \%$ & $5,58 \%$ & $5,67 \%$ \\
\hline 6 & $42,08 \%$ & $39,33 \%$ & $38,42 \%$ & $3,92 \%$ & $4,08 \%$ & $2,92 \%$ \\
\hline & \multicolumn{3}{|c|}{ BFO2-P2 } & \multicolumn{3}{|c|}{$\overline{\overline{\mathrm{BFO}} 2-\mathrm{P} 3}$} \\
\hline Classe & SPL & Agregada & Mista & SPL & Agregada & Mista \\
\hline 1 & $93,13 \%$ & $92,75 \%$ & $93,00 \%$ & $94,96 \%$ & $94,50 \%$ & $94,88 \%$ \\
\hline 2 & $70,71 \%$ & $69,63 \%$ & $69,88 \%$ & $81,50 \%$ & $81,79 \%$ & $82,54 \%$ \\
\hline 3 & $50,08 \%$ & $48,58 \%$ & $50,25 \%$ & $71,08 \%$ & $69,25 \%$ & $68,25 \%$ \\
\hline 4 & $14,75 \%$ & $13,67 \%$ & $12,50 \%$ & $68,83 \%$ & $69,42 \%$ & $69,42 \%$ \\
\hline 5 & $19,50 \%$ & $22,17 \%$ & $20,00 \%$ & $29,83 \%$ & $30,08 \%$ & $29,58 \%$ \\
\hline 6 & $15,00 \%$ & $15,92 \%$ & $17,83 \%$ & $31,25 \%$ & $32,83 \%$ & $34,83 \%$ \\
\hline
\end{tabular}

Tabela 44: Percentual de factibilidade - Heurísticas híbridas

\begin{tabular}{||c||c|c|c||c|c|c||}
\hline \multicolumn{1}{||c||}{} & \multicolumn{3}{c||}{ BFO1 } & \multicolumn{3}{c||}{ BFO2-P1 } \\
\hline Classe & SPL & Agregada & Mista & SPL & Agregada & Mista \\
\hline 1 & $100,00 \%$ & $100,00 \%$ & $100,00 \%$ & $100,00 \%$ & $100,00 \%$ & $100,00 \%$ \\
2 & $100,00 \%$ & $100,00 \%$ & $100,00 \%$ & $100,00 \%$ & $100,00 \%$ & $100,00 \%$ \\
3 & $100,00 \%$ & $100,00 \%$ & $100,00 \%$ & $100,00 \%$ & $100,00 \%$ & $100,00 \%$ \\
4 & $100,00 \%$ & $100,00 \%$ & $100,00 \%$ & $100,00 \%$ & $100,00 \%$ & $100,00 \%$ \\
5 & $100,00 \%$ & $100,00 \%$ & $100,00 \%$ & $100,00 \%$ & $100,00 \%$ & $100,00 \%$ \\
6 & $100,00 \%$ & $100,00 \%$ & $100,00 \%$ & $100,00 \%$ & $100,00 \%$ & $100,00 \%$ \\
\hline \hline \multicolumn{1}{||c||c|c||c|c|c||}{||} & BFO2-P2 & \multicolumn{3}{c||}{ BFO2-P3 } \\
\hline Classe & SPL & Agregada & Mista & SPL & Agregada & Mista \\
\hline 1 & $100,00 \%$ & $100,00 \%$ & $100,00 \%$ & $100,00 \%$ & $100,00 \%$ & $100,00 \%$ \\
2 & $100,00 \%$ & $100,00 \%$ & $100,00 \%$ & $100,00 \%$ & $100,00 \%$ & $100,00 \%$ \\
3 & $100,00 \%$ & $100,00 \%$ & $100,00 \%$ & $100,00 \%$ & $100,00 \%$ & $100,00 \%$ \\
4 & $100,00 \%$ & $100,00 \%$ & $100,00 \%$ & $100,00 \%$ & $100,00 \%$ & $100,00 \%$ \\
5 & $100,00 \%$ & $100,00 \%$ & $100,00 \%$ & $100,00 \%$ & $100,00 \%$ & $100,00 \%$ \\
6 & $100,00 \%$ & $100,00 \%$ & $100,00 \%$ & $100,00 \%$ & $100,00 \%$ & $100,00 \%$ \\
\hline
\end{tabular}

de abordagem. Em alguns casos, o tempo computacional médio da formulação Agregada foi menos de um quarto do tempo da formulação SPL e metade do tempo da formulação Mista, como pode ser visto na Tabela 42.

\subsubsection{Análise dos resultados com foco nas abordagens de solução}

Na análise com foco na formulação pudemos definir as melhores formulações para cada tipo de abordagem de solução. A formulação SPL obteve melhores resultados para as abordagens baseadas em relaxação linear ( $L P$-and-fix e relax-and-fix) e para a metaheurística BA. Já a formulação Agregada foi escolhida para as abordagens do tipo fix-and-optimize 
e para os métodos híbridos.

O gráfico apresentado na Figura 25 mostra a dispersão dos resultados médios das heurísticas com faixas de erros definidas pelo desvios padrões. A Figura 26 apresenta o mesmo gráfico com uma faixa de erros igual ao dobro do desvio padrão, como feito para o problema anterior.

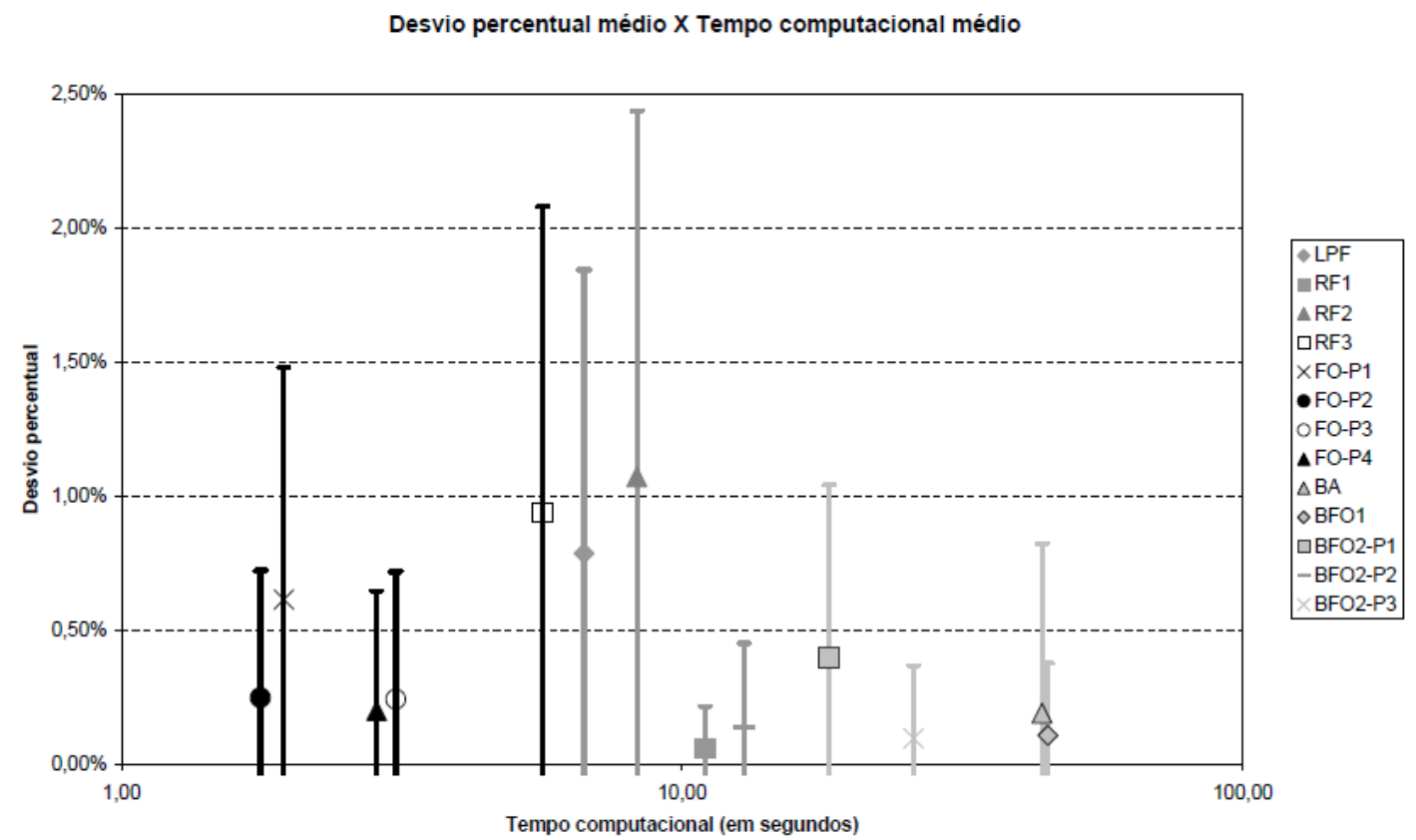

Figura 25: Gráfico de qualidade de solução com barra de erros igual ao desvio padrão.

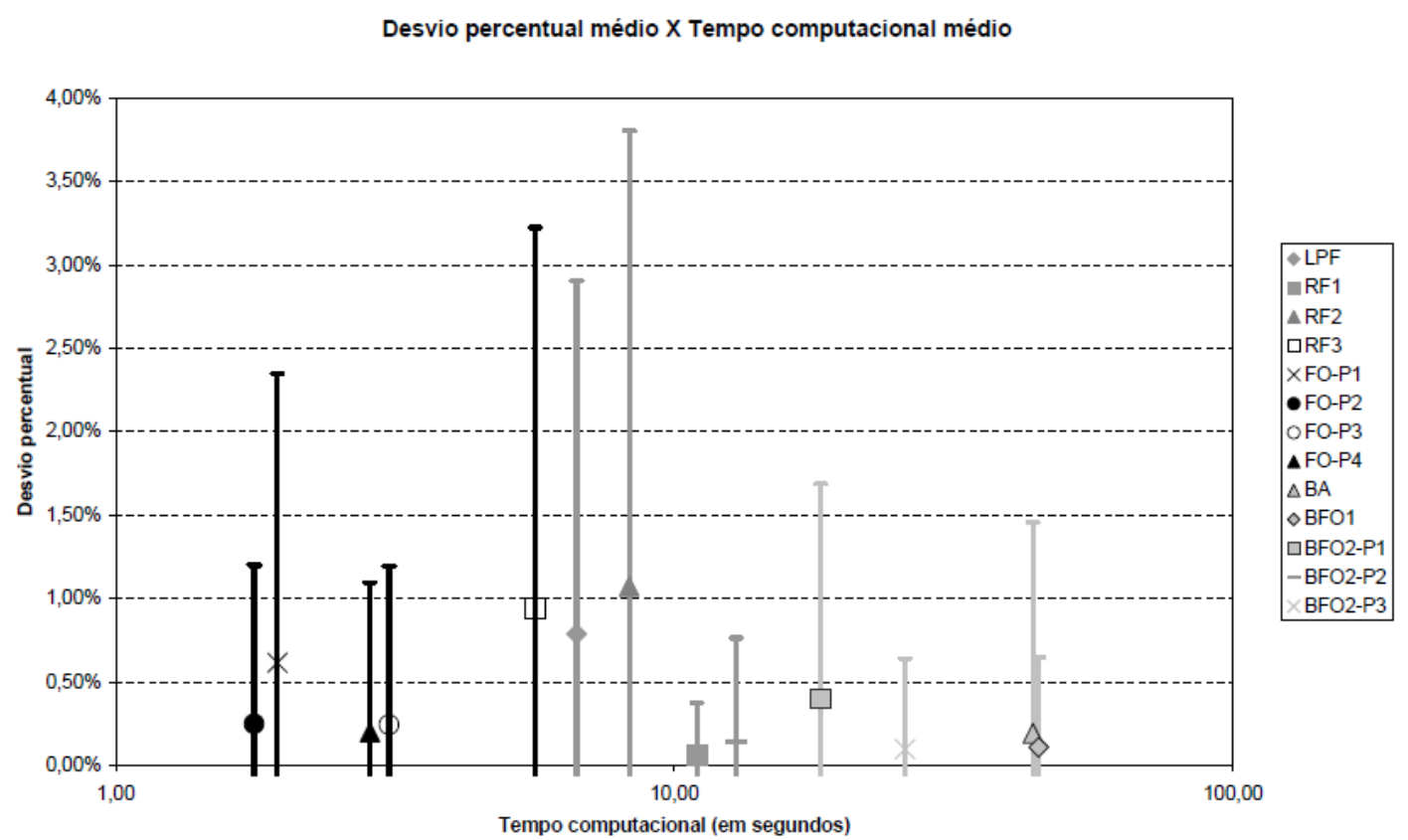

Figura 26: Gráfico de qualidade de solução com barra de erros igual ao dobro do desvio padrão. 
Com o auxílio das Figuras 25 e 26, podemos verificar que ao avaliar o tempo computacional, as heurísticas do tipo fix-and-optimize foram as mais eficientes, seguidas das heurísticas baseadas em relaxação linear e dos métodos híbridos. Sobre a qualidade de solução, a heurística RF1 é a melhor, dominando todas as demais heurísticas e dominando as heurísticas híbridas e a metaheurística BA também em relação ao tempo computacional. Outras três abordagens se destacam quanto a qualidade de solução: BFO1, BFO2-P2 e BFO2-P3, sendo que a abordagem BFO2-P2 tem tempo computacional próximo ao da abordagem RF1.

O gráfico da Figura 27 apresenta o percentual médio de otimalidade obtido em cada abordagem de solução. Observe que a metaheurística BA obteve o melhor resultado, seguida da heurística RF1, BFO1 e BFO2-P3.

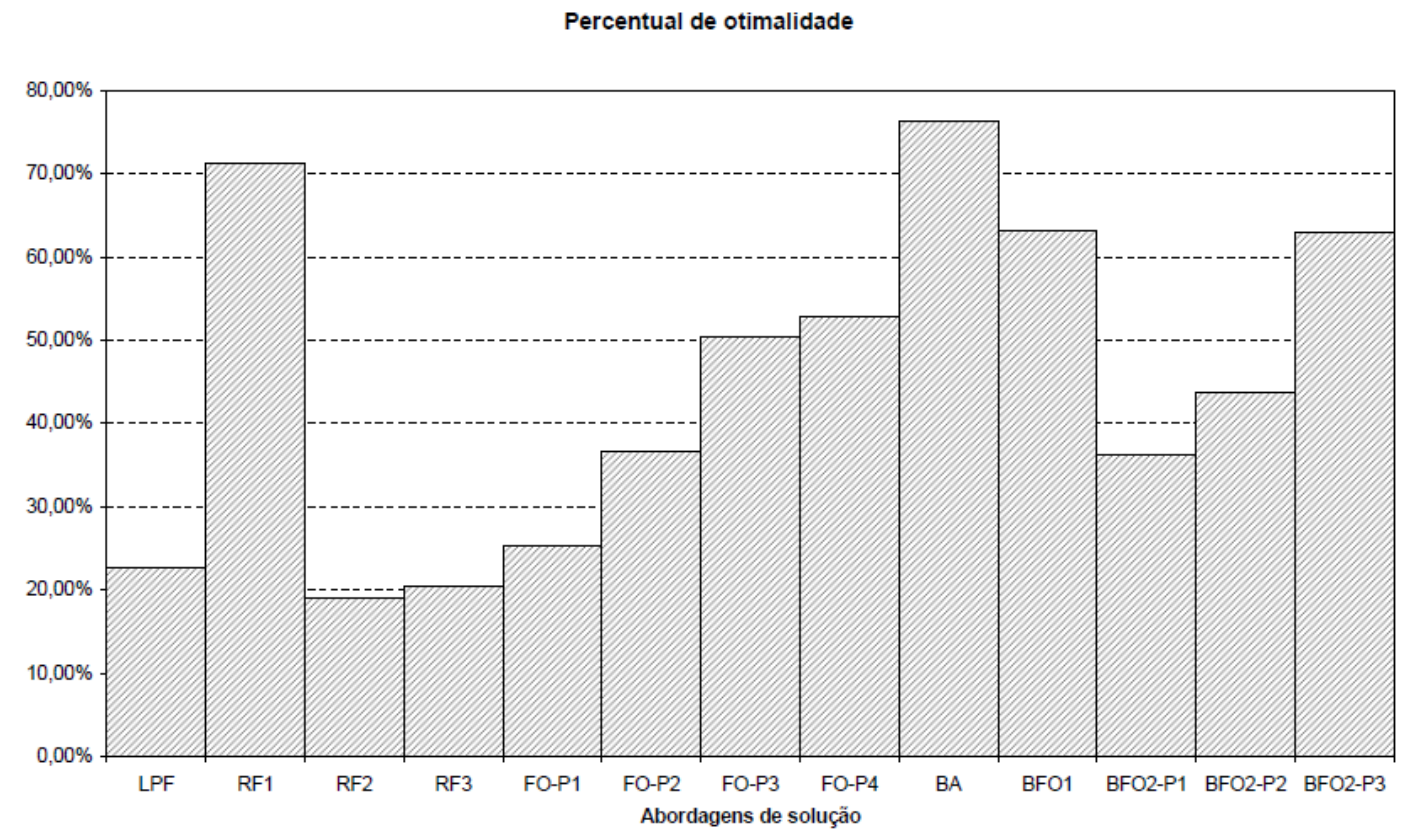

Figura 27: Gráfico de otimalidade média.

Considerando o desempenho dos métodos, neste conjunto de testes, a abordagem de solução RF1 foi a que obteve melhores resultados médios, seguida das heurísticas híbridas BFO1 e BFO2-P3. As heurísticas híbridas se mostraram adequadas, pois obtiveram resultados de boa qualidade quando observamos o desvio percentual, desvio padrão e percentual de melhoria, mesmo necessitando de maior tempo computacional médio. 


\section{CAPÍTULO 6}

\section{CONCLUSÕES E PERSPECTIVAS}

Nesta dissertação de mestrado foram abordados dois problemas de dimensionamento de lotes multiestágio que foram apresentados em Tempelmeier e Derstroff (1996) e Sahling et al. (2009). Tempelmeier e Derstroff (1996) apresentam um problema de dimensionamento de lotes multiestágio com limitação da capacidade, e tempos e custos de preparações não nulos. O problema apresentado em Sahling et al. (2009) consiste em um problema de dimensionamento de lotes multiestágio com limitação de capacidade e preservação da preparação. Neste segundo problema, consideram também os tempos e custos de preparações não nulos, lead-time positivo igual a um período apenas para itens componentes e estoques iniciais positivos.

Para obtenção de soluções para tais problemas, desenvolvemos métodos heurísticos baseados na formulação matemática do problema, metaheurísticas puras e algoritmos híbridos, bem como discutimos e analisamos algumas abordagens de solução da literatura. Os métodos de solução foram testados considerando os dois problemas abordados. Além disso, reformulamos os problemas de acordo com refomulações clássicas da literatura. Para cada uma das formulações, analisamos as soluções obtidas pelos métodos de solução, discutindo as vantagens de cada abordagem com relação as formulações dos problemas.

Com os resultados computacionais, podemos verificar o desempenho de um conjunto de abordagens de solução aplicados a dois problemas de dimensionamento de lotes multiestágio com limitação de capacidades. Alguns destes métodos foram retirados da literatura, 
como a heurística do tipo fix-and-optimize com particionamento por itens, que foi implementada como proposta por Sahling et al. (2009) e a heurística LP-and-fix proposta por Maes et al. (1991), na qual foi adicionado um intervalo de escolha das variáveis de fixação. Além disso, testamos dois métodos híbridos de solução, uma metaheurística baseada em algoritmo de abelhas e formas alternativas de particionamento para as heurísticas relax-and-fix e fix-and-optimize.

As heurísticas do tipo relax-and-fix obtiveram resultados ruins para o primeiro problema abordado, com uma utilização excessiva de horas extras, mas obtiveram bons resultados no segundo problema, onde a heurística RF1 obteve os melhores resultados de todas as abordagens com relação a qualidade de solução. Toda esta variação pode ter ocorrido pela mudança nas características do problema abordado e, principalmente, porque o tempo limite de solução de cada subproblema pode não ter sido suficiente, no caso do primeiro problema.

As heurísticas do tipo fix-and-optimize obtiveram soluções de boa qualidade, com os menores tempos, dentre as abordagens averiguadas nesta dissertação para os dois problemas. Dentre as combinações de particionamento utilizadas, a utilização do particionamento por períodos gerou um aumento no tempo computacional com relação ao particionamento por itens, mas gerou também soluções de melhor qualidade. Quando combinamos as duas formas de particionamento, ficou claro que utilizar o particionamento por períodos antes do particionamento por itens (FO-P4) gera soluções de melhor qualidade em um tempo computacional médio menor. Portanto, a heurística com FO-P4 domina totalmente a heurística FO-P3, que utiliza particionamento por itens antes do particionamento por períodos.

A metaheurística algoritmo de abelhas obteve soluções de qualidade inferior, com relação as heurísticas do tipo fix-and-optimize, em um tempo computacional médio maior. Isto se deve a forma de busca local implementada, que gera a necessidade de maior tempo computacional para a solução. Como os subproblemas contam com tempo limite de solução, os subproblemas podem não ter sido resolvidos a contento.

As heurísticas híbridas tiveram soluções bem distintas entre si. O primeiro método híbrido obteve soluções comparáveis as da heurística fix-and-optimize, no entanto, com tempo computacional bem elevado. O método demonstra que um particionamento aleatório pode gerar soluções de boa qualidade como os particionamentos que levam em consideração características do problema abordado, mas o tempo computacional torna-se mais elevado. 
O segundo método híbrido, que toma proveito do conhecimento prévio de particionamento, gerou as melhores soluções para o primeiro problema abordado (BFO2-P2 e BFO2-P3). No caso da heurística BFO2-P3, os resultados foram na média 0,49\% melhores que o limitante superior utilizado na classe de testes $\mathrm{B}+$. Os tempos computacionais médios deste híbrido foram adequados, quando verificamos que estes não chegaram a metade do tempo limite estipulado. Com este método, conseguimos demonstrar que o uso da heurística fix-and-optimize como forma de busca local é adequado. Como os mínimos locais definem o principal limitante desta heurística, verificamos que utilizando uma metodologia que tente evitar mínimos locais (algoritmo de abelhas, neste caso), podemos gerar soluções de qualidade elevada sem que o tempo computacional aumente muito.

Além disso, verificamos a influência de formulações distintas sobre o desempenho das abordagens de solução. De modo geral, a formulação SPL (formulação por localização de facilidades) foi melhor na maior parte das abordagens de solução para o primeiro problema. Para o segundo problema, a divisão entre as formulações mais adequadas para cada abordagem ficou mais caracterizada. Neste caso, uma formulação mais "forte" (SPL) trouxe ganhos em heurísticas baseadas em relaxação linear e para a metaheurística algoritmo de abelhas (BA). Nas demais abordagens, a formulação SPL gerou um aumento no tempo computacional sem uma melhora considerável na qualidade de solução, enquanto que a formulação Agregada gerou soluções próximas as geradas pelas demais formulações, mas com tempo computacional menor.

Melhorias no ajuste dos parâmetros de cada método são necessários para que o melhor desempenho de cada um possa ser obtido, bem como um método que ajuste de forma sistemática estes parâmetros a partir de um pequeno conjunto de testes. Além disso, uma possível substituição no método de resolução dos subproblemas MIP por um método heurístico baseado em relaxação linear pode vir a reduzir o tempo computacional sem fazer com que a qualidade de solução piore muito, possibilitando ainda o uso de ferramentas livres para a solução dos múltiplos problemas lineares.

Uma nova abordagem que integre as duas abordagens híbridas pode ser verificada como uma extensão dos métodos híbridos propostos neste trabalho. Esta mistura poderia ser obtida a partir da adição de partições aleatórias no conjunto de partições do segundo método híbrido. Estas partições seriam utilizadas como mais uma forma de particionamento ou como método de busca aleatória. A utilização de outros tipos de metaheurística na construção do método híbrido também pode ser verificada, como por exemplo, a metaheurística GRASP (RESENDE; RIBEIRO, 2003) ou uma metaheurística de caminho como 
a Busca Tabu (GLOVER, 1986).

Outros problemas da literatura podem ser resolvidos com estes métodos híbridos, deste que os parâmetros sejam ajustados as necessidades do problema abordado e que as formas de particionamento sejam definidas para o problema em questão, no caso do segundo método híbrido.

Em resumo, a contribuição desta dissertação foi verificar variados métodos heurísticos da literatura, observando as influências de três diferentes formulações com relação a cada abordagem de solução investigada, além de apresentar formas distintas de particionamento e propôr novas abordagens de soluções, demonstrando suas vantagens. 


\section{REFERÊNCIAS BIBLIOGRÁFICAS}

AKARTUNALI, K.; MILLER, A. J. A heuristic approach for big bucket multi-level production planning problems. European Journal of Operational Research, v. 193, n. 2, p. 396-411, 2009.

ALMEDER, C. A hybrid optimization approach for multi-level capacitated lot-sizing problems. European Journal of Operational Research, v. 200, n. 2, p. 599-606, 2010.

ALMEDER, C.; KLABJAN, D.; ALMADA-LOBO, B. Lead Time Considerations for the Multi-Level Capacitated Lot-sizing Problem. Porto, 2009.

ARAuJO, S. A.; ARENAlES, M. N. Problema de dimensionamento de lotes monoestágio com restrição de capacidade: modelagem, método de resolução e resultados computacionais. Pesquisa Operacional, v. 20, n. 2, p. 287-306, 2000.

ARAujo, S. A. de; ARENAleS, M. N.; CLARK, A. R. Lot sizing and furnace scheduling in small foundries. Computers \& Operations Research, v. 35, n. 3, p. 916-932, 2008.

BAHL, H. C.; RITZMAN, L. P.; GUPTA, J. N. Determining lot sizes and resource requirements: A review. Operations Research, v. 35, n. 3, p. 329-345, 1987.

BILDE, O.; KRARUP, J. Plant location, set covering, and economic lot size: an $\mathrm{o}(\mathrm{mn})$-algorithm for structured problems. In: Optimierung bei graphentheoretischen und ganzzahligen Probleme, Numerische Methoden bei Optimierungsverfahren, Band 3. Basel: Birkhauser Verlag, 1977. p. 155-180.

BILLINGTON, P. J.; MCCLAIN, J. O.; THOMAS, L. J. Mathematical programming approaches to capacity-constrained mrp systems: Review, formulation and problem reduction. Management Science, v. 29, n. 10, p. 1126-1141, 1983.

BITRAN, G. R.; YANASSE, H. H. Computational complexity of the capacitated lot size problem. Management Science, v. 28, n. 10, p. 1174-1186, 1982.

BRAHIMI, N.; DAUZERE-PERES, S.; NAJID, N. M.; NORDLI, A. Single item lot sizing problems. European Journal of Operational Research, v. 168, n. 1, p. 1-16, 2006. 
BUSCHKüHL, L.; SAHLING, F.; HELBER, S.; TEMPELMEIER, H. Dynamic capacitated lot-sizing problems: a classification and review of solution approaches. $O R$ Spectrum, v. 32, p. 231-261, 2010.

CHONG, C. S.; LOW, M. Y. H.; SIVAKUMAR, A. I.; GAY, K. L. A bee colony optimization algorithm to job shop scheduling. In: Simulation Conference, 2006. WSC 06. Proceedings of the Winter. Monterey, California: Winter Simulation Conference, 2006. p. 1954-1961.

CLARK, A. R.; ARMENTANO, V. A. The application of valid inequalities to the multi-stage lot-sizing problem. Computers $\& 6$ Operations Research, v. 22, n. 7, p. 669 680, 1995.

DEGROOT, M. H.; SCHERVISH, M. J. Probability and Statistics. 3rd. ed. Boston: Addison Wesley, 2002.

DENIZEL, M.; ALTEKIN, F.; SüRAL, H.; STADTLER, H. Equivalence of the lp relaxations of two strong formulations for the capacitated lot-sizing problem with setup times. OR Spectrum, v. 30, p. 773-785, 2008.

DERELI, T.; DAS, G. S. A hybrid 'bee(s) algorithm' for solving container loading problems. Applied Soft Computing, v. 11, n. 2, p. 2854-2862, 2011.

DIXON, P. S.; SILVER, E. A. A heuristic solution procedure for the multi-item, single-level, limited capacity, lot-sizing problem. Journal of Operations Management, v. 2 , n. 1 , p. 23-39, 1981.

DORIGO, M.; GAMBARDELLA, L. Ant colony system: a cooperative learning approach to the traveling salesman problem. IEEE Transactions on Evolutionary Computation, v. 1, n. 1, p. 53-66, 1997.

DORIGO, M.; MANIEZZO, V.; COLORNI, A. The ant system: Optimization by a colony of cooperating agents. IEEE Transactions on Systems, Man, and Cybernetics Part B: Cybernetics, v. 26, n. 1, p. 29-41, 1996.

EPPEN, G. D.; MARTIN, R. K. Solving multi-item capacitated lot-sizing problems using variable redefinition. Operations Research, v. 35, n. 6, p. 832-848, 1987.

FERREIRA, D.; MORABITO, R.; RANGEL, S. Solution approaches for the soft drink integrated production lot sizing and scheduling problem. European Journal of Operational Research, v. 196, n. 2, p. 697-706, 2009.

FERREIRA, D.; MORABITO, R.; RANGEL, S. Relax and fix heuristics to solve one-stage one-machine lot-scheduling models for small-scale soft drink plants. Computers \& Operations Research, v. 37, n. 4, p. 684-691, 2010.

GARCíA-MARTíNEZ, C.; CORDóN, O.; HERRERA, F. A taxonomy and an empirical analysis of multiple objective ant colony optimization algorithms for the bi-criteria tsp. European Journal of Operational Research, v. 180, n. 1, p. 116-148, 2007.

GEOFFRION, A. M. Lagrangean relaxation for integer programming. In: Approaches to Integer Programming. Berlin / Heidelberg: Springer, 1974, (Mathematical Programming Studies, v. 2). p. 82-114. 
GLOVER, F. Future paths for integer programming and links to artificial intelligence. Computers \& Operations Research, v. 13, n. 5, p. 533-549, 1986.

HELBER, S.; SAHLING, F. A fix-and-optimize approach for the multi-level capacitated lot sizing problem. International Journal of Production Economics, v. 123, n. 2, p. 247-256, 2010.

JAMES, R. J.; ALMADA-LOBO, B. Iterative mip-based neighborhood search heuristics for lotsizing and scheduling problems. Working Paper, 2010.

JANS, R.; DEGRAEVE, Z. Improved lower bounds for the capacitated lot sizing problem with setup times. Operations Research Letters, v. 32, n. 11, p. 185-195, 2004.

JANS, R.; DEGRAEVE, Z. Modeling industrial lot sizing problems: A review. International Journal of Production Research, v. 46, n. 6, p. 1619-1643, 2008.

JOURDAN, L.; BASSEUR, M.; TALBI, E.-G. Hybridizing exact methods and metaheuristics: A taxonomy. European Journal of Operational Research, v. 199, n. 3, p. $620-629,2009$.

JUNG, S. H. Queen-bee evolution for genetic algorithms. Electronics Letters, v. 39, n. 6, p. $575-576,2003$.

KARABOGA, D.; AKAY, B. A survey: algorithms simulating bee swarm intelligence. Artificial Intelligence Review, v. 31, p. 61-85, 2009.

KARIMI, B.; GHOMI, S. M. T. F.; WILSON, J. M. The capacitated lot sizing problem: a review of models and algorithms. Omega, v. 31, n. 5, p. 365-378, 2003.

KRARUP, J.; PRUZAN, P. M. The simple plant location problem: Survey and synthesis. European Journal of Operational Research, v. 12, n. 1, p. 36-81, 1983.

KUIK, R.; SALOMON, M.; WASSENHOVE, L. N. van. Batching decisions: structure and models. European Journal of Operational Research, v. 75, n. 2, p. 243-263, 1994.

LUCIC, P. Modeling transportation problems using concepts of swarm intelligence and soft computing. Tese (Doutorado) — Virginia Polytechnic Institute and State University, 2002.

MAES, J.; MCCLAIN, J. O.; WASSENHOVE, L. N. V. Multilevel capacitated lotsizing complexity and lp-based heuristics. European Journal of Operational Research, v. 53, n. 2 , p. $131-148,1991$.

MARINAKIS, Y.; MARINAKI, M.; DOUNIAS, G. Honey bees mating optimization algorithm for the vehicle routing problem. In: Nature Inspired Cooperative Strategies for Optimization (NICSO 2007). Berlin / Heidelberg: Springer, 2008, (Studies in Computational Intelligence, v. 129). p. 139-148.

MATSUMOTO, M.; NISHIMURA, T. Mersenne twister: a 623-dimensionally equidistributed uniform pseudo-random number generator. ACM Transactions on Modeling and Computer Simulation, v. 8, n. 1, p. 3-30, 1998. 
MERCé, C.; FONTAN, G. Mip-based heuristics for capacitated lotsizing problems. International Journal of Production Economics, v. 85, n. 1, p. 97-111, 2003.

PHAM, D. T.; GHANBARZADEH, A.; KOC, E.; OTRI, S.; RAHIM, S.; ZAIDI, M. The Bees Algorithm. UK, 2005.

PHAM, D. T.; KOC, E.; LEE, J. Y.; PHRUEKSANANT, J. Using the bees algorithm to schedule jobs for a machine. In: Proc Eighth International Conference on Laser Metrology. UK: Euspen, 2007. p. 430-439.

POCHET, Y.; WOLSEY, L. A. Production Planning by Mixed Integer Programming. New York: Springer, 2006. ISBN 0387299599.

PUCHINGER, J.; RAIDL, G. R. Combining metaheuristics and exact algorithms in combinatorial optimization: A survey and classification. In: Artificial Intelligence and Knowledge Engineering Applications: A Bioinspired Approach. Berlin / Heidelberg: Springer, 2005. v. 3562, p. 113-124.

RAIS, H.; OTHMAN, Z.; HAMDAN, A. Improved dynamic ant colony system (dacs) on symmetric traveling salesman problem (tsp). In: International Conference on Intelligent and Advanced Systems. Kuala Lumpur: IEEE, 2007. p. 43-48.

RESENDE, M.; RIBEIRO, C. Greedy randomized adaptive search procedures. In: HILliER, F. S.; GLOVER, F.; KOCHENBERGER, G. (Ed.). Handbook of Metaheuristics. New York: Springer, 2003. p. 219-249.

ROSLING, K. Optimal lot-sizing for dynamic assembly systems. In: Multi-Stage Production Planning and Inventory Control. New York: Springer, 1986. p. 119-131.

SAHLING, F.; BUSCHKüHL, L.; TEMPELMEIER, H.; HELBER, S. Solving a multi-level capacitated lot sizing problem with multi-period setup carry-over via a fix-and-optimize heuristic. Compututers $\&$ Operational Research, v. 36, n. 9, p. 2546-2553, 2009.

SANTOS, M. O.; ALMADA-LOBO, B. Integrated pulp and paper mill planning and scheduling. Submetido para publicação, 2011.

SATO, T.; HAGIWARA, M. Bee system: finding solution by a concentrated search. In: International Conference on Systems, Man, and Cybernetics. Orlando: IEEE, 1997. v. 4, p. 3954-3959.

STADTLER, H. Mixed integer programming model formulations for dynamic multi-item multi-level capacitated lotsizing. European Journal of Operational Research, v. 94, n. 3, p. 561-581, 1996.

STADTLER, H. Multilevel lot sizing with setup times and multiple constrained resources: Internally rolling schedules with lot-sizing windows. Operations Research, v. 51, n. 3, p. 487-502, 2003.

STADTLER, H.; SüRIE, C. Description of MLCLSP test instances. Darmstadt, 2000. 
TEMPELMEIER, H.; BUSCHKüHL, L. A heuristic for the dynamic multi-level capacitated lotsizing problem with linked lotsizes for general product structures. $O R$ Spectrum, v. 31, n. 2, p. 385-404, 2009.

TEMPELMEIER, H.; DERSTROFF, M. A lagrangean-based heuristic for dynamic multi-level multi-item constrained lotsizing with setup times. Management Science, v. 42 , n. 5 , p. $738-757,1996$.

TEMPELMEIER, H.; HELBER, S. A heuristic for dynamic multi-item multi-level capacitated lotsizing for general product structures. European Journal of Operational Research, v. 75, n. 2, p. 296-311, 1994.

TOSO, E. A.; MORABITO, R.; CLARK, A. R. Lot sizing and sequencing optimisation at an animal-feed plant. Computers $\&$ Industrial Engineering, v. 57, n. 3, p. 813-821, 2009 .

TRIGEIRO, W. W.; THOMAS, L. J.; MCCLAIN, J. O. Capacitated lot sizing with setup times. Management Science, v. 35, n. 3, p. 353-366, 1989.

WAGNER, H. M.; WHITIN, T. M. Dynamic version of the economic lot size model. Management Science, v. 5, n. 1, p. 89-96, 1958.

WEDDE, H.; LEHNHOFF, S.; BONN, B. van; BAY, Z.; BECKER, S.; BOTTCHER, S.; BRUNNER, C.; BUSCHER, A.; FURST, T.; LAZARESCU, A.; ROTARU, E.; SENGE, S.; STEINBACH, B.; YILMAZ, F.; ZIMMERMANN, T. A novel class of multi-agent algorithms for highly dynamic transport planning inspired by honey bee behavior. In: IEEE Conference on Emerging Technologies and Factory Automation. Patras: IEEE, 2007. p. 1157-1164.

WOLSEY, L. A. Integer programming. New York: Wiley-Interscience, 1998.

ÖZBAKIR, L.; BAYKASOGLU, A.; TAPKAN, P. Bees algorithm for generalized assignment problem. Applied Mathematics and Computation, v. 215, n. 11, p. 3782-3795, 2010. 


\section{APÊNDICE A}

\section{REFORMULAÇÃO POR LOCALIZAÇÃO DE FACILIDADES}

A reformulação por localização de facilidade foi proposta por Bilde e Krarup (1977) para o problema de dimensionamento de lotes com um único item e sem restrição de capacidade. Neste caso, a relaxação linear do modelo reformulado é igual a envoltória convexa do problema original, portanto, a solução ótima da relaxação é a solução ótima do problema original (WOLSEY, 1998). Esta reformulação foi inicialmente chamada de reformulação pelo problema de transporte e, posteriormente, foi denominada de reformulação por localização de facilidades.

Em Rosling (1986) esta reformulação foi apresentada para o problema de dimensionamento de lotes multiestágio com limitação de capacidades. Neste trabalho, considerou-se apenas estruturas de produto do tipo montagem (Figura 18). Em Maes et al. (1991) esta formulação foi estendida para estruturas de produto do tipo geral (Figura 18).

Os limitantes gerados pela relaxação linear da formulação por localização de facilidades foram discutidos em alguns trabalhos da literatura e foram comparados, em alguns casos, com os limitantes obtidos por outra importante formulação da literatura, a reformulação pelo problema do menor caminho proposta por Eppen e Martin (1987).

Em Stadtler (1996) foi feita uma comparação entre estas duas reformulações para problemas de dimensionamento de lotes multiestágio com limitação da capacidade. Neste 
comparativo, os autores verificaram a relaxação linear de cada formulação, bem como o tempo necessário para provar a otimalidade de um grupo de instâncias de teste. Os autores também apresentam uma tabela que estabelece o cálculo do número de restrições, de variáveis contínuas, de variáveis binárias e de coeficientes não-nulos. Demonstram assim que a reformulação por localização de facilidades gera um número maior de restrições do que a reformulação pelo problema de menor caminho, podendo gerar um maior tempo computacional para sua resolução.

Denizel et al. (2008) fez um estudo comparativo entre essas duas reformulações para o problema monoestágio multi-item com restrição de capacidade e com tempos de preparações positivos. Os autores provaram matematicamente que a relaxação das duas reformulações são equivalentes para o problema abordado.

\section{A.1 O problema de localização de facilidades}

No problema de localização de facilidades simples, temos um conjunto de locais onde podemos abrir uma facilidade e um conjunto de outros pontos com demanda que devem ser abastecidos por estas facilidades. Existe um custo de transporte para enviar a demanda da facilidade ao cliente e este custo varia de acordo com a facilidade, que atenderá a demanda, e o cliente, que terá a demanda atendida. Para abrir a facilidade, também incide um custo, e este custo varia de acordo com a localidade onde será aberta esta facilidade. Nas formulações seguintes, assume-se que a demanda é atendida sem atrasos. Em uma extensão deste problema, existe a possibilidade de abrir mais de uma facilidade, para atender a todos os pontos de demanda. O objetivo do problema de localização de facilidades é minimizar os custos de transporte e de abertura das facilidades.

Desta forma, uma formulação básica para o problema de localização de facilidades é apresentada a seguir. Para a verificação desta formulação, considere a notação matemática apresentada abaixo.

Conjuntos e índices

$N \quad$ Conjunto de facilidades $(i \in\{1, \ldots, N\})$;

$M \quad$ Conjunto de clientes $(j \in\{1, \ldots, M\})$;

\section{Parâmetros}

$C_{i j} \quad$ Custo de transporte unitário partindo da facilidade $i$ para atender a demanda do cliente $j$; 
$f_{i} \quad$ Custo de abertura da facilidade $i$;

$D_{j} \quad$ Demanda do cliente $j$;

$B_{i} \quad$ Número grande, utilizado como limitante da demanda atendida pela facilidade $i$;

Variáveis do problema

$\delta_{i j} \quad$ Quantidade da demanda do cliente $j$ atendida pela facilidade $i$;

$Y_{i} \quad$ Abertura da facilidade $i$;

$\left(Y_{i}=1\right.$, se a facilidade $i$ for aberta

$Y_{i}=0$, caso contrário.)

$$
\begin{array}{lll}
\text { minimize } & Z=\sum_{i=1}^{N} \sum_{j=1}^{M} c_{i j} \delta_{i j}+\sum_{i=1}^{N} f_{i} Y_{i} & \\
\text { sujeito a: } & \sum_{j=1}^{M} \delta_{i j} \leq B_{i} Y_{i} & \forall i \\
\sum_{i=1}^{N} \delta_{i j}=D_{j} & \forall j \\
\delta_{i j} \geq 0 & \forall i, j \\
Y_{i} \in\{0,1\} & \forall i
\end{array}
$$

A função objetivo (A.1) consiste em minimizar a soma dos custos de abertura de novas facilidades e dos custos de transporte de produtos entre as facilidades e os clientes. As restrições (A.2) definem que uma facilidade deve estar aberta para atender a demanda dos clientes. Nas restrições (A.3) garantem que todas as demandas serão atendidas, e que nenhuma cliente receberá produtos além de sua demanda. As restrições (A.4) e (A.5) são restrições de domínio.

Para maiores informações sobre o problema de localização de facilidades sugerimos o trabalho de Krarup e Pruzan (1983).

\section{A.2 Reformulação por localização de facilidades}

Na Tabela 45 relacionam-se o significado das variáveis do problema de localização de facilidades com as variáveis do problema de dimensionamento de lote, conforme proposto 
por Bilde e Krarup (1977).

Tabela 45: Definição das variáveis conforme Bilde e Krarup (1977).

\begin{tabular}{|l|l|}
\hline Localização de facilidades & Dimensionamento de lotes \\
\hline Abertura da facilidade $i\left(Y_{i}\right)$ & Preparação de máquina no período $t\left(Y_{t}\right)$ \\
\hline $\begin{array}{l}\text { A facilidade } i \text { atender parte da } \\
\text { demanda do cliente } j\left(\delta_{i j}\right)\end{array}$ & $\begin{array}{l}\text { Produzir no período } t \text { para atender parte } \\
\text { da demanda do período } \pi\left(\delta_{t \pi}\right)\end{array}$ \\
\hline $\begin{array}{l}\text { Custo de transporte da facilidade } i \\
\text { até o cliente } j\left(c_{i j}\right)\end{array}$ & $\begin{array}{l}\text { Custo de estoque do período } t \\
\text { até o período } \pi\left(\hat{h}_{t \pi}=h_{t}+h_{t+1} \ldots+h_{\pi}\right)\end{array}$ \\
\hline Custo de abertura da facilidade $i\left(f_{i}\right)$ & $\begin{array}{l}\text { Custo de preparação para } \\
\text { a produção no período } t\left(s c_{t}\right)\end{array}$ \\
\hline
\end{tabular}

É importante salientar, que nos modelos a seguir, o cálculo dos custos de estoque $\sum_{t=1}^{T} \sum_{\pi=t}^{T} \hat{h}_{t \pi} * \delta_{t \pi}$ é calculado na forma $\sum_{t=1}^{T} h_{t} I_{t}$, em conjunto com as restrições de balanceamento de estoque. Além disso, nas reformulações a seguir, consideramos que as variáveis $\delta_{i t \pi}$ são reais e representam o número absoluto de unidades produzidas no período $t$ para o atendimento da demanda no período $\pi$, como feito em Stadtler (2003). Uma outra possibilidade, seria considerar essas variáveis como frações das demandas que serão atendidas, como feito em outros trabalhos da literatura.

Considere a formulação agregada do problema de dimensionamento de lotes com um único item e sem restrição de capacidade dada por (A.6)-(A.10). Para esta formulação considere a notação apresentada a seguir. A sua reformulação utilizando a proposta de Bilde e Krarup (1977) é dada por (A.11)-(A.16).

Conjuntos e índices

$T$ Conjunto de períodos $(t \in\{1, \ldots, T\})$;

Parâmetros

$s_{t} \quad$ Custo de preparação relacionada ao período $t$;

$h_{t} \quad$ Custo de estoque relacionado ao período $t$;

$d_{t} \quad$ Demanda no período $t$;

$B_{t} \quad$ Número grande, utilizado como limitante para a produção no período $t$;

Variáveis do problema

$X_{t} \quad$ Quantidade produzida no período $t$;

$I_{t} \quad$ Estoque do produto no período $t$;

$Y_{t}$ Variável de preparação no período $t$; $\left(Y_{t}=1\right.$, se $X_{t}>0$ 


$$
Y_{t}=0, \text { caso contrário.) }
$$

\section{Formulação agregada.}

$$
\begin{aligned}
& \text { minimize } Z=\sum_{t=1}^{T}\left(s_{t} * Y_{t}+h_{t} * I_{t}\right) \\
& \text { sujeito a: } \quad I_{t-1}+X_{t}=d_{t}+I_{t} \quad \forall t \\
& X_{t} \leq M * Y_{t} \quad \forall t \\
& X_{t}, I_{t} \geq 0 \quad \forall t \\
& Y_{t} \in\{0,1\} \quad \forall t
\end{aligned}
$$

A função objetivo (A.6) consiste em minimizar a soma dos custos de preparações de máquinas e dos custos de estocagem de produtos acabados, durante o horizonte de planejamento. As restrições (A.7) fazem o balanceamento de estoque do dimensionamento de lotes. As restrições (A.8) definem que só haverá produção no período $t$, se a máquina estiver preparada para a produção no período $t$. As demais restrições são restrições de domínio.

\section{Reformulação por localização de facilidades.}

$$
\begin{aligned}
& \operatorname{minimize} \quad Z=\sum_{t=1}^{T}\left(s_{t} * Y_{t}+h_{t} * I_{t}\right) \\
& \text { sujeito a: } \quad \sum_{\pi=1}^{t} \delta_{\pi t}=d_{t} \quad \forall t \\
& I_{t-1}+\sum_{\pi=t}^{T} \delta_{t \pi}=d_{t}+I_{t} \quad \forall t \\
& \delta_{t \pi} \leq M * Y_{t} \quad \forall t, \pi \geq t \\
& \delta_{t \pi}, I_{t} \geq 0 \quad \forall t, \pi \geq t \\
& Y_{t} \in\{0,1\} \quad \forall t
\end{aligned}
$$

A função objetivo (A.11) consiste em minimizar a soma dos custos de preparações de máquinas e dos custos de estocagem. As restrições (A.12) garantem o atendimento da demanda de cada período $t$ pelas produções particionadas dos períodos anteriores. As restrições (A.13) fazem o balanceamento de estoque. As restrições (A.14) definem que só haverá produção no período $t$, se a máquina estiver preparada para a produção no período 
t. As demais restrições são restrições de domínio.

Nesta reformulação as variáveis $\delta_{t \pi}$ definem a quantidade da demanda do período $\pi$ que será produzida no período $t$. A Figura 28 apresenta um grafo que representa este problema reformulado conforme o problema de localização de facilidades. Os quadrados representam os períodos onde a produção está sendo feita (Facilidades), enquanto, os círculos representam os períodos onde a produção está sendo consumida (clientes). Por exemplo, o arco que vai do quadrado de número 1 para a bola de número 4 corresponde a variável $\delta_{14}$ que indica a quantidade que será produzida no período 1 para ser consumida no período 4 . No caso do período 2 , veja que parte da demanda pode ser atendida pelo período $1\left(\delta_{12}\right)$ e outra parte pode ser atendida pela produção do próprio período $2\left(\delta_{22}\right)$. Assim, teríamos a possibilidade de atender a demanda da seguinte forma $\delta_{12}+\delta_{22}=d_{2}$, como definido pelas restrições (A.12).

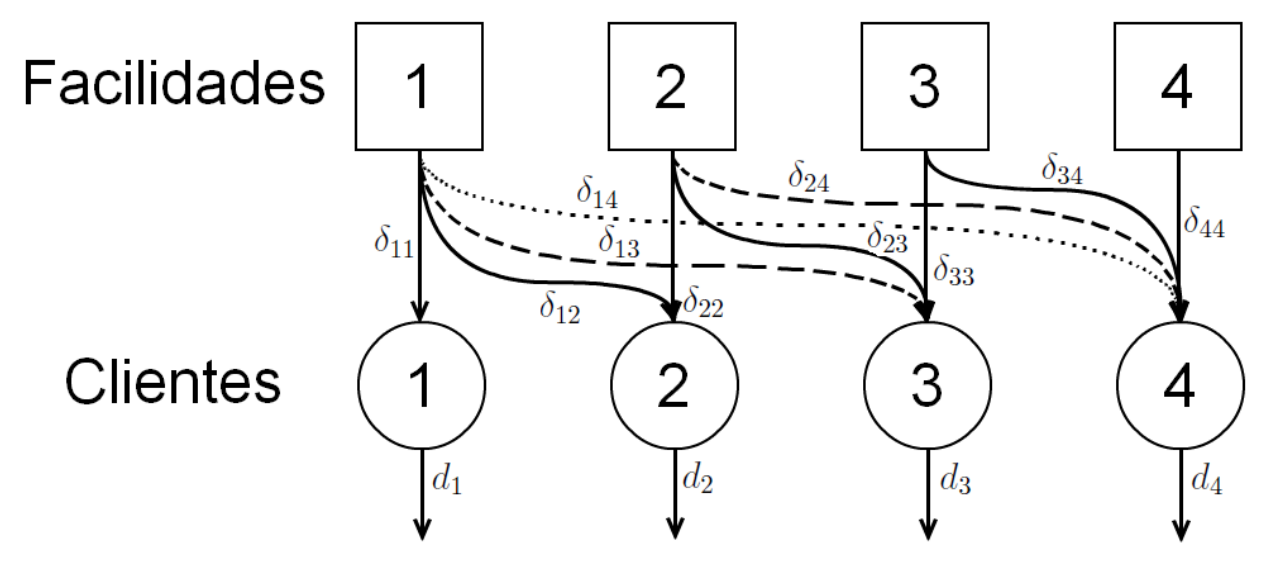

Figura 28: Grafo de rede representando o problema de dimensionamento de lotes com um único item.

Considere agora o problema de dimensionamento de lotes com múltiplos itens e sem restrições de capacidades. Para apresentar a formulação, considere ainda mais um índice $i$ nas variáveis e nos parâmetros que indica o item que será produzido.

$$
\begin{array}{lll}
\text { minimize } & Z=\sum_{i=1}^{N} \sum_{t=1}^{T}\left(s_{i t} * Y_{i t}+h_{i t} * I_{i t}\right) & \\
\text { sujeito a: } & \sum_{\pi=1}^{t} \delta_{i \pi t}=d_{i t} & \forall i, t \\
I_{i, t-1}+\sum_{\pi=t}^{T} \delta_{i t \pi}=d_{i t}+I_{i t} & \forall i, t \\
\delta_{i t \pi} \leq M * Y_{i t} & \forall i, t, \pi \geq t
\end{array}
$$




$$
\begin{array}{ll}
\delta_{i t \pi}, I_{i t} \geq 0 & \forall i, t, \pi \geq t \\
Y_{i t} \in\{0,1\} & \forall i, t
\end{array}
$$

A partir desta formulação, podemos adicionar as restrições de capacidade do problema de dimensionamento de lotes e chegaremos a um modelo similar ao abordado em Denizel et al. (2008). A formulação (A.23)-(A.29) modela o problema de dimensionamento de lotes multi-item com restrição de capacidade. Para esta formulação, considere que existem $M$ recursos e que $K_{m}$ representa o conjunto de itens que utilizam o recurso $m$. Considere também que cada recurso tem um limite de capacidade por período $\left(C_{m t}\right)$. Além disso, produção e preparação tem gastos de recurso associado a cada uma destas atividades, sendo $t s_{i t}$ o consumo de recurso durante a preparação para a produção do item $i$ no período $t$ e $a_{i t}$ o consumo de recurso para a produção de uma unidade do item $i$ no período $t$.

$$
\begin{array}{cl}
\text { minimize } & Z=\sum_{i=1}^{N} \sum_{t=1}^{T}\left(s_{i t} * Y_{i t}+h_{i t} * I_{i t}\right) \\
\sum_{\pi=1}^{t} \delta_{i \pi t}=d_{i t} & \forall i, t \\
\text { sujeito a: } & \forall i, t \\
I_{i, t-1}+\sum_{\pi=t}^{T} \delta_{i t \pi}=d_{i t}+I_{i t} & \\
\sum_{i \in K_{m}} \sum_{\pi=t}^{T} a_{i t} * \delta_{i t \pi}+\sum_{i \in K_{m}} t s_{i t} * Y_{i t} \leq C_{m t} t & \forall m, t \\
\delta_{i t \pi} \leq M * Y_{i t} & \forall i, t, \pi \geq t \\
\delta_{i t \pi}, I_{i t} \geq 0 & \forall i, t, \pi \geq t \\
Y_{i t} \in\{0,1\} & \forall i, t
\end{array}
$$

As restrições (A.26) definem o limite de capacidade do recurso $m$ no período $t$, para cada recurso e cada período do horizonte de planejamento.

Se adicionarmos uma estrutura de produto de múltiplos itens e possibilidade de utilização de horas extras, nesta formulação, chegaremos ao modelo (A.30)-(A.36), que trata o problema de dimensionamento de lotes multiestágio com limitação da capacidade. Para esta formulação, considere $S(i)$ como o conjunto de itens sucessores de $i$, ou seja, itens dos quais $i$ é componente. Considere também $r_{i j}$ como o número de unidade do item $i$ necessárias para a produção de uma unidade do item $j$. Além disso, temos as variáveis 
$O_{m t}$ que indicam as quantidades de horas extras de cada recurso $m$ que serão utilizadas em cada período $t$ e seu custos associados $o c_{m t}$.

$$
\begin{gathered}
\text { minimize } \quad Z=\sum_{i=1}^{N} \sum_{t=1}^{T}\left(s_{i t} * Y_{i t}+h_{i t} * I_{i t}\right)+\sum_{m=1}^{M} \sum_{t=1}^{T} o c_{m t} * O_{m t} \\
\text { sujeito a: } \sum_{\pi=1}^{t} \delta_{i \pi t}=D_{i t} \quad \forall i, t \\
I_{i, t-1}+\sum_{\pi=t}^{T} \delta_{i t \pi}-I_{i t}=d_{i t}+\sum_{j \in S(i)} \sum_{\pi=t}^{T} r_{i j} * \delta_{j t \pi} \quad \forall i, t \\
\sum_{i \in K_{m}} \sum_{\pi=t}^{T} a_{i} * \delta_{i t \pi}+\sum_{i \in K_{m}} t s_{i} * Y_{i t} \leq C_{m t}+O_{m t} \quad \forall m, t \\
\delta_{i t \pi} \leq B_{i \pi} * Y_{i t} \quad \forall i, t, \pi \geq t \\
\delta_{i t \pi}, I_{i t} \geq 0 \quad \forall i, t, \pi \geq t \\
Y_{i t} \in\{0,1\} \quad \forall i, t
\end{gathered}
$$

Na função objetivo (A.30) são minimizados os custos de preparações, de estocagem e de horas extras. Nas restrições (A.31) garantimos que a demanda de escalão do item $i$ no período $t$ será atendida pelas produções dos períodos anteriores até $t$. As restrições (A.32) fazem o balanceamento de estoque. Nestas restrições as demandas aparecem separadamente, a demanda independente é dada por $d_{i t}$ e a demanda dependente é dada por $\sum_{j \in S(i)} \sum_{\pi=t}^{T} r_{i j} * \delta_{j t \pi}$.

\section{A.3 Reformulação pelo problema do menor caminho}

A reformulação pelo problema do menor caminho, proposta por Eppen e Martin (1987), consiste em uma reformulação baseada na representação do problema de dimensionamento de lotes na forma de grafo, tal qual foi feito na reformulação por localização de facilidades. Para problemas do tipo Big-bucket, cada vértice representa um período $t$ e cada aresta que parte de $t$ representa o atendimento de parte da demanda de um período posterior ao período $t$. Desta forma, definimos as variáveis $Z_{i t k}$ como sendo parte da demanda do item $i$ no período $k$ que será produzida no período $t$. A partir disto, podemos fazer o controle de atendimento da demanda, com a utilização de restrições de fluxo em rede, no lugar das restrições de equilíbrio de estoque e um conjunto de restrições 
que garantem o atendimento da demanda de cada item. No conjunto de restrições de atendimento da demanda, a soma de todas as porções de demanda atendida para um item $i$ e período $t$ deve ser igual a 1. Para maiores informações, ver Eppen e Martin (1987). 